


\section{DISCLAIMER}

This report was prepared as an account of work sponsored by an agency of the United States Government. Neither the United States Government nor any agency Thereof, nor any of their employees, makes any warranty, express or implied, or assumes any legal liability or responsibility for the accuracy, completeness, or usefulness of any information, apparatus, product, or process disclosed, or represents that its use would not infringe privately owned rights. Reference herein to any specific commercial product, process, or service by trade name, trademark, manufacturer, or otherwise does not necessarily constitute or imply its endorsement, recommendation, or favoring by the United States Government or any agency thereof. The views and opinions of authors expressed herein do not necessarily state or reflect those of the United States Government or any agency thereof. 


\section{DISCLAIMER}

Portions of this document may be illegible in electronic image products. Images are produced from the best available original document. 


\title{
Boise Geothermal Aquifer Study
}

\author{
Final Report
}

for

IDWR Contract \#

DWR-89-03-46-102-54

by

Berkeley Group Inc.

1330 Broadway Street, Suite 1450

Oakland, CA 94612

January 1990

\section{DISCLAIMER}

This report was prepared as an account of work sponsored by an agency of the United States Government. Neither the United States Government nor any agency thereof, nor any of their employees, makes any warranty, express or implied, or assumes any legal liability or responsibility for the accuracy, completeness, or usefulness of any information, apparatus, product, or process disclosed, or represents that its use would not infringe privately owned rights. Reference herein to any specific commercial product, process, or service by trade name, trademark, manufacturer, or otherwise does not necessarily constitute or imply its endorsement, recommendation, or favoring by the United States Government or any agency thereof. The views and opinions of authors expressed herein do not necessarily state or reflect those of the United States Government or any agency thereof. 
This report was prepared under subcontract to the Idaho Department of Water Resources with the support of the U.S. Departient of Energy (DCE) Grant No. DE-FC07-88ID 12748. Any opinions, findings, conclusions, or recommenciations expressed herein are those of Berkeley Group Inc., and do not necessarily reflect the view of either the Idaho Department of Water Resources or DOE. 
Table of Contents

Page

Executive Summary

I. Overview of the Hydrothermal System 6

1) Geology/hydrology 6

2) Geophysical Data 10

3) Geochemistry 14

4) Conceptual Model 18

II. Review of Production and Water Level Data 20

1) BLM WeII 20

2) Capitol Mall Wells 21

3) Boise Geothermal Ltd. Wells 28

4) Veterans Administration Wells 33

5) Boise Warm Springs Water District Wells 36

6) Kanta Well 41

7) Eehrman Well 42

8) Quarry View Well 4

III. Review of Well Tests and Previous Analyses 45

1) BLM and Beard Welis 45

2) Capitol Mall Wells 47

3) BGL WeIls 48

4) VA Wells 49

5) BWSWD Welis 52

6) Quarry View Well 53

IV. Pressure Response Modeling 54

1) Description of the Mathematical Model 55

2) Well Test Matching - Model Confirmation 62

a) BGL-2 Test 62

b) CM-2 Test 65

c) BWSWD Test 68

3) History Matching $(1981-1989) \quad 72$

a) Input Data and Assumptions $\quad 77$

$\begin{array}{ll}\text { b) Results } & 78 \\ \text { c) Conclusion and Discussion of } & 83\end{array}$

c) Conclusion and Discussion of

4) Analysis of Continued Production 85

a) Continued Production at Current Levels

b) Continued Production with Additional 87 Injection

5) Analysis of Increased Future Production 89

a) Increased Future Prodution without Injection 89

b) Increased Future Production with Additional 89 Injection

6) Conclusions for Pressure Response Modeling 90 


\section{Table of Contents (cont.)}

V. Temperature Response Modeling 91

1) Description of the Model 91

2) History Match 94

3) Continued Production without Additional Injection 100

4) Continued Production with Additional Injection 103

5) Increased Production without Additional Injection 104

6) Increased Production with Additional Injection 106

7) Conclusions for Temperature Response Modeling 107

VI. Recommendations for Data Collection 109

1) Well Pressure/Water Level Data 109

2) Temperature Data 112

3) Long-Term Flow Test 114

4) Geophysical Studies 115

5) Flowrate Data 115

6) Changes to Present Monitoring Network 116

7) Geochemical Sampling 117

References

Figures

Appendix A - Available Well Temperature Profiles

Appendix B - Individual Well Data from Young, et. al. 1988

Appendix C - Available Well Completions/Lithologies 


\section{List of Tables}

\section{Page}

Table 1. Selected Well Completion Data 7

Table 2. Summary of Geophysical Logs 13

Table 3. Geochemical Data 16

Table 4. Distances Between Wells (Preceeding page) 21

Table 5. CM-2 Flowrate 26

Table 6. BGL Production 31

Table 7. BWSWD Production 38

Table 8. BWSWD Maximum Water Level Recovery 40

Table 9. Well Test Summary (Preceeding page) 46 


\section{List of Figures}

Figure 1. Map of Idaho Showing the Location of the Study Area.

Figure 2. Map of Idaho Showing Selected Well Locations.

Figure 3. Geologic Map of the Boise Area.

Figure 4. Cross-section, BGL-VA-CM Area

Figure 5. Cross-section, BWSWD Area.

Figure 6. Plot of Fluoride versus $\mathrm{pH}$ for Geothermal Waters.

Figure 7. TDS versus $\mathrm{pH}$ for Southern Idaho Geothermal Waters.

Figure 8. Fluoride versus Chloride for Southern Idaho Geothermal Waters.

Figure 9. Conceptual Model

Figure 10. Hydrograph of the BLM Well.

Figure 11. Hydrograph of BGL-3.

Figure 12. Hydrograph of BWSWD-1.

Figure 13. Hydrograph of BWSWD-3.

Figure 14. Hydrograph of the Kanta well.

Figure 15. Hydrograph of the Behrman well.

Figure 16. Hydrograph of the Quarry View well.

Figure 17. Schematic diagram and plot of fracture flow behavoir.

Figure 18a. Log-Log plot of BGL-2 Test data and calculated match.

Figure 18b. Linear plot of BGL-2 Test data and calculated match.

Figure 19a. Linear plot of the CM-2 Test with the calculated match. 


\section{List of Figures (cont.)}

Figure 19b. Log-Log plot of the CM-2 Test.

Figure 20. Data and calculated match for the BWSWD-1. history match "test" for one year of normal operation.

Figure 21. Observation well water level data taken from water level recorder measurements and plotted as high and low values for each year.

Figure 22. High and low water level data in BWSWD-1.

Figure 23. Capitol Mall-2 well head pressure (yearly maximum), converted to approximate (hot) water level elevation.

Figure 24. BWSWD and BGL annual geothermal production.

Figure 25. Boise area precipitation and historical average.

Figure 26. BLM data and history match.

Figure 27. Kanta well data and history match.

Figure 28. BWSWD-1 data and history match.

Figure 29. CM-2 data and history match.

Figure 30. BWSWD-3 data and calculated history match.

Figure 31. BLM well data and calculated drawdown from year 1990 to 2000. Assuming no additional production.

Figure 32. Kanta well data and calculated drawdown from year 1990 to 2000. Assuming no additional production.

Figure 33. BLM calculated drawdown assuming $50 \%$ additional production.

Figure 34. Kanta well calculated drawdown assuming $50 \%$ additional production.

Figure 35a. Sample TBLOCKS model.

Figure 35b. Schematic diagram of injection with a cylindrical model. 


\section{List of Figures (cont.)}

Figure 36. Schematic illustration of injected fluid distribution around injection wells, including the relative location of a hypothetical $B G L$ injection well (BGL-I).

Figure 37. Schematic illustration of the pressure reponse model. 


\section{References (cont.)}

13) Burnham W., Wood S., 1988, Geologic Map of the South Boise Quadrangle, unpublished.

14) CH2M Hill, Inc., 1979, Environmental Impact Assessment for a Space Heating Project for the City of Boise, Idaho: 101 p. plus appendices.

15) Cinco-Ley, H., Samaniego V., F., 1984, Application of the Pseudolinear Flow Model to the Pressure Transient Analysis of Fractured Wells, Society of Petroleum Engineers of AIME, SPE 13059 p. 1-11

16) , 1981, Transient Pressure Analysis for Fractured Welis, Journal of Petroleum Technolgy, p. 1749-1766.

17) , 1977, Determination of the Orientation of a Finite Conductivity Vertical Fracture by Transient Pressure Analysis, Society of Petroleum Engineers of AIME, SPE $6750, \mathrm{p} \cdot 1-11$

18) City of Boise, Turner, D., personal communication, 1989.

19) Earlougher, R.C., 1977, Advances in Well Tests Analysis, SPE Monograph Volume 5, SPE, 264 p.

20) Gringarten, A.C. and Witherspoon, P.A., 1972 A Method of Analyzing Pump Test Data From Fractured Aquifers, International Society for Rock Mechanics Symposium, p. $1-9$

21) Hanley, E.J. and Bandyopadyay, P., Pressure Transient Behavior of the Uniform Flux Finite Capacity Fracture, SPE paper No. 8278, 1979.

22) Higginson, $R$. Keith, 1987, Investigation of the Boise Idaho Geothermal System, Higginson-Barnett Consultants, Report to Boise State U., 20 p. plus appendices.

23) Kasameyer P.W., Schroeder R.C., Thermal Depletion of a Geothermal Reservoir with Both Fracture and Pore Permeability, UCRL - 77323, Journal of Geophysical Research Preprint, August 1976.

24) Kelly, J.E., 1986, Response of the Boise Geothermal Aquifer to Earth Tides; Proceedings of the 22nd Symposium on Engineering Geology and Soils Engineering, Idaho Department of Transportation, Boise, Idaho, $4 \mathrm{p}$. 


\section{References (cont.)}

25)

, 1987, Report on Drilling Development and Testing of Veterans Administration Medical Center Geothermal Production Well and Test Injection Well, Prepared JMM Consulting Engineers, 12 p. plus appendices.

26) Mayo, A.L., Muller, A.B., and Mitchell, J.C., 1984, Geochemical and Isotopic Investigations of Thermal Water Occurrences of the Boise Front Area, Ada County Idaho: Idaho Department of Water Resources Water Information Bulletin 30, pt. 14, 55p.

27) Mink, L, 1976, Final Report, Geothermal Testing of Statehouse Well, Prepared by Boise State University.

28) Mink, L., Hollenbaugh, K., Donaldson, P., Applegate, J. and R. Stoker, 1977, Boise Geothermal Project: GRC Transactions, vol. 2, p. 225-227.

29) Mink, L.L., and Graham, G.L., 1977, Geothermal potential of the west Boise area: U.S. Dept. of Energy, $37 \mathrm{p}$.

30) Mitchell, J.C., Johnson, L.L., and Anderson, J.E., 1980, Geothermal investigations in Idaho, Part 9, Potential for direct heat application of geothermal resources: Idaho Dept. of Water Resources Water Information Bull. No. $30,396 \mathrm{p}$.

31) Nelson, Lynn B., Warren L. Niemi, and Roger C. Stoker, 1980, Geothermal Resource Exploration in Boise, Idaho, EG\&G Idaho. Report \#EGG-2011, 24 p. separate reference

32) Peaceman D.W., Fundamentals of Numerical Reservoir Simulation, Elsevier, 1977

33) Richtmyer R.D., Morton K.W., Difference Methods for Initial-Value Problems, Interscience - Wiley and Sons, 1967

34) Veterans Administration, Johnson, D., Engineer, 1989, Boise, Personal communication.

35) Waag, C.J., and Wood, S.H., 1985, Base Line Data Analysis of a Developing Geothermal System, Boise, Idaho: Research Technical Completion Report, Idaho Water Resources Research Institute, University of Idaho, Rept \#C-903-09, $25 \mathrm{p}$. 


\section{References (cont.)}

36) , 1987a, Analysis of Historical and Current Drawdown and Production Data from the Boise Geothermal System: submitted to the Idaho Water Resources Research Institute, Rept \#14-08-0001-C1222-02,47 p.

37) , 1987b, Evaluation of the Boise Geothermal System: Final Report to the Idaho Department of Water Resources, unpublished, $83 \mathrm{p}$.

38) Waag, C., Personal communication, 1989.

39) Wood, S.H., and Burnham, W.L., 1983, Boise Idaho, geothermal system: Transactions of the Geothermal Resources Council, v.7, p. 215-225

40) , 1983, Geology of Boise, Idaho: Implications for Geothermal Development and Engineering Geology: 1983: Proceeeding of the 20 th Annual Engineering Geology and Soils Symposium.

41) , 1987, Geologic Framework of the Boise Warm Springs Geothermal Area, Idaho: Decade of North American Geology, Rocky Mountain Section of the Geologicai Society of America, Centennial Field Guide, v.2., p. 117-122.

42) _ Personal communication, 1989

43) Young, H.W., 1985, Geochemistry and Hydrology of Thermal Springs in the Idaho Batholith and Adjacent Areas, Central Idaho, U.S.G.S. Water-Resources Investigations Report $85-4172,1985$

44) Young, H.W., Parliman, D.J. and R.H. Mariner, 1988, Chemical and Hydrologic Data for Selected Thermal-Water Wells and Nonthermal Springs in the Boise Area, U.S. Geological Survey Open File Report 88-471. 


\section{Executive Summary}

This report is the final product of a detailed review and quantitative evaluation of existing data for the Boise Front Geothermal Aquifer. Upon review of the many publications, and raw data for the Boise geothermal aquifer, it became clear that adequate data only exists for analysis of current and proposed development within a limited area. This region extends approximately 1.5 miles southeast of the state Capitol to 0.5 mile northwest. Though there are geothermal wells located along the Boise Front outside of this area, the lack of production and water level data preclude any detailed discussions and analys is of their relationship to the central resource. As a result, discussion will concentrate on major users such as the Capitol Mall (CM) Boise Geothermal Ltd. (BGL), Veterans Administration (VA) and Boise Warm Springs Water District (BWSWD).

The objectives of this study and a summary of the conclusions are as follows:

\section{Define the inter-relationship of the existing wells and/or portions of the geothermal aquifer.}

Well test interference data and long-term water level monitoring of inactive wells indicates that wells drilled along the Boise Front Fault communicate readily. This includes BLM, BGL-2, 3, 4, BWSWD 1, 2, 3, Kanta and VA-1. 
Testing indicates less direct communication between the Capitol Mall wells and wells along the fault. This implies a limited degree of communication between $C M$ wells and BWSWD wells .

Due to the apparent masking effect of injection (CM-2 production into $(M-1)$ and the position of the $C M$ wells (down gradient from other major wells), there appears to be little impact of Capitol Mall operations on BGL or BWSWD production and vice versa. The lack of monitoring data from wells located between $C M$ wells and the Boise Front Fault prevents more precise analysis.

It is evident from production and observation well data that interference occurs between BGL and BWSWD production welis, which affects not only those wells, but water levels along the fault zone in general. There is little that can be determined, regarding the impact of VA wells on the aquifer due to the lack of well test data and because of the short-term operating history of the VA system. There are no measureable effects on record which coincide with VA system startup. Therefore, it appears that the impact of VA operations (up to $7 / 89$ ) is minor. 


\section{Evaluate the effects of current and proposed development on the geothermal aquifer.}

The static water level of the Boise Geothermal Aquifer has been declining in the area along the Boise Front Fault since 1983. However, less severe declines appear to occur off the fault, to the west. The nature of use, erratic demand and widely varying precipitation in the $1980^{\prime} \mathrm{s}$, has hindered attempts at correlating production to geothermal aquifer level declines along the Boise Front Fault. Furthermore, effect of simultaneous production/ injection operations, such as Capitol Mall, are poorly understood due to the lack of data.

The Boise Front Geothermal Aquifer, like any other aquifer, is responding to net production, which has increased since 1983. The water level decline should establish a new equilibrium level. The new equilibrium water level will be lower than that which occurred between 1890 and 1982 with BWSWD operating alone.

Future water levels in observation wells along the fault are estimated to be between $2730 \mathrm{ft}$. and $2710 \mathrm{ft}$. (elevation) for the next 10 years, assuming production does not increase from present amounts. If production is increased by $50 \%$, the water ievels along the fault are predicted to be between $2710 \mathrm{ft}$. and $2680 \mathrm{ft}$. elevation. These estimates are based on the assumption that recharge 
remains constant, production is relatively stable from year to year and no additional injection wells are utilized.

There is significant uncertainty in estimating temperature effects resulting from injection, due to the lack of injection monitoring data. Minor temperature effects are predicted using an isotropic temperature response model. However, the potential for cooler injectate breakthrough (from VA-2 and/or CM-1 into CM-2) exists if the orientation of large fractures and/or pressure gradients allows selective cross-flow between those wells.

\section{Estimate longevity of the geothermal resource.}

The original scope of this study included a very long-term water level prediction calculation of 30 or more years to estimate the longevity of the resource. It became apparent, after a detailed review and analysis of the data, that predictions of that extent could not be performed with sufficient accuracy. This is due to the quality of the data, the erratic production totals in recent years, and possible fluctuations in recharge. Instead, this study attempt to define factors that control recharge, and investigate various boundary effects which may lead to a better undertanding of what additional data is required 
before long-term calculations can be perfomed with reasonable certainty.

\section{Make recommendations for an on-going monitoring program.}

Prior to commencement of this study, measures were underway to improve the frequency and accuracy of data collection and to unify the data base. Most of these measures have not been active long enough to evaluate their reliability or effectiveness. The results of this study have focused on the need for additional monitoring wells and more accurate flowrate and temperature measurements. The need for longer term, constant rate testing of existing and new wells is discussed. Such data will allowed better definition of aquifer parameters, inter-relationships between wells and water level predictions for flowing wells, rather than just observation wells.

Recommendations regarding geophysical methods, geochemical sampling, and changes to the present monitoring network, are also described. 


\section{I) OVERVIEU OF THE HYDROTHERYAL SYSTEM}

In the last ten years, there have been a number of studies concerning the geology, geochemistry and hydrology of the Boise Front Geothermal System. There now exists considerable understanding of the nature of the resource such that a conceptual model has been developed which is recognized by most investigators. The following is a summary of significant data contributing to the construction of the model.

\section{1) Geology/Hydrology}

Detailed geologic investigations in the region of interest have been carried out (Waag and Wood 1985, 1987; Wood and Burnham 1983) through geologic mapping and study of well logs. Figure 1 shows the location of the study area and Figure 2 shows the location of geothermal wells. Table 1 lists the depths and completions of wells with sufficient data to be included in this study.

The geology of the region is characterized by layered sediments and volcanics overlying a granitic basement, at the margin of the Idaho batholith. The layered units dip gently to the southwest due to uplift of the Idaho batholith.

The local structure is dominated by a major NW-SE trending normal fault dipping steeply to the southwest. This range front fault has caused offsets of approximately $800 \mathrm{ft}$. in the Boise 
Table 1. Summary of Selected Well Completions

WeII

BWSWD-1 (Eas $t$ )

BWSWD-2 (West)

BWSWD-3

Kanta

Botanical

Garden (OId Pen.) 2780

Behrman

Quarry View

VA-1 (Prod.)

2740

2728

2763

VA-2 (Inj.)

VA-Test

2720

2718

CM-1 (Inj.)

2716

CM-2 (Prod.)

2709

BGL-1

2749

2749

2770

2749

2743

2747

Beard

Harris

2890
Depth

$400 \mathrm{ft}$.

400

600

1015

872

unknown

865

1666

2312

1839

2152

3030

2008

880

1897

1103

1222

1282

890
Completion

$160-400$ open

160-400 open

210-600 open

635-1015 open

220-862 perf.

unknown

468-865 open

630-1500 slots

1500-1666 open hole

$1300-2300$ slots

1272-1472 slots

1472-1839 open

1750-2152 open

1260-2550 perf. 2550-3030 open

857-1657 perf. 1657-2008 open

642-880 open

680-1050 perf. 1050-1897 open

720-1040 perf.

610-1222 slots

823-925 screen 964-1279 perf.

548-890 open 
area. This offset displaces layered volcanics sediments and the underlying granitic basement of the Idaho batholith. Figure 3 shows a portion of the geologic map from Wood and Burnham $(1983)$.

Minor faults are significant in the Boise area in that they contribute to the structural complexity of the region. The extensive fracturing allows the thermal fluid to flow up and into the more permeable layered units. The complex structure along the fault zone causes highly variable aquifer properties to be exhibited by wells in close proximity. In general, the hottest and most productive wells, such as those of the Boise Geothermal Ltd. (BGL) and Boise Warm Springs Water District (BWSWD), are drilled into the fault zone at the base of the foothilis.

Successful wells, such as $\mathrm{CM}-2$, can also be drilled west of the fault into the main geothermal aquifer, a fractured porphyritic rhyolite of the Upper Miocene, Idavada Group. Wells west of the fault are drilled deeper than geothermal wells in the Boise Front Fault zone to reach the rhyolite unit. This is due to a combination of down-faulting and tilting (approx. 6 degrees) to the southwest.

Figures 4 and 5 show generalized cross-sections of the two main geothermal well producing areas, the BWSWD area and the CM-VA-BGL area. The stratigraphy is roughly the same in both 
areas with some variation in the depth and thickness of beds.

The stratigraphic section consists of Cretaceous granitic rocks of the Idaho batholith, which have been encountered in BGL-1 and at least one of the Harris wells. The latter has the highest flowing temperature of any well in the Boise (180 F) area. The granite is not usually targeted for drilling as a geothermal water source since it is believed to have fewer fractures than the overlying rhyolites and requires drilling deeper than necessary to produce hot water. Along the fault zone however, the granite can be relatively shallow and may exhibit a high degree of fracture permeability.

The granite is overlain by the silicic volcanic rocks and sediments of the Idavada Group. This group consists primarily of two thick rhyolite layers (the primary geothermal aquifer units) separated by sediments. The upper portion of the shallower rhyolite is believed to have the greatest fracture permeability, as evidenced by the productivity of wells completed into that zone. Secondary minerals have been found to fill fractures within this unit which is likely to reduce local permeability. This may offer a partial explanation for the lower productivity/injectivity of wells such as; CM-1, VA-Test and $V A-2$ (Inj.) wells.

overlying the upper rhyolite is up to $600 \mathrm{ft}$. Of volcani-clastic sediments and basaltic tuffs which are also 
included in the Idavada Group. These tuffs generally have low permeability and contain abundant clay alteration zones. This unit is believed to act as a confining layer over the more permeable rhyolites, though some upward leakage into this unit from fluid at greater depth is likely, particularly in the vicinity of the main fault zone.

An unconformity separates the Idavada Group from the overlying sediments and basalts of the Idaho Group. The Idaho Group has been defined as two units (Wood and Burnham, 1983), an upper unit of deltaic sand and lower unit of silts and clays with occasional sand and gravel layers. Wells completed into the lower unit, which is up to $800 \mathrm{ft}$. thick, provide domestic water for Boise area residents. Temperatures and fluid chemistries of wells completed near the bottom of the Lower Idaho unit indicate leakage from the geothermal aquifer is occurring.

A shallow groundwater system also exists in the area at depths of 100-300 ft. (Waag and Wood, 1987a). This aquifer is essentially isolated from the geothermal system, responding seasonally to recharge from precipitation, the Boise River and imported irrigation water.

\section{2) Geophysical Data}

The Boise area has been included in regional geophysical 
surveys conducted by the USGS, resulting in aeromagnetic and gravity maps and interpretation (Mayo, et. al., 1984). The Idaho Department of Water Resources (IDWR), published heat flow results on the region (Brott, et. al., 1978). Though of interest on a regional scale regarding geology and structure, these surveys did not significantly affect the approach taken to development of the geothermal system at Boise. Since geothermal development there has progressed beyond exploration, the regional surveys do not offer detailed enough information for the purposes of this study.

A local seismic reflection survey described by wood and Burnham (1983), is of interest since it shows the magnitude of the regional dip of the layered sediments and volcanics to the southwest. The survey also shows the depth to the top of the shallowest volcanic unit and confirms the general trend of geology and structure. Knowledge of the structure assists in the siting and design of wells farther west of the fault zone than CM-2. Siting of wells in those areas is probably of interest for injection purposes only.

Other data of interest includes borehole geophysical logs of geothermal wells. Full suites of logs are available for a few of the wells of interest to this study. Only temperature logs were available for wells in the BWSWD area. Table 2 gives a summary of existing logs, not all of which were available for 
review. The most important features of the logs is the contrast between the tighter, more dense, basalts relative to the fractured and more productive (for geothermal fluid) silicic volcanics. In general, both the basaltic tuffs and silicic volcanics have low (sonic log) velocities, correspondingly high porosity and lower density (density log) than the basalt flows. The silicic volcanics show higher resistivity and higher natural gamma counts than the tuffs and basalt flows. The rhyolite also displays a roughly isothermal temperature profile indicative of high fracture permeability and convection in the geothermal aquifer.

The electric logs from wells drilled into less disturbed layered rocks (such as $C M-1$ and $C M-2$ ), away from the fault zone, seem to be more conducive to correlation with lithologic logs than those wells completed into the fault zone (such as the BGL wells). Temperature logs can be more helpful than the E-logs for identifying major fracture zones in the geothermal reserviors, are more cost effective and easier to obtain.

of the logs listed in Table 2, the temperature logs are the most common to wells in the Boise area. These are presented in Appendix A. No other geophysical logs were reproduced for this report. They were not of assistance for this study other than their highlights mentioned above, which confirm the lithologies. 
Table 2

Summary of Borehole Geophysical Logs

\begin{tabular}{|c|c|c|c|}
\hline WeII & Date & $\underline{\operatorname{LOg}}$ & By \\
\hline $\mathrm{CM}^{\prime \prime}-1$ & $\begin{array}{l}10-3-80 \\
10-4-80\end{array}$ & $\begin{array}{l}\text { Natural Gamma } \\
\text { Resistivity }\end{array}$ & INEL \\
\hline$"$ & $\begin{array}{c}10-4-00 \\
11\end{array}$ & $\begin{array}{l}\text { Resistivity } \\
\text { Neutron-Gamma }\end{array}$ & $\underset{n}{\text { USGS }}$ \\
\hline$"$ & $"$ & Natural Gamma & $"$ \\
\hline$"$ & $10-5-80$ & Gamma-Gamma & $1 "$ \\
\hline$"$ & $"$ & Temperature & $"$ \\
\hline$"$ & $"$ & Acoustic Velocity & $"$ \\
\hline$"$ & $10-3-80$ & Temperature & $"$ \\
\hline$"$ & $"$ & Neutron & $"$ \\
\hline$"$ & $"$ & Caliper & $"$ \\
\hline${ }_{11}^{C M-2}$ & $7 / 28 / 81$ & & Schlumberger \\
\hline$n$ & $"$ & $\begin{array}{l}\text { Sonic } \\
\text { Neutron Density }\end{array}$ & " \\
\hline$"$ & " & Dual Induction & $"$ \\
\hline$"$ & $"$ & Temperature & $"$ \\
\hline$\underset{\|}{B G L-1}$ & $\underset{n}{4 / 9 / 81}$ & Neutron Density & Schlumberger \\
\hline$"$ & $n$ & Dual Induction & $" n$ \\
\hline$"$ & $4 / 10 / 81$ & Temperature & $n$ \\
\hline $\mathrm{BGL}_{\|}-2$ & $4 / 27 / 81$ & $\begin{array}{l}\text { Sonic } \\
\text { Neutron Density }\end{array}$ & $\underset{\|}{\text { Schlumberger }}$ \\
\hline$"$ & $"$ & Dual Induction & $n$ \\
\hline$" 1$ & " & Temperature & $"$ \\
\hline \multicolumn{4}{|c|}{ VA-1 (Prodo) } \\
\hline$"$ & $9 / 9 / 83$ & $\begin{array}{l}\text { Caliper } \\
\text { Density }\end{array}$ & $\underset{n}{\text { Goodwell, Inc. }}$ \\
\hline \multirow{2}{*}{\multicolumn{2}{|c|}{ 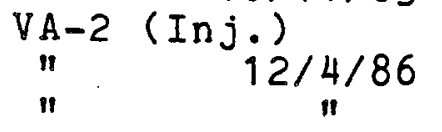 }} & Temperature & Anderson \& Kelley \\
\hline & & $\begin{array}{l}\text { Cement Bond } \\
\text { Natural Gamma }\end{array}$ & $\underset{n}{\text { Petro-Log, Inc. }}$ \\
\hline $\begin{array}{l}\text { BLM } \\
\text { Beard }\end{array}$ & $8 / 23 / 77$ & $\underset{\|}{\text { Temperature }}$ & $\underset{n}{E G \& G}$ \\
\hline $\begin{array}{l}\text { Harris } \\
\text { BWSWD-1 }\end{array}$ & $8 / 20 / 87$ & $"$ & $\underset{n}{I D W R}$ \\
\hline BWSWD-2 & $8 / 24 / 87$ & $n$ & $n$ \\
\hline BWSWD -3 & & " & \\
\hline
\end{tabular}


Several of the logs in Appendix A were taken during non-stabilized conditions. They were either performed with other logs during a break in drilling, or in between periods of pumping. These logs are presented for completeness and will continue to be of value for comparison when repeat (preferably static) surveys can be plotted with them, as they become availabie. IDWR has been conducting temperature surveys as opportunities (pumps removed for repairs, etc.) arise. Repeat surveys of selected wells (e.g. VA-Test) may be useful for monitoring the effects of injection on the geothermal aquifer. Recommendations are discussed further in section VI of this report.

\section{3) Geochemistry}

The geochemistry of the Boise Geothermal Aquifer fluid is well documented, both on a regional scale (Young, 1985 and Mitchell; 1980) and locally (Mayo, 1984 and Waag \& Wood, 1987b, and Young, 1988). These studies include analyses of ionic and isotopic composition of spring and well waters. Of particular interest to this study, is whether the major producing wells in the Boise area share a common source.

Other aspects of geochemistry, such as the results of geothermometer calculations or isotopic age dating, although of interest on a regional scale will not be discussed at length 
here. Only a limited amount of that type of data is available and the range of results does not provide sufficient evidence of any distinction between wells, which would be of use for this study. Age dating analyses and geothermometer calculations, are discussed fully in recent publications (Mayo, 1984; Waag and Wood 1987b).

Boise geothermal wells have not been sampled extensively or repeatedly such that a definitive comparison of ionic concentrations of wells or identification of progressive changes over time. Several of the principal wells have published geochemical analyses (Table 3 ). Few have been sampled repeatedly, but there are sufficient analyses to group the Boise geothermal fluids in comparison to fluids of the Idaho batholith and other Southern Idaho geothermal systems (Waag and Wood, $1987 \mathrm{~b})$.

The Boise Geothermal waters are of the sodium bicarbonate type, with a TDS of $200-300 \mathrm{mg} / \mathrm{l}$ and moderate alkalinity (pH 7.5-9.0). Wood (Waag and Wood, 1987b) suggests that the ionic content (particularly fluoride) distinguishes Boise geothermal fluids from those of nearby geothermal systems (Figures $6,7,8)$. The plots show the wide scatter in the data of single wells (such as (M-2), which prevents analysis of any tell-tale trends which would distinguish specific geothermal fluids within the Boise area. 
Table 3. Geochemical Data (in mg/1 except $\mathrm{SiO}_{2}$ )

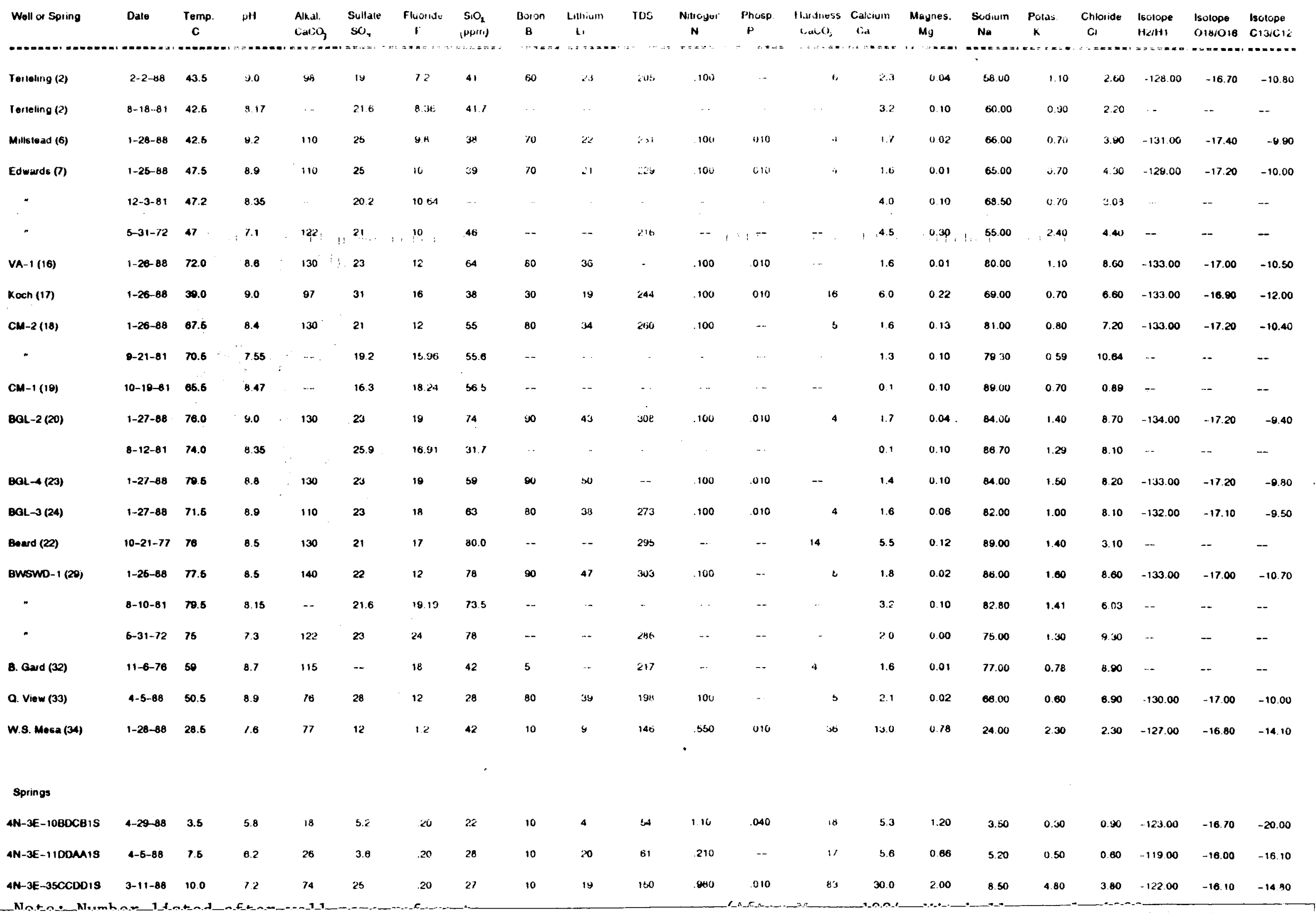


Repeated sampling could reduce the amount of scatter such that geochemical analyses from particular zones or locations could be distinguished from other zones or areas.

In general, the Boise waters share common characteristics due to chemical interaction with rock types encountered as it flows through the main rhyolite aquifer, after deep circulation in the granite batholith. Samples from wells located southwest of the main fault zone indicate a greater degree of mixing with cool fresh groundwater. One major obstacle in defining specific geothermal well water characteristics, is that many geothermal wells in the Boise area are completed through more than one stratigraphic unit, preventing fluid samples from representing, exclusively, the geothermal fluid from a specific zone.

In spite of the scatter in the data, those wells intercepting the main fracture zone at the base of the Boise foothills generally show the highest fluoride concentration and temperature, and the oldest radiocarbon dates. This indicates as expected, a less dilute composition (Wood, 1987b).

The BWSWD well samples show the least mixing and greatest age, while the BGL wells give more dilute and younger samples. This is not indicative of the complex geology which allows fresh water leakage and mixing in localized areas. However, this evidence sheds little light on the hydraulic communication between these areas. The fact that fluids from the two areas 
are geochemically similar does not prove the wells are in communication. But, it does discount the possibility of separate source areas, which could imply lack of communication.

The potential benefits of greater and more systematic sampling frequency as a monitoring tool are apparent. More data, and continued analysis such as that by Wood (Waag and Wood 1987b) could be valuable in defining differences between individual wells. It could also allow detection of progressive changes in the system which may result from cold water influx or injection breakthough, prior to temperature changes being detected in producing wells.

\section{4) Conceptual Model}

The conceptual model of the Boise Front Geothermal Aquifer is not unlike other range front fault systems in the western U.S. The fluid path is generally believed to be as shown in Figure 9. Meteoric waters from the Idaho Batholith circulate deep into the granite basement and are heated by contact with rock warmed by radiogenic decay. The thermal fluid rises upward through the fault zone driven by convection and hydrostatic head, and flows outward into the more permeable silicious volcanics. There are structural complexities which affect flow paths locally in the region of the main fault. Leakage into the shallower, less permeable volcanics and sediments is also 
believed to occur both within the fault zone and upward from the confined rhyolite geothermal aquifer, away from the main fault zone.

The fluid then flows laterally west to southwest toward the Boise river while remaining confined in the rhyolite. Conductive heat loss and mixing with cooler fresh water causes the geothermal fluid to cool as it travels away from the Boise Front Fault. Subsurface flow is likely to progress generally westward to the center of the valley. The lack of geothermal well data to the west limits analysis of the ultimate destination of the geothermal fluid. 


\section{REVIEU OF PRODUCTION AND WATER LEVEL DATA}

Data available from the wells shown in Figure 2 were reviewed for this study. Specifications and drillers logs for a majority of the wells were compiled by Young et. al (1988) (see Appendix B). Table 4 gives the distances between wells. A search was made for other geothermal wells within and beyond this area through IDWR files, but none were found on record. of those shown, a select group from the CM-VA-BGL area and BWSWD area have sufficient water level, production and testing data to be included in this analysis. There were insufficient production and water level data in the southern-most area (in the vicinity of the Harris wells) and northern-most area (near the Edwards and Terteling wells) for analysis of geothermal aquifer behavior or trends. As a result, these outlying areas will be included in the analysis primarily by extrapolation.

\section{1) BLM HeII}

The BLM well is the primary monitoring well for the CM-BGL-VA area because of its location and long-term water level record. The test results (discussed in section III) indicate this well is in communication with the geothermal aquifer. Though it is not completed into the rhyolite unit, it probably interrupts the main fault zone. The BLM well water level record 


\section{Table 4}

Distances Between We11s (in feet)

CM-1 CM-2 VA-1 VA-2 VA-Test BLM BGL-1 BGL-2 BGL-3 BGL-4 Beard BWSWD-3 BWSWD-1 BWSWD-2 Behrman Q. V1ew Kanta B.Gard.

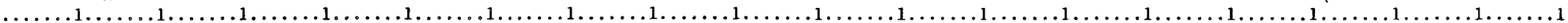
CM-1 -

CM-2 $\quad 1237$

VA-l (Pro) $2290 \quad 2330$

$\operatorname{VA}-2(\operatorname{Inj}) \quad 2420 \quad 2050 \quad 1900$

VA-Test $\quad 2440 \quad 2060 \quad 1940 \quad 40$

$\begin{array}{lllll}\text { BLM } & 2240 \quad 3158 & 690 & 2550 \quad 2590\end{array}$

$\begin{array}{lllllll}\text { BGL-1 } & 3280 & 4197 & 1680 & 3600 & 3640 & 1000\end{array}$

$\begin{array}{llllllll}\text { BGL-2 } & 2896 & 3818 & 1100 & 3040 & 3080 & 673 & 462\end{array}$

$\begin{array}{lllllllll}\text { BGL-3 } & 2800 & 3466 & 840 & 2770 & 2810 & 600 & 850 & 524\end{array}$

$\begin{array}{llllllllll}\text { BGL-4 } & 3104 & 4043 & 1430 & 3350 & 3390 & 978 & 151 & 318 & 836\end{array}$

$\begin{array}{lllllllllll}\text { Beard } & 3134 & 4118 & 1450 & 3390 & 3430 & 1008 & 130 & 346 & 866 & 29.5\end{array}$

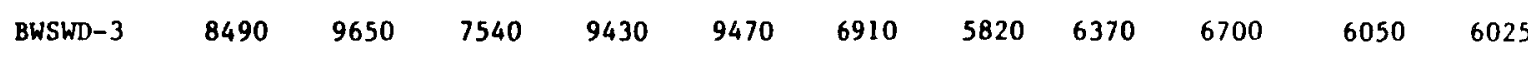

$\begin{array}{lllllllllllll}\text { BWSWD-1 } & 9135 & 10295 & 8180 & 10075 & 10115 & 7580 & 6470 & 7015 & 7370 & 6695 & 6670 & 645\end{array}$

$\begin{array}{llllllllllllll}\text { BWSWD-2 } & 9105 & 10265 & 8160 & 10045 & 10085 & 7560 & 6450 & 7015 & 7370 & 6695 & 6670 & 645 & 30\end{array}$

$\begin{array}{lllllllllllllll}\text { Behrman } & 8550 & 9720 & 7680 & 9710 & 9750 & 7050 & 6020 & 6580 & 6880 & 6360 & 6340 & 440 & 750 & 720\end{array}$

$\begin{array}{lllllllllllllllll}\text { Q.View } & 8700 & 9880 & 7920 & 9830 & 8870 & 7270 & 6240 & 6840 & 7128 & 6500 & 6480 & 800 & 910 & 890 & 350\end{array}$

$\begin{array}{lllllllllllllllll}\text { Kanta } & 10460 & 11670 & 9700 & 11620 & 11660 & 9060 & 8000 & 8615 & 8900 & 8295 & 8275 & 2200 & 1675 & 1675 & 1990 & 1800\end{array}$

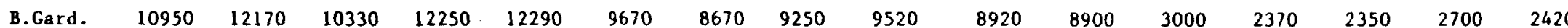


is shown in Figure 10 as a composite of BLM and VA-1 (Prod) records. The two were combined by Waag (Waag and Wood 1987b) because of their parallel behavior. The only apparent difference being that the VA-1 record was consistantly $0.8 \mathrm{ft}$. below that of the BLM well. The VA-1 record accounts for the period from September 1983 to January 1986. Not shown on the hydrograph is older data from the BLM well for the period, September 1976 to October 1978 (from Nelson, 1980). The water level elevation during that period was within the same range as for 1981-1982 (i.e. 2754-2764 ft. elevation) prior to production by major users in the area (BLM, VA or CM systems). Data prior to 1982 , though not continuous, help to establish a background trend with only the BWSWD wells producing in large volumes from the geothermal aquifer. This background trend had apparently stabilized, except for the annual $10 \mathrm{ft}$. fluctuation, prior to the start-up of other major geothermal water users.

\section{2) Capitol Mall Mells}

The Capitol Mall system consists of two wells CM-1 (Injection) and CM-2 (Production). Daily flowrate, pressure and temperature records have been kept on these wells since October 1983 with periodic records kept during the period from system start-up in November 1982 to October 1983. 


\section{a) Water Level/Pressure}

There is sufficient uncertainty in the quality of the data such that reconstructing static or pumping water levels from the records is error prone. The data was not recorded with the intent that it be used for aquifer studies. Improved measurement equipment is to be installed sometime in 1989 . Since start-up, a computer logging system has been used to track selected operations data. Periodically, the computer prints this data for a permanent record.

Due to the shear volume of paper and occasional lack of record because of system malfunction, the most useful data for this study are the daily handwritten $\log$ sheets. This data is usually taken at a time when the system is near its peak flow for the day (i.e. 5-8 am.). It is difficult to extract an average daily or monthly rate from the record or plot a representative or average wellhead pressure with confidence. In addition, pressure readings of thermal wells that have been recently pumped or injected into, show higher than static well head pressures until cooled. Cooling to a static condition can take hours to days depending upon the circumstances. Thus, the records cannot be used directly for plotting and analysis.

The well head pressure of $\mathrm{CM}-2$ is positive even when pumping, except when flowing at a maximum rate (approximately 700-800gpm) during the peak heating season. This (high 
flowrate) condition can last more than one month depending on the severity of the winter. During at least one year (since 1983), the well head pressure (or "casing pressure" as it is referred to in the $l \circ g$ ) at $C M-2$ remained positive year round.

Given occasional periods of down-time and seasonal fluctuations, it is difficult to determine whether the average CM-2 well head pressure is declining. Even analysis of the number of days with water levels below ground elevation during peak season (at the highest pumping rate), failed to establish a trend. The longest continuous below well head water levels on record occur during the period from 12/86 to 4/87. None occured during the 87-88 season. The greatest number of, less than zero wellhead pressure (water level below well head), days for CM-2 occurred during the 86-87 heating season. A large number of days of downtime (and no records) in winter 1988-1989 prevents data from that period from being used for comparision.

Unfortunately, the equipment in place at $\mathrm{CM}-2$ does not allow the water level to be recorded in the well head pressure drops below zero (water level below well head) which contributes to the difficulty in determining a trend. A new measurement method is planned which should solve this problem.

From data during drilling and testing, it appears that the pre-production, shut-in (cold) pressure of $C M-2$ was equal to approximately $24 \mathrm{ft}$. above ground level (on $4 / 7 / 82$ ). This does 
not compare well to a recent stabilize measurement of approximately 15 psi (or $34 \mathrm{ft}$. ) taken after a down-time period of 20 days in september/October 1988 . An actual pressure increase over the $41 / 2$ year period is not likely in light of the records from other wells. Rather, this example serves to illustrate the problems in using data that have been taken since start-up, even allowing for a possible (1-2 ft.) error caused by differences in reference point elevation.

A comparison of the maximum pressure recorded in the $10 \mathrm{~g}$ sheets each year was also reviewed for possible trends. No significant change in the yearly maximum pressure at $C M-2$ has been recorded since the daily records were estabiished, upon start-up, in 1982. This is suprising given the declines seen in other Boise area wells.

Pressure data from the injection well (CM-1) is subject to more variation during normal operations than CM-2. No trend or correlation with pre-production data could be detected. In general, during periods of downtime, the (static) water level in CM-1 is above ground elevation only during August and early September. A summer rebound, above ground level, occurred in 1988, but did not occur in 1987 .

It is unclear whether the data for $\mathrm{CM}-1$ indicates a well head pressure decline trend. This "trend" could be due to error inherent in the measurement method rather than actual aquifer 
response. Future data will assist in establishing a trend. It may be that injection of cooled geothermal water (at approximately 20-30 F below CM-1 original pumping temperature) has caused cooling in the vicinity of CM-1 and a localized reduction in aquifer pressure.

\section{b) Production Data}

The flowrate history for CM-2 cannot easily be reconstructed from the data sheets. Yearly production totals have been published by others (Waag and Wood, 1987) and (Higginson and Barnett, 1987). Table 5 shows the annual production/injection totals for the CM system along with a calculated average flowrate based on best estimates of system down-time and shut-in days during summer.

The calculated average flowrate is probably more useful for analysis purposes than flowrate from the daily log. The daily log generally shows a higher than average flowrate (for a given day) due to the time of day chosen for recording the data.

Currently, the CM flow measurement system does not record artesian flow. During summer shut-in days or down-time, an unrecorded artesian flowrate of 20-150 $8 \mathrm{pm}$, occurs when the pumps are off, depending upon the season and recent pumping history. This rate is much lower than during an artesian flow test in 1981 of $800+$ gpm (Anderson and Kelly, 1981). The 


\section{Table 5}

Capitol Mall Production/Injection

\begin{tabular}{|c|c|c|c|c|}
\hline Year & TotaI & & $\begin{array}{l}\text { Operating } \\
\text { Days }\end{array}$ & $\begin{array}{l}\text { Average } \\
\text { Rate (1) }\end{array}$ \\
\hline 1982 & $\mathrm{~N} / \mathrm{A}$ & & $\mathrm{N} / \mathrm{A}$ & $N / A$ \\
\hline 1983 & $79.1 \times$ & ${ }^{06} \mathrm{gal}$. & $300 ?$ & 183 \\
\hline 1984 & 204.8 & $"$ & 279 & 510 \\
\hline 1985 & 196.4 & $"$ & 252 & 540 \\
\hline 1986 & 188.6 & $"$ & 276 & 474 \\
\hline 1987 & N/A & $n$ & 294 & N/A \\
\hline 1988 & 212.6 & $" \quad(2)$ & 254 & $\mathrm{~N} / \mathrm{A}$ \\
\hline 1989 & 106.3 & " (2) & $\mathrm{N} / \mathrm{A}$ & $\mathrm{N} / \mathrm{A}$ \\
\hline
\end{tabular}

(1) Assumes pumping 24 hours/day on operating days.

(2) Estimated from Totalized value of $3.10 \times 10$ gal. for the period of January 1988 through June 1989, provided by the state.

difference may be due to inherent back pressure of the $\mathrm{CM}$ system. In any case, this unrecorded flow could add up to at least 864,000 gallons/month (or 10 million gal./yr.) to total production figures. Of course, all of the water is reinjected, though at a lower temperature. 


\section{c) Temperature Data}

The daily production and injection temperatures for $C M-1$ and CM-2 were reviewed. Both were observed to vary with flowrate. Measurements of produced water temperature as low as $115 \mathrm{~F}$ were recorded for $C M-2$ with the pumps off. But, as with the flowrate and pressure measurements, it is difficult to distinguish, from the records, if the well is shut-in or is flowing artesian when the pumps are off.

With the production well pump on, the production temperature at CM-2 has varied from 150-160 F. Higginson and Barnett (1987) plotted peak flow temperature for the month of January for the years 1984-1987 and showed that production temperatures were declining at a rate of approximately $1 F$ per year from a pre-production value of 158.5-159 F. This was suggested to be due to injection breakthrough from CM-1. Though this data suggests a trend, the accuracy and calibration of the measurement may allow an error of $\pm 2 F$. Also, recent temperature data does not show a continuing decline through January 1988 or 1989. The January flowing temperature has essentially been constant at roughly $155 \mathrm{~F}$ since 1987.

Measurements in February 1989, at peak flow, shows a recorded value of $158 \mathrm{~F}$. This measurement may have been taken with an instrument other than the one previously used, due to recent maintenance. These recent measurements shed some doubt 
on the accuracy of past measurements. Whether such declines occurred or are continuing is uncertain, pending verification of measurement locations and accuracy.

The majority of the data indicates the production temperatures are highest during peak flow. It follows that cold water influx from cooler aquifers is not a likely cause of temperature declines. If declines have occurred, the data tends to indicate that injection would be the most likely cause.

The possibility of cold water breakthrough to $\mathrm{CM}-2$ from $\mathrm{CM}-1$ was explored through simulation by Papadopulos and Associates (in Anderson and Kelly, 1981). The conclusions in that report were that the potential for a production temperature decline as a result of injection in CM-1 was low, based on their assumptions of aquifer properties.

The previous discussion involved the production well temperature. The injected fluid temperature varies from approximately $115 \mathrm{~F}$ to $140 \mathrm{~F}$ with an average of approximately $125 \mathrm{~F}$. The data may be skewed by the time of day (early morning hours) when the data is recorded.

\section{3) Boise Geothermal Ltd. (BGL) Hells}

The City of Boise owns the four (BGL) production wells which are used to supply a heating system serving central Boise. The production wells are aligned with the Boise Front Fault in the 
Military Reserve Park area (Figure 2). Each is completed somewhat differently (Table 1) and all except BGL-1 are good producers. Continuous production began in October 1983.

\section{a) Production Data}

BGL-4 is used as the primary production well. It produces approximately $750 \mathrm{gpm}$ at $174-175 \mathrm{~F}$. This continuous pumping rate exceeds the current needs of the BGL's customers for most of the year. The excess is automatically injected into BGL-2, and is not run through the heating system. During periods of peak demand (winter), the primary producer has been BGL-2 which can produce up to approximately $1500 \mathrm{gpm}$ at $172 \mathrm{~F}$. BGL-3 has rarely been used except for brief periods, primarily, as a backup during BGL-2 down-time or maintenance. It can produce up to $2000 \mathrm{gpm}$ at $161 \mathrm{~F}$.

At times, both BGL-2 and BGL-4 have been pumped simultaneously. During these and other periods when production exceeds demand, excess water is injected down the annulus of BGL-2 (between casing and pump riser pipe). This is the only geothermal water injected by BGL. Once water enters the heating system piping, it is not re-injected. Disposal of this water is by discharge to the Boise River.

Flowrate data is recorded on a (7-day) circular chart for the heating system delivery line but not for individual wells. 
Cummulative discharge to the heating system is recorded by a flow totalizer.

Data on specific flowrates and times of discharge of the pumping wells cannot be obtained. Total well flow versus flow to the system is automatically controlled and not recorded. An operations log contains data on which pump is running, rate of discharge to the heating system (not well pumping rate), total flow to-date into the heating system, flow line pressure and occasionally flowline temperature. It is updated about once a day (similar to the Capitol Mall system record). This data is not necessarily recorded for the purpose of aquifer monitoring.

A new monitoring system was being brought on line as of April-May 1989. It will log the total flow into the heating system and the pressure (converted to water level elevation) in the nearby Beard well.

Though there is no recent data from the BGL wells, the static water levels are likely to fluctuate with both flowrate and seasonal changes, as they do for other Boise area geothermal wells.

The BGL heating system average flowrate has varied yearly. Table 6 shows the yearly system consumption (not actual well flowrate which is not recorded) and calculated average system rate. The rate of injection of excess water can be determined roughly from the rated pump capacity, less the heating system 
discharge rate. There is no record of the injection flowrate, when production exceeds demand.

Table 6

City of Boise Heating System Production

(BGL Wells)

\begin{tabular}{|c|c|c|c|}
\hline $\begin{array}{l}\text { Year } \\
\end{array}$ & Total & Days & $\begin{array}{l}\text { Average } \\
\text { System } \\
\text { Flowrate } \\
\end{array}$ \\
\hline 1983 & $53.76 \times 10^{6} \mathrm{gal}$. & 92 & $405 \mathrm{gpm}$ \\
\hline 1984 & 153.27 & 365 & 292 \\
\hline 1985 & 129.15 & 365 & 246 \\
\hline 1986 & 199.00 & 320 & 432 \\
\hline 1987 & 172.08 & 365 & 327 \\
\hline 1988 & 122.41 & 365 & 233 \\
\hline 1989 & $68.79 \quad(1)$ & 90 & 530 \\
\hline
\end{tabular}

(1) Through March 1989

BGL has recorded monthly (consumption) totals since startup and, more recently, average monthly flow rates. The average monthly rate varies from a maximum of $773 \mathrm{gpm}$ in February 1988 to $47 \mathrm{gpm}$ in July 1988 . 


\section{b) Water Levels}

There are no water level data for the $B G L$ wells since production began. However, the BLM monitoring well is nearby (see Figure 10 and Table 4). Early data gathered during drilling and testing of $B G L$ and $V A$ wells indicates the $B G L$ wells were capable of flowing artesian (except BGL-3 which is at a higher elevation). There is no record of artesian flow since start-up. However, few instances of down-time have occurred since start-up to allow measurements of static water levels. Thus, only estimates can be made of BGL well static levels from recent measurements at the BLM well.

Measurements recently begun in the Beard well indicate a water level elevation of 2705 to $2707 \mathrm{ft}$. (mid-May 1989). This is approximately $40 \mathrm{ft}$. below ground level at the Beard well. These measurements were recorded with BGL-4 ( $30 \mathrm{ft}$. away) pumping at approximately $750 \mathrm{gpm}$. Meanwhile, the BLM water level was at approximately $2720 \mathrm{ft}$. (elevation). Figure 11 shows a brief record of pre-production levels at BGL-3 during 1981-1982. The water level response during various well tests suggests $B G L-3$ is in communication with other $B G L$ and the $C M$ wells. The erratic trace is due to nearby well testing during the period. Also, note the exaggerated depth scale compared to the other water level plots. 


\section{c) Temperature}

No fluid temperature changes have been recorded for any of the BGL wells since system start-up (October 1983). These pumping temperatures are reported as:

$\begin{array}{ll}\text { BGL-2 } & 172 \text { F } \\ \text { BGL-3 } & 175 \\ \text { BGL-4 } & 161\end{array}$

No declines would be expected since the $B G L$ wells are up gradient of all other production/injection wells in the area and intersect the main feeder fault. Re-injection of excess fluid into BGL-2 does not appear to result in any localized temperature decline, since little temperature loss is believed to occur. However, no static or flowing temperature profiles have been conducted to confirm this.

\section{4) YA Hospital Yells}

The VA wells include a production well (VA-1), an injection well (VA-2) and an intitial test injection well (VA-Test). The VA heating system operates 24 hours a day with all fluid produced at VA-1 and injected into VA-2. VA-Test is not used.

System start-up was November 11,1988 . Written daily records of total flow, production and injection temperature, production well water level (via bubble tube), and injection pressure (guage on flow line) were begun in March 1989. 


\section{a) Production Data}

The production well pump has two rates, approximately 150 gpm and over $1000 \mathrm{gpm}$. The injection well capacity had limited production to approximately $400 \mathrm{gpm}$. That has been increased to $600 \mathrm{gpm}$ as a result of a recent hydro-fracturing project. From the record to-date, it seems that a rate of $150 \mathrm{gpm}$ is sufficient to satisfy VA system demand from March through october. A rate of $400 \mathrm{gpm}$ has been sufficient for other periods except during the severest weather of the year.

As of April 21, 1989, 11.422 million gallons of geothermal water were produced from VA-1 and injected into VA-2. Assuming purpage 24 hours a day since November 11,1988 ( 161 days), the average rate is calculated to be $49 \mathrm{gpm}$. This is not consistant with the $150 \mathrm{gpm}$ (low speed) pumping rate, indicating some down-time occurred which is not on record.

\section{b) Water Level Data}

The VA-1 well was monitored for pressure/water level from November 1, 1983 to January 20,1986 . This record has been combined with the BLM record in Figure 10. Prior to production at VA-1, the two wells showed similar responses, though the BLM well water level is approximately $0.8 \mathrm{ft}$. higher in elevation than the VA-1 level. Both $B L M$ and VA-1 wells are believed to be completed in the main Boise Front Fault zone but the BLM well is 
completed in the shallower basalts and basaltic tuffs, whereas the VA-1 well was completed in rhyolite at a greater depth. The production well water level data for the same period, shows a rising pumping level from mid-March to mid-April 1989, while at a relatively constant rate. The water level while pumping, rose from approximately $52 \mathrm{ft}$. depth (27ll ft. elevation) to $40 \mathrm{ft}$. (2723 ft. elevation) over the one month period of record.

Injection pressure is recorded once daily. The pressure appears to rise in conjunction with the aquifer level rebound in the spring. The injection pressure rose approximately 4 psi from 36 to 40 psi over the one month period (March-April, 1989) of record, while the flowrate averaged approximately $110 \mathrm{gpm}$. During normal operations the drawdown in VA-1 is reported to be within 1-2 ft. of static water level at the low pump speed $(100-150 \mathrm{gpm})$. No continuous monitoring of VA-2 or the test injection well is proposed.

Continuous computerized logging of VA-1 water level (via bubble tube and pressure transducer) was to begin in late 1989 .

\section{c) Temperature Data}

The production temperature has remained constant at $163 \mathrm{~F}$. Injection temperatures vary from 134F-149F. The static temperature of $\mathrm{VA}-1$ is presented in Appendix A. It displays an isothermal section, characteristic of a well intercepting a 
fracture zone (starting at $800 \mathrm{ft}$. in this case).

\section{5) Boise Yarm Springs Yater District (BWSWD) Hells}

This group consists of three wells. Two production wells, BWSWD-1 (East) and BWSWD-2 (West), both $400 \mathrm{ft}$. deep, and a monitoring well (BWSWD-3), $600 \mathrm{ft}$. deep. The two production wells are located on the Boise Fault trace and are separated by a distance of $30 \mathrm{ft}$. BWSWD-3 is located $645 \mathrm{ft}$. northwest along the fault zone from the production wells. There is no injection of the water BWSWD produces. It is disposed of, via the city sewer system, by individual users.

\section{a) Production Data}

Production began in the early $1890^{\prime}$ 's and, for approximately 90 years, it was the only major producer from the Boise geothermal aquifer. The existing production wells were drilled in the early 1900's. Recent records (since 1977) show they are pumped at rates up to $1600 \mathrm{gpm}$. However, since 1983 , production has been curtailed due to seasonal lowering of the pumping level to the pump intake elevation. The pumps in BWSWD-1 and 2 were lowered from 160 to $200 \mathrm{ft}$., into the uncased portion of the well in 1987. However, this action did not extend the period of high rate pumping adequately during periods of peak demand. The pumps cannot be lowered further since the main 
fracture/producing interval is at approximately $200 \mathrm{ft}$. and the pump bowls are already in the uncased portion of the well.

BWSWD-2 is warmer and used as the primary producer. Pumping levels are obtained by bubble tube in BWSWD-1. Figure 12 is a plot of water levels and flowrates from BWSWD-1 and 2 since 1977 (Waag, 1989). No records of production prior to 1977 are available.

The yearly production totals are given in Table 7 . The data available (BWSWD, 1989) is reported in terms of total production over a heating season year. Though some down-time is likely to have occurred, it was not reported.

The production data in Table 7 includes summer artesian flows which occurred through 1983. Flowrates vary from less than $100 \mathrm{gpm}$ to over $1600 \mathrm{gpm}$ over the 12 year period of record. 


\section{Table 7}

\section{BWSWD Production}

Year (1)

$$
77-78
$$

$78-79$

$79-80$

$80-81$

$81-82$

$82-83$

83-84

$84-85$

$85-86$

$86-87$

$87-88$

$88-89$ (2)
Total

$273308 \times 10^{3} \mathrm{gal}$.

304720 "

$305493 \quad$

241053

275020 ."

280922 "

$299043 \quad$

$276773 \quad "$

260100 n

191279 "

$190529 \quad$

220893 "
Average

Rate

$520 \mathrm{gpm}$

580

581

459

523

534

569

526

495

364

362

723

(1) Sept. to August heating season

(2) Through March 1989 


\section{b) Water Leve1}

Warm water had also issued from springs in the Boise foothills prior to geothermal aquifer production. It is not clear when these springs ceased to flow. In addition, original static water levels in early wells on the fault in the BWSWD area, may have had static water levels 60-70 ft. higher than at present.

The recent water level record (hydrograph) of BWSWD-1 and 2 is shown in Figure 12. The most significant feature of Figure 12 is that, since 1983, there has been a decline in water level while production has also been declining. BWSWD-1 and 2 have been reaching a maximum drawdown (to the pump bow Is) for a longer period each year, automatically curtailing production. Table 8 shows another indication of the steadily declining water levels in the BWSWD area.

These phenomena indicate that recent production by BGL is causing the geothermal aquifer to seek a new (deeper) equilibrium level to balance total production. Just as a level was achieved for long-term BWSWD-1 and 2 production alone, which is lower than historic accounts of original static levels, so a new level will be reached for the system.

On top of the effect of well production, seasonal precipitation and longer term climatic influences are likely to affect the geothermal aquifer recharge and pressure. These 
influences would be difficult to distinguish without long-term water level records prior to the start of production by major users.

\section{Table 8}

Maximum Water Level Recovery in BWSWD-1 and 2

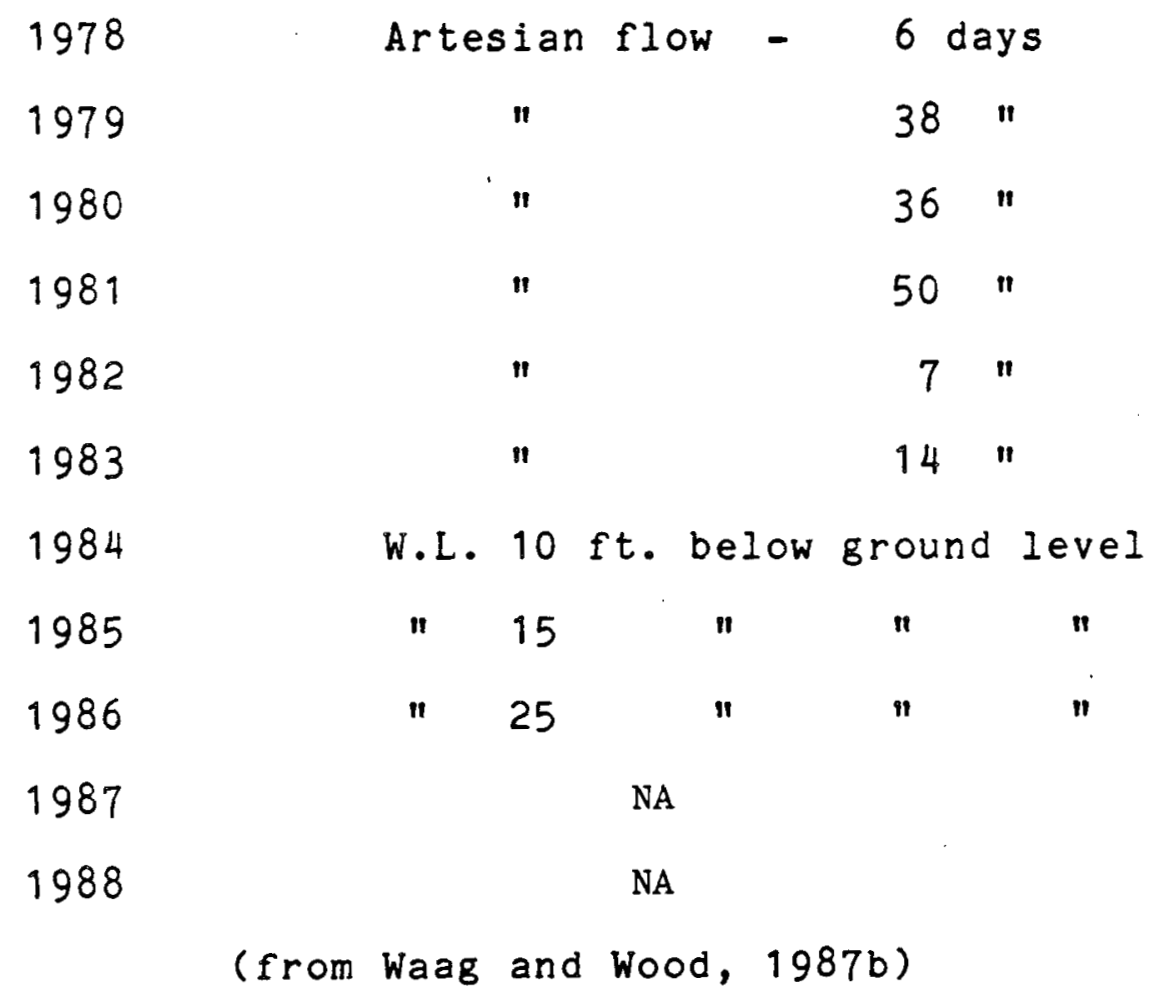

Note: BWSWD-1 and 2 cannot be shut-in. The discharge line for both wells is approximately $3 \mathrm{ft}$. below ground level (G.L. $=2764.9 \mathrm{ft}$. elevation).

Water level data for BWSWD-3 has been recorded since 1982 (Waag, 1989), and is shown in Figure 13. This well is used for observation only. The water level shows obvious parallels with 
those of BWSWD-1 and $2,645 \mathrm{ft}$. away. A decline in peak recovery is evident as is a shorter recharge period as shown by the area under the curve for each yearly cycle. The decline in recovery averages $4.5 \mathrm{ft}$. per year since 1983 , and the decline in maximum drawdown averages $1.7 \mathrm{ft}$. per year. This trend does not show signs of leveling of even though total BWSWD production has decreased in the period from the 1983 to 1984 season to the 1987-1988 season. Production was up somewhat. during 1988-1989 season.

\section{c) Temperature Data}

No changes in flowing temperature have been observed since production began. No static temperature logs have been done on BWSWD-1 or 2. Until recently, they have flowed artesian in late summer and fall, and have essentially been in constant use year round with the pumps in place.

The temperatures profiles for BWSWD-1 and 2 (Appendix A) were taken just after the pumps were removed for servicing in 1987. At that time, the water column was disturbed in both wells.

\section{6) Kanta Well}

The Kanta well is located $1675 \mathrm{ft}$. southeast of BWSWD-1 and 2. It has been monitored for several years by Boise state 
University (BSU). It is deeper than the BWSWD wells, and is completed in the rhyolite geothermal aquifer (Table 1). The location and lithology indicate this well is west of the main fault zone (Figure 3). The water level data indicates a decline in water level similar to the BWSWD-3 well (Figure 14) and it is appears the Kanta well is in communication with BWSWD-1 and 2 . The Kanta well has an annual decline (averaging $4.6 \mathrm{ft} / \mathrm{yr}$ during 1984-1989) in peak recovery and maximum drawdown decline of 6.4 ft/yr. The Kanta well is likely to be influenced by pumping at the Botanical Gardens well (Old Pen. Well) which is used intermittently for irrigation (Waag and Wood, 1987). No flowrate data is available for the Botanical Gardens well.

\section{7) Behrman Ve11}

This is an old well, located west of BWSWD-3 (Figure 2). No lithology, depth, or completion data are available. It is not in use, but has been monitored for water level by BSU since 1985 (Figure 15). It appears, from the water level data, to be completed into the fault zone or rhyolite aquifer, such that it responds to BWSWD production. The water level has been declining much like the Kanta and BWSWD-3 wells.

There is a significant difference in water level elevation between the Behrman well and BWSWD-3 which are only $320 \mathrm{ft}$. 
apart. This difference (approximately $62 \mathrm{ft}$. in Feb. 1989) has been attributed by Waag $(1987 \mathrm{~b})$ to a semi-permeable boundary between the two wells.

This well behaves somewhat anomalously in other ways. In 1987, the water level recovery was comparatively lower than other wells such as BLM, BWSWD and Kanta, and the 1988 recovery was comparatively higher. These differences may be due to production at the Quarry View well (see below), and possibly to the Behrman well completion, which is unknown. Production at Quarry View would likely suppress the water level rebound in the Behrman well during the summer months. The completion or corrosion of casing may allow communication with shallower aquifers. Unfortunately, the well could not be accessed through the well head for a temperature survey.

\section{8) Quarry View Park Well}

The Quarry View Park well is located Southwest of the Behrman and BWSWD wells (Figure 2). It's depth and completion are given in Table 1. This well had been used for irrigation of the park during the summer months, therefore, it has a water level record (Figure 16) with highs and lows opposite to that of geothermal wells used for heating. It produces water up to 132 F .

In summer, the well was pumped intermittently, as needed. 
Figure 16 shows the drawdown resulting from greater production during the drought year of 1987-88. The well was taken out of service for irrigation at the end of the 1988 season. There are no flowrate records for this well but estimates were calculated by Waag (1987a) based upon power consumption.

Given the temperature, relatively shallow depth and lithology of the well (Appendix B), it appears to be completed above the main geothermal aquifer rhyolite. The fluid is apparently a mixture of thermal water and fluid from the deep fresh water aquifer (Table 3 ). As a result, pumping of the Quarry View well may have had a relatively low impact on the geothermal aquifer and a lesser drawdown effect in nearby monitoring wells. 


\section{REVIEH OF UELL TESTS AND PREVIOUS ANALYSES}

There have been numerous tests of Boise area geothermal wells by government agencies and private consultants. These studies have focused on the selected wells described in the previous section, specifically, in the CM-BGL-VA and BWSWD areas. Though wells in outlying areas may have been tested privately, no such information is publicly available.

The following is a brief summary of each test with particular attention given to those with the most abundant and accurate data. Three of these have been selected for further analysis using the pressure response model developed for this study.

\section{1) BLY and Beard Hells}

The BLM and Beard Wells were drilled in 1976, along with three (abandoned) test holes, by EGG/INEL for exploration of the Boise Geothermal system (Nelson, et al, 1980). These were the first known geothermal wells in this area, and are believed to be the most extensively tested of any Boise area geothermal wells up to that time.

Table 9 gives a summary of the well tests. Aborted or inconclusive tests are not presented if there was no analysis or the findings were not significant. 
We11 Test and Analysis Summary

\begin{tabular}{|c|c|c|c|c|c|c|c|}
\hline $\begin{array}{c}\text { Well } \\
\text { (Pumped/Flowed) }\end{array}$ & Date & $\begin{array}{l}\text { Pumped/ } \\
\text { Artesian }\end{array}$ & Flowrate & $\begin{array}{l}\text { Maximum } \\
\text { Drawdown }\end{array}$ & $\begin{array}{l}\text { Background } \\
\text { Influence? }\end{array}$ & Results & Reference \\
\hline Beard & $10 / 28-10 / 29 / 76$ & A & $100 \mathrm{gpm}, 26 \mathrm{hrs}$ & Beard, $2.89 \mathrm{psi}$ & BWSWD & $\mathrm{T}=6,370 \mathrm{gpd} / \mathrm{ft}, \quad \begin{array}{r}\text { Flowing } \\
165^{\circ} \mathrm{F}\end{array}$ & (31) \\
\hline$"$ & $9 / 13 / 77$ & $\mathrm{p}$ & $250 \mathrm{gpm}, 16 \mathrm{hrs}$ & BLM, $0.3 p s i$ & $"$ & $\begin{array}{l}\mathrm{T}=68,800 \mathrm{gpd} / \mathrm{ft} \\
\mathrm{S}=0.000035\end{array}$ & " \\
\hline$"$ & $10 / 13-10 / 25 / 77$ & A & $150 \mathrm{gpm}, 12$ days & $\begin{array}{l}\text { Beard, 5psi } \\
\text { BLM, 1.5psi }\end{array}$ & $"$ & $\mathrm{~T}=8000 \mathrm{gpd} / \mathrm{ft}$ & $"$ \\
\hline$"$ & $1 / 19-1 / 20 / 78$ & $\mathbf{P}$ & $380 \mathrm{gpm}, 27 \mathrm{hrs}$ & $\begin{array}{l}\text { Beard, 47.4psi } \\
\text { BLM, 1.7psi }\end{array}$ & $"$ & $\begin{array}{ll}\text { Beard } & T=6000 \mathrm{gpd} / \mathrm{ft} \\
\text { BLM } & T=91,000 \mathrm{gpd} / \mathrm{ft} \\
& \mathrm{S}=0.000037\end{array}$ & $"$ \\
\hline BLM & $10 / 10-10 / 11 / 77$ & $\mathrm{P}$ & $90 \mathrm{gpm}, \quad 30 \mathrm{hrs}$ & Beard, 49psi & $"$ & $T=600 \mathrm{gpd} / \mathrm{ft}$ & $"$ \\
\hline$"$ & $1 / 4-1 / 7 / 78$ & $\mathbf{P}$ & $120 \mathrm{gpm}, 72 \mathrm{hrs}$ & BLM, 71psi & " & $\begin{array}{l}\mathrm{T}=20500 \mathrm{gpd} / \mathrm{ft} \\
\mathrm{S}=0.000023\end{array}$ & " \\
\hline$"$ & $1 / 10-1 / 11 / 78$ & $\mathbf{P}$ & $120 \mathrm{gpm}, 30 \mathrm{hrs}$ & $\begin{array}{l}\text { BLM, 40psi } \\
\text { Beard, 2psi }\end{array}$ & $"$ & $\begin{array}{ll}\cdot \mathrm{BLM} & \mathrm{T}=1170 \mathrm{gpd} / \mathrm{ft} \\
\text { Beard } & \mathrm{T}=100,100 \mathrm{gpd} / \mathrm{ft} \\
& \mathrm{S}=0.00054\end{array}$ & " \\
\hline \multicolumn{8}{|c|}{ Capitol Mall Wells } \\
\hline Statehouse Well & $1 / ? / 75$ & $\mathbf{P}$ & $?, 24 \mathrm{hrs}$ & ? & $"$ & $\begin{array}{l}\mathrm{T}=25,900 \mathrm{gpd} / \mathrm{ft} \\
\text { Flowing } 104^{\circ} \mathrm{F}\end{array}$ & (27) \\
\hline $\mathrm{CM}-1$ & $12 / 8 / 80$ & A & $205 \mathrm{gpm}, 1.75 \mathrm{~h} \mathrm{rs}$ & -- & $"$ & - & (2) (3) \\
\hline$"$ & $12 / 12-12 / 15 / 80$ & $\mathrm{P}$ & $\begin{array}{l}350 \text { to } 806 \mathrm{gpm} \\
60 \text { hrs. total }\end{array}$ & $\mathrm{CM}-1,356 \mathrm{ft}$ & $"$ & $\begin{array}{l}\mathrm{T}=5000 \mathrm{gpd} / \mathrm{ft} \\
\mathrm{S}=0.00005, \text { Flowing } 153^{\circ} \mathrm{F}\end{array}$ & $"$ \\
\hline$"$ & $12 / 15 / 80$ & A & $300 \mathrm{gpm}$ & $\mathrm{CM}-1,22 \mathrm{psi}$ & $"$ & Flowing $153^{\circ} \mathrm{F}$ & " \\
\hline
\end{tabular}




\section{Table 9 (cont.)}

We11 Test and Analysis Summary

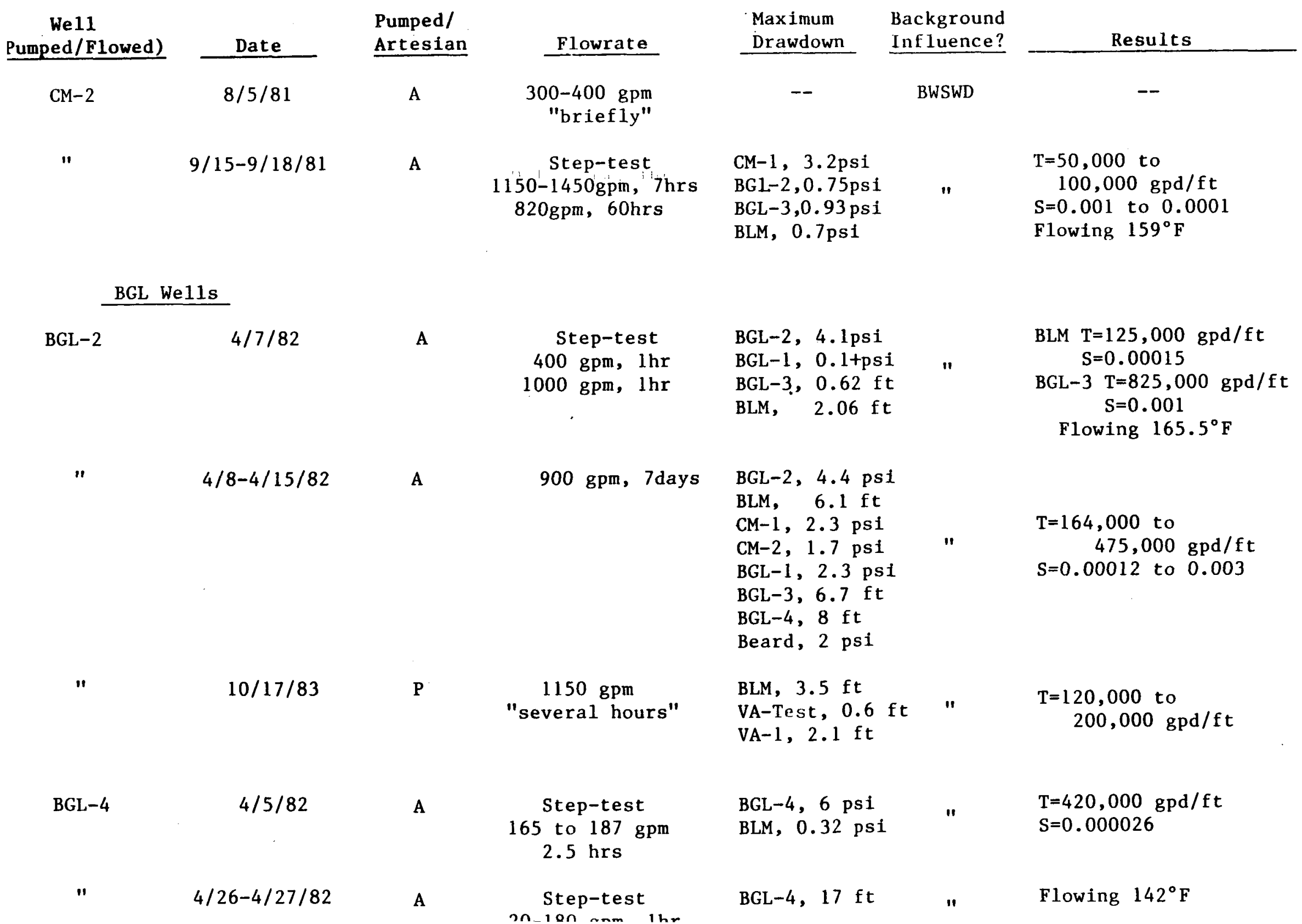

$\underline{\text { Reference }}$ 
We11 Test and Analysis Summary

We11

(Pumped/Flowed)

BGL-4

$4 / 28-4 / 29 / 82$

BGL-2

and

BGL-4

Operations
Pumped/

Artesian

A

Flowrate

$160 \mathrm{gpm}, 46 \mathrm{hrs}$

$-2,0.3 \mathrm{ft}$ BGL-3, $0.35 \mathrm{ft}$ $\mathrm{CM}-1,0.2 \mathrm{ft}$

$\mathrm{P}$

$P$

Normal

\section{Maximum} Drawdown

500 gpm, 19days and

1300 gpm, 17days
Background

Influence?

Results

Reference

BWSWD.

$\mathrm{T}=112,600-820,000 \mathrm{gpd} / \mathrm{ft}$ $\mathrm{S}=0.00018-0.00054$

BWSWD

CM

$\mathrm{T}=100,000 \mathrm{gpd} / \mathrm{ft}$

$\mathrm{S}=0.00008$

VA We11s

$\mathbf{P}$

Step-test

A

A

A 400-1245 gpm

$5.5 \mathrm{hrs}$

$180 \mathrm{gpm}, 15 \mathrm{hrs}$

$35 \mathrm{gpm}, 1 \mathrm{hr}$

$\mathrm{VA}-1,78 \mathrm{ft}$

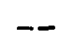

$-$

$-\infty$

$65 \mathrm{gpm}, 2 \mathrm{hrs}$

180-580 gpm

$1 / 2 \mathrm{hr}$
Inject.

Test

$\begin{array}{cc}\text { VA-1 (Prod) } & 10 / 11 / 83 \\ \text { " } & 10 / 11-10 / 12 / 83 \\ \text { VA-Test } & 11 / 3 / 83 \\ \text { VA-2(Inj) } & 12 / 16-12 / 17 / 83 \\ & \\ & 1 / 8 / 87\end{array}$

$1 / 8 / 87$
"

$\begin{array}{cc}\text { VA-1 (Prod) } & 10 / 11 / 83 \\ \text { " } & 10 / 11-10 / 12 / 83 \\ \text { VA-Test } & 11 / 3 / 83 \\ \text { VA-2(Inj) } & 12 / 16-12 / 17 / 83 \\ & \\ & 1 / 8 / 87\end{array}$


Table 9 (cont.)

We11 Test and Analysis Summary

We11 Pumped/Flowed)

Date

BWSWD Production We1ls

$\begin{array}{ll}\begin{array}{c}\text { BWSWD } \\ 1 \& 2\end{array} & 9 / 81-3 / 82 \\ \text { " } & 9 / 84-9 / 85 \\ & \\ \text { " } & 7 / 85-6 / 86\end{array}$

\section{Quarry View Park We11}

$\begin{array}{ll}\begin{array}{l}\text { Quarry } \\ \text { View }\end{array} & 11 / 4 / 83 \\ \text { " } & 2 / 23 / 84 \\ \text { " } & 2 / 24 / 84\end{array}$

Pumped/

Artesian

Flowrate
Maximum Background

Drawdown Influence?

Results

Reference
$\mathbf{P}$

100-1500 gpm (avg. 730 gpm)

$\mathbf{P}$

0-850 gpm

(seasona1)

200-850 gpm
BLM, $10 \mathrm{ft}$.

BWSWD $1 \& 2,140 \mathrm{ft}$

\section{See Figures}

$10,12,13$.

See Figures

$10,12,13,14,15$.
$\mathrm{T}=25,000-240,000 \mathrm{gpd} / \mathrm{ft}$ $\mathrm{S}=0.0005-0.00005$

$\mathrm{T}=3500-25,000 \mathrm{gpd} / \mathrm{ft}$ Lower $T$ values attributed to fracture storage.

Analysis based on earlier calculated values of $T$. (see above)
$\mathrm{P}$

Steptest 44-265 gpm 1.5 hours

Steptest 55-250 gpm 4 hours

$175 \mathrm{gpm}$ 8 hours
QV, $226 \mathrm{ft}$

BWSWD

BGL

$\mathrm{CM}$

QV, $195 \mathrm{ft}$

"

QV, $185 \mathrm{ft}$
$\mathrm{T}=2000-3000 \mathrm{gpd} / \mathrm{ft}$.

Flowing $132^{\circ} \mathrm{F} \max$.

Flowing $133^{\circ} \mathrm{F} \max$.

Flowing $131^{\circ} \mathrm{F}$ 
The Beard well was tested four times, from 1976 to 1978 . Two tests were with artesian flow and two were pumped. At the time, the only observation well was the BLM well. Measurements taken in the pumped well were either by electric tape or bubble tube and Heise pressure guage. Observation well measurements were by quartz pressure transducer at the well head. At the time, both wells had positive well head pressure. Pressure measurements taken at the flowing well are complicated by thermal effects for artesian flow tests and to a lesser extent pump tests. This is a problem common to all geothermal flow tests. The flowing temperature of the fluid was rarely reported for these tests of the BLM and Beard wells.

The BLM well was pump tested three times in 1977-1978, with the Beard well as the only observation well. As Table 9 shows, the BLM well had a lower flow capacity. The range of aquifer parameters calculated from the pressure data varied considerably, with the interference data yielding the higher calculated parameters. The BLM well test interference data was reported to display a break in slope, indicating a potential recharge boundary (Nelson, et. al., 1980).

The cyclic pressure response of the BLM well recorded during 1977-1978 prompted consideration of an interference pressure response due to BWSWD well pumping. The findings (regarding interference) were inconclusive and Nelson (1980) even considers 
aquifer loading from irrigation during spring and summer, as a possible cause of the fluctuations.

\section{2) Capitol Mall Nells}

The first geothermal well drilled in the area (The Statehouse well) was tested in 1975 (Mink, 1976). The Statehouse well is located next to the Capitol building, and was completed from approximately 830 to $1100 \mathrm{ft}$. It was used for irrigation for some time but is now shut-in, though not abandoned. It is not considered a significant well for this report because there is no operational or monitoring data for it. The test data is included in Table 9 for completeness. The well flowed at a temperaure of $104 . F$. Results indicated mixing with cooler shallower water occurred due to the relatively moderate depth of the well completion.

The other two Capitol Mall wells ( $\mathrm{CM}-1$ and $\mathrm{CM}-2)$ were tested immediately after drilling. No interference data was taken during the CM-1 tests. The CM-2 well had not yet been drilled, but the BLM and Beard wells were presumably available. The aquifer parameters calculated for $\mathrm{CM}_{-1}$ (Table 9) were based on measurements taken during flow testing of $\mathrm{CM}-2$ (Anderson and Kelly, 1981).

A number of observation wells were used for the longer CM-2 ( 67 hour) test. These test results gave a wide range of aquifer 
parameters. Overall, a transmissivity of $60,000 \mathrm{gpd} / \mathrm{ft}$. was considered to be a conservative regional average (Anderson and Kelly, 1981).

The report by Anderson and Kelly (1981) includes not only test analysis of $\mathrm{CM}^{-1}$ and $\mathrm{CM}-2$ data but also a theoretical production/injection pressure simulation (conducted by Papadopulos, Assoc.) indicating the likelihood of possible injection breakthrough from $C M-1$ to $C M-2$. The results were that breakthrough was not likely if the assumptions of the simulation $(Q=320 \mathrm{gpm}, T=60,000 \mathrm{gpd} / \mathrm{ft}$, Gradient $=0.008 \mathrm{ft} . / \mathrm{ft}$. to the southwest) were valid. Thermodynamic effects were not input to the simulation.

Maximum flowing temperatures during testing were measured at $153 \mathrm{~F}$ for $\mathrm{CM}-1$ and $159 \mathrm{~F}$ for $\mathrm{CM}-2$.

\section{3) BGL Ye11s}

BGL-2 was flow tested twice; once short-term ( 2 hours) and once long-term ( 7 days). A number of wells were available for observation during the test (see Table 9). The analysis of the drawdown and interference data yielded a wide range of calculated aquifer parameters. The method of measurement varied between wells and the results depended upon the well data being analyzed and the method (semi-log or type curve) used. Two breaks in slope were identified on the semi-log plots for 
several of observation wells, indicating potential boundaries.

BGL was also monitored in connection with the VA-1 well test in 1983 (Anderson and Kelly, 1983). In addition, BGL-2 and BGL-4 operating history data was analyzed by BGI for the Department of Energy in 1985 (BGI, 1985). Two breaks in slope were identified for a semi-log plot of BLM well data. A log-log type curve analysis was inconclusive and a computer history match gave the parameters listed in Table 9. The production history match indicated the aquifer was not well suited to the use of a homogeneous reservoir model. A fracture type model was considered to be more appropriate and such a model is used for this study (See Sections IV and V).

\section{4) YA He11 Test}

of the three VA wells (VA-1, VA-2, VA-Test), the VA-1 well was most extensively tested and was the only one of the three that was pump tested. All the wells were subjected to testing of sorts when they were cleaned out under close observation, after drilling. Only actual test data is presented in Table 9. Three of the tests consisted of brief artesian flow with some observations but without much interference data gathered due to the lack of response expected.

During the pump test of VA-1, in October 1983, instrumentation was set up to record interference measurements 
of $C M$ and BGL wells, as well as, the BLM and VA-Test wells. No significant drawdown (over the background effects of BWSWD and CM operations) was measured in any of these weIls even though VA-1 was pumped at rates up to $1245 \mathrm{gpm}$. The test was quite short $(5-1 / 2$ hours).

In general, the instrumentation in the interference wells was accurate enough to detect a response of less than $1 / 2$ foot of water level change. Data from tests of other wells in the area indicate the test length should have been sufficient to register a measureable response. It is unclear why none was recorded. No aquifer parameters were calculated from the drawdown data from pumped well (VA-1). The pumped fluid temperature was measured at $161.5 \mathrm{~F}$.

The VA-1 well flowed artesian overnight after the well test, October 1983 at a rate of approximately $180 \mathrm{gpm}$. The temperature of the flow was measured at $160 \mathrm{~F}$.

The VA-Test well was not tested in the conventional sense, but was developed (air-lifted) extensively over a period of a few days. The airlift was occasionally halted to allow brief observations of artesian flowrate and temperature. The well could sustain an artesian flow of $35 \mathrm{gpm}$ at $106 \mathrm{~F}$. This well was drilled for test purposes rather than intended for actual injection.

WeIl VA-2 (Inj) was drilled and tested three years after 
VA-1 (Prod) and VA-Test. It was also alternately air lifted and flowed briefly during development. The flow was measured at 65 gpm at $142 \mathrm{~F}$. No pressure drawdown or interference data was observed or recorded.

Well VA-2 was injection tested on two occasions. The first was December 12, 1986 at $165 \mathrm{gpm}$ for 68 minutes with a pressure buildup of $162 \mathrm{psi}$. This brief test is not listed in Table 9 since the well was further cleaned out (by airlift) which improved its characteristics. A second injection test was performed January 8,1987 at various rates from 180 to $580 \mathrm{gpm}$ with a maximum pressure of $47 \mathrm{psi}$. The pressure during this test did not appear to have stabilized due to the short test duration but a significant improvement over the first test is indicated. This improvement is attributed due to the additional clean out procedures.

Analysis of the second test results indicated the wells' injectivity was $900 \mathrm{gpm}$ at $100 \mathrm{psi}$. VA system operations indicate the present injectivity was 160 psi pressure at $430 \mathrm{gpm}$ before the recently completed hydro-fracturing job was completed. As a result of that stimulation the injectivity is now reported as $600 \mathrm{gpm}$ at $150 \mathrm{psi}$ (J.M. Montgomery Engineers, 1989). 


\section{5) BUSWD Hells}

The two BWSWD production wells, BWSWD-1 (East) and 2 (West) were believed to have been drilled in the early 1900's. No well test data was available for this study. However, they were analyzed recently on the basis of their operating (production and drawdown) history (Waag and Wood, 1985, 1987a, 1987b). In addition, the water level records of BWSWD-3, Kanta, Behrman, Quarry View and BLM wells were considered as interference (monitoring) wells. Though they are not tests in the conventional sense, these analysis are summarized here and in Table 9 for completeness. No other test data or analyses are available for wells in this area.

The water level data was not given for all of the analysis periods listed in Table 9 (for BWSWD-1 and 2) because it is cyclic and requires a somewhat lengthy description as to which portions are attributable to which wells. Listing a single maximum drawdown for each period would be somewhat misleading. However, the water level data is shown in the hydrographs of Figures 10 through 15.

The analysis approach taken by Waag and Wood $(1985,1987 a$, 1987b), is both qualitative and quantitative. Aquifer parameters were calculated from the pumping well drawdown and observation well water level data. Also, a range parameters were calculated from tests of other Boise area wells. 


\section{6) Quarry View Hell}

As mentioned previously, this well was used for park irrigation, and completed into somewhat shallower lithologic units than most Boise area geothermal wells. It is unclear what fraction of its total flow it is drawing from the geothermal aquifer and what fraction is coming from shallower cooler aquifers.

It was pumped at a reported $132 \mathrm{~F}$ temperature (Anderson and Kelly, 1984) when tested (Table 9). Drawdowns of up to $100 \mathrm{ft}$. were measured (measurements at Quarry View are taken just after pumps shut off). The calculated transmissivity was $1000 \mathrm{gpd} / \mathrm{ft}$. No other tests are believed to have been performed.

Because its operation cycle (summer) is opposite from that of other geothermal wells in the area, it is not clear from the water level data (Figure 16) how nearby wells respond to it and vicé-versa. 


\section{PRESSURE RESPONSE MODELING}

Pressure response modeling for the Boise geothermal aquifer involved simulation of the aquifer response to, 1) recent pumping (1980-1989), 2) continued use at the present level for the years 1990-2000 and 3) potential effects of expanded development for the years 1990-2000. The calculations were performed using BGI's PC program MRMW (Multi-Rate Multi-Well). A description of the programs used for this study are included below.

Computer simulation was required due to the number of flowing wells and changing flowrates. Previous attempts to interpret test and production data by various investigators, using standard graphical techniques, have been inconclusive, yielding a wide range of aquifer parameters. Previous analysis difficulties are believed to be due primarily to the fact that the Boise Geothermal Aquifer should be analyzed as a fracture controlled system and not a homogeneous isotropic system. Analyzing the aquifer using a homogeneous isotropic (or Theis) approach results in overly large values for transmissivity ( $T$ ) to be calculated (see Table 9). This is because these values of transmissivity $(T)$ and storativity (S) attempt to compensate for the high conductivity of the fractures. Rather, the $T$ and $S$ parameters should apply only to the formation matrix and should be incorporated into a fracture model. 
BGI has developed a fracture flow model for the Boise system. The level of complexity of such a model is greater than isotropic, line source (Theis) models due to the larger number of parameters needed to define a fractured reservoir (such as; fracture length, fracture aperture, fracture storage, relative location of fracture center, fracture orientation, etc.). Due to the number of unknown parameters, the model was first used to analyze individual well test data. This approach allowed definition of aquifer parameters with an individual well flowing, at an approximately constant rate. This information was then used to history match the aquifer response to simultaneous production by the major users (i.e. CM, BGL, BWSWD and VA) from 1980 to 1989. If individual well test data had not been available, the number of unknown parameters, together with the extremely variable and imprecise operational flowrate data, would have made a unique history match difficult to achieve. The stepwise approach taken, helped define aquifer parameters individually. However, a number of factors remain unknown due to the lack of data from long-term well test or long-term (constant flowrate) production history of one or more major production wells.

\section{1) Description of the Mathematical Model}

The calculation methods employed in the program MRMW 
(Multi-Rate, Multi-Well) to model a fracture fed reservoir required substantial effort to develop and are proprietary. MRMW uses linear superpostion of the line-source solution for radial flow to or from a well that penetrates a homogeneous liquid reservoir or aquifer of constant height. Through the use of image wells, constant pressure and no-flow boundaries can be modeled.

The program consists of 5 modules that must be "chained" together due to the limited memory available in PC's (in the past). The main calculation module has numerous subroutines required for the calculation of the special functions that comprise the solutions of the different model options. The fracture solution is an iterative process. The equations and algorithm are complex and are partly proprietary and will not be given in detail. The aquifer pressures (head) are obtained by linear superposition of solutions (a form of convolution intergration). Both the line source (Theis) and fracture solutions are commonly used for flowing wells but required adaptation for observation wells.

The fracture model is based on published research (Gringarten and Witherspoon 1972; Cinco-Ley and Samaniego 1977, 1981, 1984; Hanly and Bandyopadhyay, 1979), and has been modified to include the effects of wellflow both outside the fracture, inside the fracture, and a flowing well on the 
fracture.

The program calculates the transient pressure drawdowns and/or buildups at specified locations in an underground single-phase liquid reservoir or aquifer. The drawdowns or buildups or any combination of drawdowns and buildups can be calculated from wellflow occurring in specified wells. The flowrates in each of the wells can be specified with any combination of production or injection. MRMW can be used (a) to analyze single well drawdowns or buildups, step-rate tests, or variable rate tests, (b) to generate patterns of wells and to calculate pressure changes in the wellfield for prediction of long-term behavior of single-phase reservoir, (c) to estimate drawdowns at interference wells for proper match up of test instrumentation, (d) to enable parametric studies of reservoir formation variables, and (e) to compare multi-well, multi-rate well tests data with model calculations. The calculated results can be plotted with actual well test data points to determine the best fit of the formation parameters. A linear, semi-log or log-log output can be specified.

Boise well test data displays the characteristics of a fracture fed reservoir. This is most apparent when drawdown versus time is plotted on a log-log scale. The pressure (or water level) data of observation wells in fractured reservoirs behaves at very early time by displaying fracture storage 
control on a "Unit Slope" (slope of one log cycle to one log cycle) trend, followed by bi-linear flow. Bi-linear flow is so called because two forms of linear flow occur simultaneously, in the fracture and in the formation (Figure 17). Bi-linear flow is characterized by a "Quarter Slope" (one log cycle of drawdown or build-up for every four log cycles of time). A "Half slope, Linear flow", section follows the "Quarter Slope" section until very late time. At very late time, fracture storage and conductivity are no longer the factors controlling fluid flow and the matrix parameters ( $T$ and $S$ ) recome dominant. Here the drawdown curve flattens out to steady state much like a pressure drawdown curve of a non-fractured system ( $C$ inco-Ley and Samaniego, 1981, 1984) (Figure 17).

In cases where aquifer pumping is cyclic, (i.e. seasonal) it is difficult to determine when these characteristic flow periods occur since the long-term data cannot be plotted on a log-10g scale due to flowrate changes. For the Boise aquifer, the early BLM-VA data from 1976-1978 and 1981-1982 suggests a steady state had been reached (with only BWSWD as the major user) up until 1982-1983. This is due to the relatively consistent return to the same recovery level. Water level fluctuations of $10 \mathrm{ft}$. in the BLM well each year are believed to be due primarily to BWSWD pumping, and appeared to recover anually to 2760 to $2765 \mathrm{ft}$. elevation. 
If the Boise geothermal system were bounded in any significant sense, a continous water level decline would have been evident in the 1976-1982 data (given the relatively consistant yearly production by BWSWD) for BLM, rather than the observed steady state. Further, if recharge available to the aquifer were approximately equal to BWSWD production prior to 1982, then the original static level would never have declined (approximately $70 \mathrm{ft}$. by historic accounts) since the $1890^{\prime} \mathrm{s}$.

Unfortunately, there is no known record of the flow rate or pressure decline from 1890 to 1982 . This would have been of great value to this study. Estimates of past production may be available from those familiar with local water lore. Diligent research into the growth of the BWSWD system and probable demand from 1890 to 1980, was outside the scope of this study, but may be a worthwhile topic for future studies. For this study, past flowrates were assumed to equal the average pumping, by BWSWD, for the period 1977-1983.

In the model used for the following calculations, the Boise Front Fault is represented as a series of large connecting fractures tapped by the major wells BGL, BWSWD and VA. The Capitol Mall wells are also believed to tap fractures though perhaps not as large as those along the Boise Front Fault. A recharge area is assumed to be located to the east, parallel to the Boise Front Fault, to represent a recharge boundary (Figure 
37). A discharge area is located far to the west to represent discharge through the geothermal aquifer toward the valley.

This model (Figure 37 ) is not conceptually different from that shown in Figure 9 and is common to Basin and Range geothermal systems. No new data has allowed any change in the model shown in Figure 9 or improved upon it.

It was necessary to simplify some features of the local geology and hydrology, either due to the lack of data, or for adaptation to computer simulation. The primary simplifications are; 1) the geometry of the recharge and discharge area relative to the fault 2) a straight fault or fracture zone, representing the geothermal anomaly, of approximately 40,000 ft. in length 3) a tablular aquifer of constant elevation and thickness (if shown in cross-section) 4) no pressure boundaries (impermeable partial or full pressure support) to the northwest or southeast. The latter assumption was made after numerous attempts to model the system (using both well tests and history match data) with boundaries of various types and distances in each of those areas.

The recharge boundary to the east and a discharge boundary to the west simulate the effective flow through the system. The word effective is emphasized since, for this geothermal aquifer, and many others like it, the actual flow through the system cannot be measured. Modeling efforts rely on the relative 
amount of through-flow which affects the system as indicated by the monitoring well water level data. It is likely that much more recharge enters the system than the effective through-put value used. But, because subsurface recharge and discharge characteristics are poorly understood (e.g. along a undetermined length of fault, into an unknown and variable thickness of material at unknown rates), effective through-put is approximated.

The factors that control recharge and whether recharge varies with season or year to year will be difficult to interpret due to the lack of (pre-production) background water level data. There appears to be a vague correlation between water level and recent local precipitation (Figures 21 and 25), however, significant "cultural noise" prevents direct correlation. It is likely that cold water on the fringes of and in cold water zones above, the geothermal aquifer, provide some pressure support to the system. This relationship will affect recharge estimates.

The geochemical data indicates the fluids have ancient origins, but it is likely that the pressure head driving the system has contemporary origins, judging from the water level data. In general, pressure tends to dissipate rapidly, whereas, ancient waters can circulate at depth for extended periods. 


\section{2) Well Test Matching - Model Confirmation}

In order to obtain aquifer parameters for later use in the long-term calculations, two well tests and one short-term history match were selected for analysis. The specific tests and history match were chosen out of many available (see Table 9) on the basis of the data quality and period in which they occurred. The period of interest was prior to October 1982 when BWSWD was the only major user of the aquifer sufficient to cause background effects. Under these (relatively) controlled conditions, the pressure response of each monitoring well can be more easily attributed to the single flowing well being tested. This allows more precise analysis of the model's performance and reservoir parameters. These test data, in particular, were selected in order to study the drawdown effects in various regions of the aquifer, specifically in the CM, BGL-VA and BWSWD areas.

The cases selected were:
a) BGL-2 Test, 4/8/82 - 4/15/82
b) CM-2 Test, $9 / 15 / 81-9 / 18 / 81$
c) BWSWD-1 and 2, History Match, $9 / 81-8 / 82$

\section{a) BGL-2 Test Analysis (4/8/82-4/15/82)}

This BGL-2 test is probably the best of all the well tests for Boise due to the relatively constant high flowrate, minimum of disturbance to the aquifer prior to the test, number of monitoring wells both on and off the fracture, accuracy of the 
monitoring well data and test length. A longer test would have allowed analysis of the late transient behavior; specifically, how long linear flow continues and when it changes to pseudo-radial flow (Figure 17).

The test data for the three monitoring wells with best data are plotted in Figure 18 on $\log -\log$ and linear scales (as data points) and include the calculated matches (as lines). The data and calculated match for the two observation wells on the main fracture (BGL-4 and BLM) display the quarter and half slope sections. For the monitoring well of the fracture $(C M-1)$ only half slope behavior is displayed.

The linear plot (Figure 18b) shows the magnitude and slope of the calculated match to be quite good. The parameters used for this match (same in linear and $10 \mathrm{~g}-10 \mathrm{~g}$ plots) are:

$$
\begin{aligned}
T & =5750 \mathrm{gpd} / \mathrm{ft} . \\
S & =3 \times 10^{-5} \\
L_{f} & =40,000 \mathrm{ft} . \\
F_{C D} & =\frac{k_{f} \mathrm{~b}}{\mathrm{k} \mathrm{X}_{\mathrm{f}}}=11 \quad(1<0<100) \\
\text { where: } \quad L_{f} & =\text { Fracture Length } \\
\mathrm{F}_{\mathrm{CD}} & =\text { Fracture storage coefficient } \\
\mathrm{k}_{f} & =\text { Fracture permeability } \\
\mathrm{b} & =\text { fracture aperture } \\
\mathrm{k}_{\mathrm{f}} & =\text { matrix permeability } \\
\mathrm{X}_{f} & =\text { Fracture half length }
\end{aligned}
$$


The terms of $F_{C D}$ are unknown for the Boise area fractures so that its value is chosen simultaneously with $T$ \& $S$ to give a unique solution. The most important feature allowing the solution to be unique is the transition (in the actual data) from $1 / 4$ to $1 / 2$ slope. A wide range of $T, S$ and $F_{C D}$ were attempted, to achieve a calculated match of the data, but always resulted in a return to the above values.

In contrast, the dotted line of both plots is the Theis (or line source) solution for BGL-4 with the same data, achieved with:

$$
\begin{aligned}
T & =125,000 \mathrm{gpd} / \mathrm{ft} . \\
\mathrm{S} & =0.0001
\end{aligned}
$$

The purpose was to attempt to fit the maximum drawdown for the test, but clearly the shape is not consistent with the actual data. Altering $T$ and $S$ could move the dotted (Theis) fit down so that it crosses through the data. However, even large changes in $T$ and $S$ cannot significantly alter the shape of the Theis curve fit, and the data clearly shows the drawdown in BGL-4 was not leveling of to steady state at the end of the test, as the Theis curve predicts.

This example shows how previous analyses arrived at abnormally high values for $T$ and $S$ (see Table 9 ) using graphical techniques. The parameters $T$ and $S$ are intended to represent the formation properties not including fracture conductivity. Using high values for $T$ and $S$ will not allow correct drawdowns 
to be calculated for long-term simulation because they predict a steady state would occur much sooner than it actually does for the Boise geothermal aquifer and would not match actual data.

It was a severe setback to this analysis not to have long-term test data which would allow a full analysis of a single, constant rate test through to a steady state condition. The theory predicts a transition from the half slope to a line source at large values of dimensionless time (Figure 17). When, and if this transition occurs in the Boise aquifer is not clear due to lack of constant rate test data. It is apparent that the aquifer achieved a steady state with respect to BWSWD pumping until new wells began pumping in 1982 and 1983 .

\section{b) $\mathrm{CM}-2$ Test $(9 / 15 / 81-9 / 18 / 81)$}

The CM-2 test was only three days long, but was the longest available test of either $C M$ well with interference well data. This test was the best available to show aquifer response to a well flowing, at a significant distance from the Boise front fault zone. It was hoped that this flow test data would show the relationship of a flowing well in the matrix to one (BGL-2) on the main fault.

Unfortunately, no meaningful pressure data could be collected from the flowing well ( $\mathrm{CM}-2)$ to show the production well drawdown with time. Wellhead pressure is difficult to 
interpret for geothermal wells (flowing artesian) due to thermal effects in the wellbore during the early portion of the test. Only downhole pressure can give a true measure of drawdown in such cases. However, since the well was flowed artesian during the test, drawdown would not have been more than the initial static head (when hot) above the discharge line (approximately $50 \mathrm{ft}$. in the case of $\mathrm{CM}-2$ in $9 / 81)$.

A Iinear plot of the data (derived from Anderson and Kelly, 1981) is shown in Figure 19a along with the calculated match of the data. Only the CM-1 data is well defined enough to match. The BGL observation wells on the fault all show similar responses (only one is plotted here for clarity). The response on the main fault, due to CM-2 flowing, is much lower than if the observation wells on the fault were in an isotropic aquifer. It appears that fracture storage (along the Boise Front Fault) is influencing the drawdown along the fault at the early times. No behavior other than fracture storage is observed on the fault due to the short test duration. The log-log plot is shown in Figure 19b, though not enough observation well data points are available to describe specific details of fracture behavior.

In order to match the data shown in Figure 19, and given the known high productivity of $\mathrm{CM}-2$ relative to $\mathrm{CM}-1$, it was necessary to assume that $\mathrm{CM}-2$ intersected a moderately large fracture or fracture network. Unfortunately, there are no well 
logs (such as flowing Pressure, Temperature, Spinner ( $P / T / S$ ) logs) which can be used to determine whether $C M-2$ produces from a few large fracture feedzones or throughout the thickness of ryholite aquifer penetrated.

To allow a reasonably low drawdown for $\mathrm{CM}-2$ and $\mathrm{CM}-1$ during the three day test, a fracture of $15,000 \mathrm{ft}$. was assumed to intersect $C M-2$. Further, because the drawdown of observation (BGL) wells on the fault are low in proportion to CM-1, a constant pressure boundary is incorporated in the analysis along the main fault. A steady state had not been reached at the end of the test, so a mathematical expression for the boundary is difficult to obtain from this data, particularly since there is no evidence of a boundary in $\mathrm{CM}_{-1}$ monitoring data.

The match in Figure 19 for $C M-1$ and $B G L-3$ is achieved using a fracture on $\mathrm{CM}-2$ and a partial recharge pressure support boundary. The assumption of partial support (in relation to $100 \%$ support) is due to there being some measurable drawdown along the fault. This drawdown appears to be fracture storage on the log-log plot (BGL-3). The partial pressure support used for the match of this test is equal to $50 \%$ of production at $\mathrm{CM}-2$. 
The parameters in this case were:

$$
\begin{aligned}
& T=5750 \mathrm{gpd} / \mathrm{ft} . \\
& S=3 \times 10^{-5} \\
& F_{C D}=11 \\
& L_{f}=8,000 \mathrm{ft} .
\end{aligned}
$$

c) BWSWD-1 and 2 History Match $(9 / 87-82)$

Test data for these wells was not available. Instead, a one year period of operational data was used in the absence of better data. This set of data was chosen because it is the least disturbed data (i.e. prior to CM startup in 1982) available for isolating the effects of production of BWSWD wells alone. During the period considered here $(9 / 81-8 / 82)$, there was (at first) only one monitoring well in use (BLM). Monitoring at BWSWD-3 well was not begun until April 1982, halfway into this "test" period. The observation well data plotted on Figure 20 is from BWSWD-1 and 2, BLM and BWSWD-3. The drawdown portion shown in Figure 20 for BWSWD-3 is estimated from the late 1982 and early 1983 data. A later period could not be used because of increased pumping activity in 1983, due to BGL start-up. This estimated drawdown is likely to be accurate to within $2 \mathrm{ft}$. in $75 \mathrm{ft} .(\sim 3 \%)$ due to the very consistent response of BWSWD-3 each year.

It is possible that the BWSWD-3 data for the late-1982 
early-1983 period is influenced by the startup of the CM wells. However, the distance to $\mathrm{CM}-1$ and $\mathrm{CM}-2$, which began production in late 1982, and the fact that simultaneous injection occurred, virtually cancelled any potential response in BWSWD- 3 which could have significantly altered the data.

Though this data may not be accurate enough for a precise analysis, it does show the effectiveness of the model to predict the drawdown on the fracture at great distances with a varying flowrate. Of particular importance is the fit of BLM drawdown with the varying flowrates at BWSWD 1 \& 2 using similar parameters to the other two tests.

The calculated match of the data is also shown on Figure 20.

The parameters used to get a best fit to the data were:

$$
\begin{aligned}
& T=5750 \mathrm{gpd} / \mathrm{ft} \\
& S=3 \times 10^{-5} \\
& F_{C D}=10 \\
& L_{f}=17,000 \mathrm{ft} .
\end{aligned}
$$

This data also shows the difference between the calculated and actual magnitude of the drawdown in BWSWD-3. The larger actual drawdown in BWSWD-3 is not matched by the model because the model is based on drawdown-distance relationships of all the Boise area wells. The model cannot allow for special localized effects within a single fracture such as that which occurs in the fracture intesected by BWSWD-1, 2, and 3. Clearly, it is a 
phenomenon local to the fracture into which BWSWD-1, 2 and 3 are completed and not a regional effect, such as a lower $T$ or $S$. This is because of the long-term data from the BLM, Behrman and Kanta wells (Figure 21), which indicate BWSWD-3 is an exception. Also, note that a similiar effect (large drawdown near producing wells on the fault) is not observed in the BLM well relative to BGL-2 production.

This phenomena of a large drawdown in BWSWD-3, relative to other wells, in response to BWSWD 1 and 2 pumping is believed to be due to the conductivity of the fracture into which all three BWSWD wells are completed. The fracture in this region appears to have a high conductivity, allowing the drawdown in BWSWD-3 to be similar to that of BWSWD 1 and 2; unlike other wells in the Boise area which display a much more finite conductivity behavior.

In the Iiterature (Earlougher, 1977), a fracture of "infinite" conductivity allows a monitoring well to display the same amount of drawdown as the flowing well. Fractures of finite conductivity require an additional coefficient ( $\left.F_{C D}\right)$ to describe how drawdown varies along the fracture. In practice, it is difficult to allow the fracture conductivity coefficient to vary along its length. The model used here allows each separate fracture to have a different $F_{C D}$ but it cannot be varied along its length. Further, there is not yet enough data 
to precisely define fractures tapped by wells in the Boise area. 


\section{3) History Matching $(1981-1989)$}

A history match of the data from 1981 to 1989 was performed using all the available pressure and flowrate data. The period was chosen to begin in 1981 since relatively continuous data from BWSWD and BLM were available since that time.

Significantly, this date is prior to the beginning of additional production from the Boise geothermal aquifer by major users except BWSWD.

The analysis period for history matching was 1981-1989, but early (1976-1978) BLM data was taken into account for establishing baseline conditions. The lack of early flowrate data, particularly at the startup of the Capitol Mall and VA systems make a precise match of the data difficult to achieve. For the simulation, flowrate input data was averaged every two months, due to flowrate data quality and computer memory limitations .

To match the fluctuating yearly cycle of aquifer pressure, it would have been preferable to use daily, or at least weekly, flowrate input data. However, this would amount to over 1000 flowrate entries for the 9-year history match.

Good quality flowrate data was the greatest single factor limiting the confidence in the input data for the history match. However, we realize this data is not easily obtained, requiring either more manpower or costly equipment. 
At the BGL wells, the flowrate data is now recorded by a computer logger and a flow totalizer. This data now can be more easily handled. Even so, the circumstances are less than ideal, since the recorded value is that being discharged to customers, not actual production and injection (of the excess). Furthermore, it is uncertain whether the net flow will yield accurate simulation results since the excess is injected into another BGL well (usually BGL-2). No test is known to have been performed with this production-injection doublet but the effect is assumed to be negligible, on the basis of the previously described BGL-2 Test and in the absence of (doublet test) data.

Only flowrate data from the major users is considered for the History Match calculations since there was none available from the other (private) users. Attempting to estimate flowrates and pumping periods for small private geothermal well users probably would only have introduced error into the calculations. None of these users are reported to pump a significant amount and usually only in the summer months. Due to the distance of most of these private users wells from central Boise, it is unlikely they have a significant impact on the resource or the wells included in this study.

Most private geothermal wells are belived to produce mixed (geothermal and fresh) water due to their shallower well completions. Further, little or no historic water level data is 
available (Young, et. al. 1988). More than one year of accurate flowrate and water level data would be required for wells in outlying areas in order to include them in any analysis or history match. Without such data it is difficult to predict the relationship of those wells to those of the major users (BWSWD, $C M, V A, B G L$ ) in Boise.

Because of the overall quality (or lack) of flowrate data and water level measurements in flowing wells, and their erratic pumping schedules it is difficult to match pumping well data with calculated values using the model. Even with precise operational flowrate data and downhole pressure measurements, good matches would be difficult to achieve without reliable step rate test data. Such tests would allow analysis of skin factors and other wellbore effects at different rates. In the absence of good flowing/pumping well data, this study will focus on the aquifer wide response as seen in the high quality observation well data from the BLM, BWSWD-3, Kanta wells. The water level data for the Behrman well is also good, but it begins later. The well completion for the Behrman well, its depth and extent of communication with shallow cold groundwater water aquifer is unknown. Figure 21 and 22 show plots of the high and low water level values for each of these wells.

The data for Figures 21 and 22 were derived from Figures 10-15 and serve to show the general trend in the aquifer 
pressure and is the most useful format for showing the calculated history match results. It is clear from Figure 21 , given all the data to-date, that the two regions (BLM-VA-BGL and BWSWD) behave as if connected to one aquifer. Note that the difference, or spread, between a given year's high and low value has increased from $10 \mathrm{ft}$. with only BWSWD flowing, to 15-20 ft. since 1983 with more wells in use. Of particular interest, is the reservoir recovery in the summer of 1989 and the subsequent maximum drawdown in early 1990 (not available from all wells for this study, but can easily be plotted on Figure 21). This will show whether the system is beginning to stablize after an above average rainfall year (1988-1989) in spite of heavy winter pumping from the geothermal aquifer.

Note that data collection did not begin in the same year for each well. Unfortunately, the pre-1983 data is not available for most wells, leaving the pre-1983 water levels to be undefined in most areas. The pre-1983 value is important to the history match calculation and was estimated where necessary based on early CM-2 and BLM well data.

The data for CM-2 presents a special problem since it is recorded as pressure at the well head which can lead to various interpretations in water level due to thermal effects. If both static and flowing temperature profiles are available, it is possible to calculate water level based on down hole pressure. 
However, since neither the profiles or downhole pressure are available, it is difficult to correlate "hot" well head pressure to cold static or hot water level. The well head pressure is dependent upon the temperature (density) in the column of fluid. The hot (flowing) pressure is not easily referenced to the original static cold pressure reported by Anderson and Kelly (1981). It is estimated that the hot static column is about 20 ft. higher than the cold column for this well. It is easier to compare the recent hot water level or pressure measurements to one another but not to the pre-production static (cold) level.

Figure 23 shows the pressure data, converted to hot column water level elevations for the yearly high pressure/water level during the summer of each year. Note that a lesser decline is seen here than in Figures 21 and 22. No low (winter) water level data are shown because of the method of measurement (soon to be improved). 


\section{a) Input Data and Assumptions}

The history match calculations were performed in two phases; 1) Establishing a background condition to approximate pre-1980 aquifer response to BWSWD (and predecessors) production and 2) Using actual flowrate data for the period 1978 to 1989, averaged over two month intervals, to calculate a history match. Figure 24 shows the yearly (net) production from the aquifer. One major assumption is that the flowrates reported by various users are accurate to within $10 \%$. The purpose of using detailed flowrates was to match to maximum and minimum water levels recorded in key observation wells from 1980 to early 1989 (Figure 21).

For this study, an average recharge-discharge deficit of $-3200 \mathrm{gpm}$ allowed the appropriate long-term drawdowns needed to match the observation well data. A greater than average deficit was required to match the data in some years which coincided roughly with lower than average annual rainfall. This points toward, but does not conclusively prove, the influence of rainfall on geothermal aquifer pressure.

Other input included the $T$ and $S$ values and fracture parameters derived from the well tests. Because of the relatively short duration of the well tests and variable data quality, the fracture parameters were subject to slight changes based on the history match results. 


\section{b) Results}

Over one hundred model calculation runs were made. The different scenarios focused on fracture length and trend, effective recharge rates, boundaries, well flowrate sensitivity, and matrix parameter ( $T \& S$ ) studies. These were used to determine what combination of factors would allow the test data, early (pre-1982) monitoring data with BWSWD flowing alone, and recent (post-1983) declines to be fitted with one model.

This was found to be very difficult with the data to-date, primarily due to the varying annual flowrates and the fact that no test data is available to describe the drawdown-distance relationship at late times. Figure 21 indicates a very uniform aquifer drawdown. However, based on the well tests, one would expect a greater drawdown at BLM and lesser effect at Kanta after BGL came on-line. Instead, both areas are affected similarly. This apparent discrepancy in short-term test drawdown-distance relationships versus long-term aquifer response could be answered by a long-term constant rate test.

For this study, various combinations of the following scenarios were considered in order to history match the data. 
- Isotropic aquifer.

- Varying $T$ \& S.

- Varying fracture lengths of each well producing from fractures.

- Approximating recharge short-fall.

- Boundaries, varying in number and orientation.

- Continuous decline on log-log $1 / 2$ slope.

- Effects of yearly average rainfall.

- Recharge - Discharge Ratios

Numerous cases involving no-flow boundaries in various geometries failed to produce a reasonable match. With a closed system, the overall drawdowns were too large to match the well test data or the history match data. Even a seven day flow test (such as BGL-2 in 1982) would show the effects of a boundary several miles away. No test data indicates such a boundary or boundaries exist.

Most scenarios were run with the history match input and then checked using the individual well test data (discussed earlier). The scenario or model was rejected if the calculated results did not match the recent history data (Figures 21,22 and 23) and the individual well test data.

As previously mentioned, the results focused on the fit of both BLM and Kanta observation well data since they had the best quality data and the longest monitoring period. The history 
match to the BLM data is shown in Figure 26 and the match for Kanta is shown in Figure 27. The data for these plots are derived from Figure 21.

Note that a good match to BLM historical data (1981 - 1989) can be found, but the same input does not result in as good a match at the Kanta well. The primary difficulty with matching the uniform, aquifer wide, overall drawdown is the lack of data with which to define drawdown-distance relationships which account for both long-term water level monitoring data and short-term well test data. However, the use of a fracture model allows a much more even distribution of pressure drop than an isotropic (or Theis) solution.

Pumping wells were difficult to match in the absence of data to define wellbore effects. However, an effort was made to match the existing data.

The match for BWSWD-1 is shown in Figure 28. The maximum drawdown remained constant due to the depth of the pump bowls, but the plot does not reflect the length of time the maximum drawdown was achieved each year (see figure 12). The model, of course, is unaware of the pump bowl setting and predicts drawdowns based only on flowrate and aquifer parameters. Wellbore effects (skin, non-Darcy flow, etc.) probably play a significant role in the behavior of BWSWD pumping wells. The fit shown in Figure 28 and that of BWSWD-3 (see below) could be 
improved if step-rate well test data were available for BWSWD-1 and 2 .

The pump was lowered $60 \mathrm{ft}$. in 1988 to obtain greater capacity, but little improvement in productivity was observed, probably due to the increased influence of wellbore effects at high flowrates.

The match of $\mathrm{CM}-2$ is shown in Figure 29. Limited success in matching the data was obtained on the basis of current data. The results are somewhat inconclusive in the absence of downhole pressure data during testing and normal operations.

The match of BWSWD-3 is shown in Figure 30. The difficulty with matching the maximum drawdown was discussed earlier (see Part IV.2.c.) and may be improved when the program is modified to allow a variable fracture coefficient within a given fracture. Meanwhile, the recovery (upper) curve is matched quite well. It is a better indicator of aquifer trends since it is less susceptible to localized pumping effects from BWSWD-1 and 2 .

Another interesting feature of Figure 30 , is the decline shown in BWSWD-3, from peak recovery 1982 to 1983 , even though BGL production had not yet begun. BLM and BWSWD-1 data do not show this decline, but it may indicate the potential for factors, other than well pumping, to influence aquifer pressure. 
The calculated results discussed above for the existing history match data were obtained with the following parameters:

$$
\begin{aligned}
& T=5750 \mathrm{gpd} / \mathrm{ft} \\
& S=3 \times 10^{-5} \mathrm{ft} / \mathrm{ft}
\end{aligned}
$$

Estimated fracture lengths of producing wells: .

$\begin{array}{lcl}\text { BGL-4 } & \text { Approx } & 6,300 \mathrm{ft} \\ \text { BWSWD-1 \& } 2 & " 1 & 8,500 \\ \text { CM-1 } & " 1,000 \\ \text { CM-2 } & " 1,000 \\ \text { VA-1 } & " 1,300 \\ \text { VA-2 } & \text { " } & 8,300\end{array}$




\section{c) Conclusion and Discussion of Inter-relationship Between WeIIs}

In general, the model appears to mirror aquifer behavior though flowing well behavior is more difficult to match without better flowing well test data. At this point, some conclusions can be drawn with respect to the inter-relationship between wells.

A finite conductivity fracture zone is believed to feed a fractured rhyolite formation of moderate transmissivity. Due to the conductivity along the fracture, the wells completed into it communicate readily (e.g. BWSWD $1,2,3, \mathrm{BLM}, \mathrm{BGL} 2,3,4, \mathrm{VA-1}$ \& 2 etc.). Since the conductivity is finite, the effects of one well on another are relatively minor even at high flow rates, except in the case of BWSWD-3 while pumping BWSWD 1 or 2 . Whether VA-1 and VA-2 behave as if completed in the fracture or in the matrix formation is unclear from the limited test and historical data to-date (up to 6/89). But VA-1, at least, is very likely to be in communication. with wells along the fracture.

From the well test of CM-2, we have seen that it communicates with BLM and BGL-3 and, by association, must also communicate with other wells in the fault zone. The same is likely to be true of $\mathrm{CM}-1$. Though no $\mathrm{CM}-1$ test data proves this except indirectly by the $C M-2$ test data. 
In the absence of long-term, high rate, individual well tests it is difficult to precisely gauge the effect of specific production wells on other production wells while both pump simultaneously. Clearly, some wells have significant wellbore effects, completion problems, or are located in zones with a greater or lesser fracture conductivity, perhaps due to the relative degree of fracture vein filling in selected areas.

In general, the wells behave as expected given the present conceptual and mathmatical model. The basis for each wells pressure response is its proximity to the main fracture and net production on the fracture. The effect of the $\mathrm{CM}$ production and injection doublet on other wells, in terms of pressure, is probably negligible due to their distance from the fracture and other wells and injection of all fluid produced.

It is too early in the operating history of the VA system, with only limited historical data (up to June 1989) to determine its effect. None of the observation well data showed any response directly attributable to the start-up of VA wells. The test of VA-1 also did not create a measureable response in nearby wells (Anderson and Kelly, 1983). The flowrate data upon startup is not available, therefore it is difficult to calculate a potential response. Production at VA-1 seems to have caused little drawdown in that well. No measurements were taken in the VA-1 Test injection well just before or after system startup 
which could give some indication of its impact. It appears, from the daily bubble tube readings from March to June 1989 , that the pumping water level elevation at $\mathrm{VA-1}$ is the same as the water level in the BLM well.

\section{4) Analysis of Continued Production}

a) Continued Production at Current Levels

For this calculation the same parameters were used as for the history match. The flowing wells included in the calculation were also the same as for the history match (BWSWD 1 \& $2, B G L-4, C M-1, C M-2, V A-1, V A-2)$. Average flowrates were assumed for each, based on available data. Six flowrates per year were used for each well to actieve a cyclic pressure response. Average effective recharge values were also used.

The model was used to calculate drawdowns for the period of 1990 to 2000. Given the present data for the system and the current transitional nature of the bulk of the data base, the calculations were not projected beyond 10 years. Among the more difficult assumptions was that BWSWD production will be maintained at former (1977-1983) levels. This was assumed because of the difficulty in projecting available flowrates for the present BWSWD wells given the lack of test data. Since even present demand is not always met, production from other wells may be used to meet future demand. The daily pumping demand is 
difficult to predict but it is possible that with a careful pumping schedule that pre-1982 production could occur.

Anticipating demand or siting alternative production well locations was outside the scope of this study.

Due to the several factors (number of wells in use, severity of winters, rainfall or other recharge effects), no assumptions were made regarding the ability of wells to continue or increase production. At present, the aquifer can provide geothermal fluid at required rates as long as an appropriate well (depth and design) is used.

The average monthly flowrates used for the period 1990-2000 are shown below.

\begin{tabular}{|c|c|c|c|c|c|c|}
\hline & $\underline{J-F}$ & $\underline{M-A}$ & $\underline{M-J}$ & $\underline{J-A}$ & $\underline{s-0}$ & $\underline{N-D}$ \\
\hline BWSWD $1 \& 2$ & $922 \mathrm{gpm}$ & $618 \mathrm{gpm}$ & $315 \mathrm{gpm}$ & $168 \mathrm{gpm}$ & $390 \mathrm{gpm}$ & $812 \mathrm{gpm}$ \\
\hline$B G L-4$ & 542 & 459 & 187 & 82 & 233 & 444 \\
\hline CM $1 \& 2$ & 500 & 388 & 175 & 55 & 250 & 450 \\
\hline VA $1 \& 2$ & 350 & 120 & 90 & 90 & 200 & 300 \\
\hline
\end{tabular}

The net flow from the aquifer is assumed to be approximately 450 million gallons per year under this scenario. This is somewhat above the average of the last few years (Figure 25) because it assumes all users (including BWSWD) can satisfy demand.

The results were calculated for the BLM and Kanta wells 
which have the best and longest term data for the two main producing areas to-date. The results for the flowing wells are not shown, since, as explained above, the flowing well test and operational data is not sufficient to make long-term assumptions regarding wellbore effects and thermal effects which dominate the drawdown and buildup behavior of those wells. More assumptions were required (due to lack of data) for flowing wells than for observation wells. The data and projected drawdowns for BLM and Kanta are more indicative of actual aquifer response than flowing wells.

As shown in Figures 31 \& 32 , the rate of aquifer drawdown is calculated to decrease (level off) at later time due the assumption that flowrates will not increase and recharge will remain constant. How recharge is controlled, and whether it is changing, cannot be determined from the data to-date, but it clearly dominates the aquifer response. A much greater decline could be expected without constant recharge.

\section{b) Continued Production with Additional Injection}

A calculation was performed to assess the impact of injection of all BGL produced fluid at a location near BGL's discharge point at the Boise River. The location is shown on Figure 37 and is approximately $8500 \mathrm{ft}$. west of the BGL production wells. 
This hypothetical injection well site (BGL-I) is not a suggested injection site or based on site specific studies. It is used for analysis purposes assuming geologic conditions are similar to the CM-2 well region, though the geothermal aquifer rhyolite is proably somewhat deeper than at $\mathrm{CM}-2$ due to fault offsets and/or minor westerly dip. The simulations involving this injection site are for comparision to cases without additional injection. Site selection for injection was not the primary focus of this study. This selection was based primarily on proximity to the BGL outflow pipeline. Actual well siting, for this or any other project, would be preceded by site specific studies with consideration of well design for the application.

The input data for this case is identical to the previous calculation except that BGL system flow is injected into the hypothetical well (BGL-I). The flowrate of injection is assumed to be identical to production (see $\mathrm{Table} 10$ ). Injection is assumed to begin on January 1, 1990, for the purpose of this study.

The results are plotted on Figures 31 and 32 for the BLM and Kanta wells. As expected, injection at a distance of $8500 \mathrm{ft}$. from the fault, does not cause significant pressure support to the aquifer in the area (along the Boise Front Fault) where the major producing wells are located. The hypothetical injection 
is calculated to reduce the overall drawdown of the aquifer by approximately ten feet.

\section{5) Analysis Increased Future Production}

a) Increased Future Production without Injection

For the purposes of this study, it was assumed that a $50 \%$ increase in production would occur for all the primary geothermal aquifer users (BWSWD, CM, VA, BGL). The flowrates for each user were assumed to be those of Table 10 multiplied by 1.5. Whether these assumed rates are practical, feasible, or desirable was not the focus of this study. Of primary interest is the overall effect of increased production on the geothermal aquifer.

The results, for BLM and Kanta observation wells, are shown in Figures 33 and 34 . Increasing production by $50 \%$ is calculated to increase drawdown by approximately $30 \mathrm{ft}$. in the winter and $16 \mathrm{ft}$. in the summer after 10 years assuming all factors, including recharge, remain the constant.

b) Increased Production with Injection

The hypothetical injection well (BGL-I), used in the calculations discussed in Part 4b, was also used in this case of increased production with injection. Flowrates for all wells, including the injection well were increased $50 \%$ as above.

The result of injection in this case is to decrease drawdown in the aquifer by approximately $12 \mathrm{ft}$. in the BLM and Kanta 
areas (Figures 33 and 34) compared to the previous case. Again, as in Part 4b, injection near Boise River does not significantly affect drawdown near the Boise Front Fault.

\section{6) Conclusions on Future Draudown Calculations}

A number of assumptions have been made regarding recharge and well flowrates. These assumptions have been discussed and should be considered when interpreting results. The scarcity of data, in some respects, make such assumptions difficult (see Section II).

The calculations indicate that if no increase in production from the aquifer occurs and recharge is constant, a relatively stable new equilibrium recovery level will be established near $2730 \mathrm{ft}$. (elevation). If injection by BGL occurs near BGL's out-flow line then drawdown will be less by 5-10 ft. depending upon season.

The effect of increasing production by $50 \%$ for all wells (BWSWD, CM, VA, BGL) is calculated to draw the system down an additional $30 \mathrm{ft}$.

It is evident that continued flowrate and water level data are necessary to refine long-term prediction calculations. Improved assumptions regarding subsurface recharge and discharge may be possible after the aquifer drawdown approaches a new steady state. More precise flowrate and drawdown data for 
individual wells is necessary for a better understanding of the nature of the recharge. The bulk of the data available is of a transient nature which is of limited use for long-term calculations.

\section{TEMPERATURE RESPONSE MODELLING}

\section{1) Description of the Hodel}

The temperature response modelling was done with the aid of BGI's TBLOCKS program. TBLOCKS is a two dimensional, finite difference, thermal reservoir simulator that can be used to perform parametric studies, analysis of reservoir thermal history (evolution), analysis of production/injection effects, and single well thermal behavior. The program allows heat and mass boundary conditions to be simulated very easily. Caprock, basement, boundaries, spring flow, and faults can be modelled. The program is limited in the number of blocks (discrete volumes) that can be modelled due to PC memory limitations. Those limitations were not critical to this study.

TBLOCKS uses a finite difference method (Richtmyer and Morton, 1977) that is unique. The conservation of mass and energy give equations that can be solved using the finite difference techniques described in the references. The simulator uses a proprietary form of these partial differential equations that is similar to the Integrated Finite Difference Method (IFDM) developed at the University of California at 
Berkeley (Peaceman, 1977; Kasamyer and Schroeder, 1976).

The program, TBLOCKS, uses a simplified form of the IFDM equations to provide a geometry-independent solution of aquifer blocks joined at a single interface through which fluid can flow in any direction. The result is the solution for convective effects of production, injection, upwelling, inflow, discharge, etc. The method uses boundary conditions that are supplied by the user as common parameters, such as velocity of the inflow and outflow, and temperatures of fluid flowing into and out of the reservoir or aquifer.

Typical applications of TBLOCKS include resource evolution, effects of production and injection on reservoirs and surface features (springs, etc.) and the thermal behavior of one well or a group of wells during production and/or injection.

It calculates average reservoir temperature changes based on:

1) Reservoir volume

2) Porosity

3) Rock thermal properties

4) Natural recharge and discharge

5) Production and injection rates and temperatures.

The primary consideration for analysis of temperature effects is the potential for cooling the reservoir particularly near production wells. There were two different methods considered for analysis of the potential for these effects to 
occur in the Boise Geothermal Aquifer. One is a block model of the reservoir, with blocks sized and shaped to represent basic reservoir geometry. Such a model is shown in Figure 35a, where the fault can be represented by a long narrow element with a variable or constant recharge rate and temperature.

This type of model is useful if the approximate recharge rate can be estimated from long-term background and spring flow data and production/injection occur in a relatively limited area or in a regular pattern geometric well spacing. Also critical to the type of model used, is some estimate of the aquifer volume swept by a given recharge rate. Some of these criteria could not be met for analysis of the Boise geothermal aquifer.

Attempts to estimate these input resulted in a very small calculated decline in average reservoir temperature because a very large volume had to be used to incorporate all the wells in the system ( $B G L, V A, C M$ and hypothetical $B G L$ injection well near the Boise River). A number of smaller blocks could not be used to represent the same reservoir since there is no evidence of physical or thermal boundaries or other structural controls to justify such division.

An alternative method was chosen to calculate the cooling of the reservoir around existing or proposed injection wells. Figure 35b shows a simple schematic of the method used. When analyzed as a cylinder with concentric shells, an accurate 
analysis of progressive temperature changes can be made for individual injection wells, particularly when they are widely or irregularly spaced, as in Boise.

The calculations assume a uniform vertical front of constant thickness, which is an approximation since both gravity and dispersion will affect the injection plume, causing it to lose its tabular form unless confined. The TBLOCKS program does not account for the effects of pressure which may induce distortion of the front due to preferred flow paths or a strong hydraulic gradient. However, boundary conditions can be defined to allow for these phenomena given the known pressure response.

\section{2) History Match}

The data from Boise (see Section II.2.c. above), thus far, indicates that the production temperature at the fault zone has and will remain constant. This conclusion is derived from data sheets from geothermal well operators and comparisons with early test data for those wells (Anderson and Kelly, 1982, 1983). As yet, there is no indication that thermal boundaries (e.g. cold groundwater) will affect the temperature of the fault zone source of the fluid. The BWSWD wells have caused significant drawdown to the system since the $1890^{\prime} \mathrm{s}$, apparently without drawing cold water into the system. However, it is conceivable that very large drawdowns could induce cooler water influx but 
such drawdowns would probably have to be much greater than at present. The only temperature changes to be considered in this study will be due to injection of cooled fluid.

Currently, there is little temperature data to refer to or use for history match purposes which may give clues as to future behavior. The Capitol Mall system has the only injection well (CM-1), and the only production well, operating for sufficient time to be affected $(C M-2)$. CM-2 has shown an apparent production temperature decline of approximately $7 \mathrm{~F}$ since the 1982 system startup. In general, the flowing temperature of CM-2 varies with flow rate. The highest temperatures were measured at the highest flowrates. But, at all rates the decline has been approximately the same according to the data thus far.

Based on the analysis by. Papadopulos Associates (in Anderson and Kelly, 1981) the injection plume from CM-1 could intersect CM-2 during periods at which flow is above average. This is consistent with the data, except that a continued or increased temperature decline would be expected with time as more rock, closer to the producing wells, is cooled by injection. However, the production data shows lower total production from 1988 and 1989 than previous years which may have prevented more of the injected fluid from reaching $\mathrm{CM}-2$.

The Papadopulos analysis was based on a homogeneous 
isotropic aquifer with $\mathrm{T}=60,000 \mathrm{gpd} / \mathrm{ft}$., $\mathrm{Q}=320 \mathrm{gpm}$ avg and a gradient of $0.08 \mathrm{ft} . / \mathrm{ft}$. ( S $55 \mathrm{~W}$ ). The aquifer thickness assumed for that calculation is not given. This method is based on pressure, not temperature. Therefore, it does not provide an estimate of temperature decline in the production well or the aquifer thickness affected. Such a decline could be calculated which could include the effect of reheating and mixing fluid in the formation. This analysis is performed for the VA injection well (Anderson and Kelly, 1983).

For this study, the program TBLOCKS was used to calculate temperature declines caused by injection. The model approximates a worst case scenario regarding breakthrough to CM-2 because the hydraulic gradient is not incorporated. The gradient would be expected to deflect fluid (injected into CM-1) away from $\mathrm{CM}-2$.

The aquifer thickness and porosity are important in calculating the progression of cooled fluid by this method. These properties are difficult to measure and are not generally known for the Boise aquifer. An effective aquifer thickness of $500 \mathrm{ft}$. was assumed based on the CM-1 well completion. An average porosity of $10 \%$ was considered a reasonable estimate for this highly fractured volcanic rock.

The region around $\mathrm{CM}-1$ was assumed to represent a cylinder with concentric shelis (see Figures 35 b and 36). Five 
concentric cylinders of $250 \mathrm{ft}$. width were used, up to a radius of $1250 \mathrm{ft}$. which is the approximate distance from $\mathrm{CM}-1$ to $\mathrm{CM}-2$. The input data for this calculation was as follows:
a) 5 blocks, concentric cylinders $250 \mathrm{ft}$. wide, extending from $C M-1$ to $C M-2$ (Figure 36 ).
b) Porosity $=10 \%$
c) Rock Density $=2600 \mathrm{~kg} / \mathrm{m}$
d) Rock Heat Capacity $=1000 \mathrm{~J} / \mathrm{kg}-\mathrm{K}$
e) Injection/Flowrate $=500 \mathrm{gpm} @ 51.7 \mathrm{C}(125 \mathrm{~F})$
f) Injection $=500 \mathrm{gpm}(30.3 \mathrm{~kg} / \mathrm{s})$
8) Production $=500 \mathrm{gpm}(30.3 \mathrm{~kg} / \mathrm{s})$
h) Initial temperature of geothermal aquifer $70.5 \mathrm{C}(159 \mathrm{~F})$
i) Effective aquifer thickness $=500 \mathrm{ft}$.

Neither CM-1 or CM-2 have stabilized temperature profiles available from which to obtain accurate initial temperature data for the production zone. The original flowing temperature for CM-2 was chosen as this value. Also, the depth and effective thickness of the production/injection zone is not known. The calculation was run for six years to simulate the average production/injection from 1983 through 1988. The results are shown in the table below. Block five (1000-1250 ft. from CM-1) contains CM-2 (Figure 36 ). 


\section{Wel1 CH-1}

Distance

$\begin{array}{cccccc}\text { Year } & \text { O-250! } & \text { 250-500: } & 500-750 ! & 750-1000^{\prime} & \text { 1000-1250! } \\ 1982 & 158.9 \mathrm{~F} & 158.9 \mathrm{~F} & 158.9 \mathrm{~F} & 158.9 \mathrm{~F} & 158.9 \mathrm{~F} \\ 1983 & 145.2 & 157.5 & 158.7 & 158.9 & 158.9 \\ 1984 & 137.1 & 154.6 & 158.4 & 158.7 & 158.7 \\ 1985 & 132.3 & 151.2 & 157.6 & 158.5 & 158.7 \\ 1986 & 129.4 & 147.7 & 156.7 & 158.4 & 158.5 \\ 1987 & 127.6 & 144.5 & 155.5 & 158.0 & 158.4 \\ 1988 & 126.5 & 141.6 & 154.0 & 154.4 & 158.2\end{array}$

The results indicate the temperature of water produced from $\mathrm{CM}-2$ would drop only $1 \mathrm{~F}$ over the six year period rather than the $5 \mathrm{~F}$ shown by the collected data (see section II.2., above). The calculated value would be even less than $1 F$ if the effects of an east-west hydraulic gradient were incorporated in this model. The gradient would cause most of the injectate to be swept toward the southwest away from $\mathrm{CM}-2$.

These calculations indicate that either: 1) The cooler injection fluid does not move outward from $\mathrm{CM}-1$ as a uniform front or 2) the effective aquifer thickness is less than 500 ft. or 3) preferred flow paths allow the cooled fluid to reach CM-2 sooner than predicted or 4) the flowing temperature measurements for CM-2 may not be accurate (see Section II.2., above). Whether the latter is likely, would be known by those 
more familiar with maintenance and calibration of the measurement equipment at $\mathrm{CM}-2$. The measurements can be easily verified by occasional spot checks with an accurate hand held device. If the effect (decreasing temperature) is real, then it is likely that some breakthrough of injected water from $\mathrm{CM}-1$ has occurred, due to anisotropy caused by the presence of fractures. Periodic flowing temperature profiles of $\mathrm{CM}-2$ would be of great value in determining if the measured declines are real and, if so, the depth of entry of cooled fluid.

Given the relative locations and completions of $\mathrm{CM}-1$ and CM-2 and the Papadopulos calculations, there is potential for breakthrough along preferred flow paths (NW-SE oriented fractures). However, the data is inconclusive in that the measured decline began to occur in 1983-1984 soon after operations began and has not accelerated (or changed slope) as one might expect.

The region of the flow path should become cooler with time, allowing more cooled fluid to reach CM-2. But, the flowing temperature data shows the decline has leveled off to $153-154 \mathrm{~F}$ over the last two years. This is not consistent with thermodynamic processes and it may be that another effect (such as, precipitation clogging of flow paths and/or cooler shallow groundwater invasion, rather than breakthrough) is responsible. Without verification of flowing temperature and downhole 
temperature profiles, further interpretation of the $\mathrm{CM}-2$ flowing temperature history would be speculation.

\section{3) Continued Production Hithout Additional Injection}

This calculation involves the same scenario as was used for the pressure drawdown calcualtions.

The calculation was performed in the same manner as the History Match. The impact of injection was estimated for 20 years with distances up to $1250 \mathrm{ft}$. divided into five blocks (Figure 36). Results were calculated for the two injection wells with the following average injection rates and temperatures:

$$
\begin{aligned}
& \mathrm{CM}-1=500 \mathrm{gpm} \text { e } 125 \mathrm{~F} \\
& \mathrm{VA-2}=220 \mathrm{gpm} \text { e } 130 \mathrm{~F}
\end{aligned}
$$

The rock properties were assumed to be the same as for the history match in the absence of site specific data. The initial aquifer temperature values for $C M-1$ are those calculated from the history match for 1988. The initial temperature around VA-2 was assumed to be $161 \mathrm{~F}$ though the flowing temperature for VA-2 was $141 \mathrm{~F}$ during testing. The higher temperature was used for the calculation due to the low flowrate during testing and possible cold water leakage in to the wellbore as a result of the completion. Due to its proximity to the fault, the higher temperature is likely to represent that region. However, no 
static or flowing temperature profiles are available for verification of VA-2 initial conditions.

The results of the calculations are given below. Year zero is 1989 .

Hell CM-1

Distance

\begin{tabular}{|c|c|c|c|c|c|}
\hline Year & $\underline{0-250^{\prime}}$ & $250-500^{\prime}$ & $500-750^{\prime}$ & $750-1000^{\prime}$ & $1000-1250^{\prime}$ \\
\hline 0 & $126 \mathrm{~F}$ & $142 \mathrm{~F}$ & $154 \mathrm{~F}$ & $158 \mathrm{~F}$ & $158 \mathrm{~F}$ \\
\hline 5 & 125 & 132 & 146 & 155 & 157 \\
\hline 0 & 125 & 128 & 139 & 150 & 155 \\
\hline 15 & 125 & 126 & 133 & 144 & 152 \\
\hline 20 & 125 & 125 & 130 & 140 & 150 \\
\hline
\end{tabular}

Well VA-2

Distance

\begin{tabular}{|c|c|c|c|c|c|}
\hline Year & $\underline{0-250}$ & $250-5001$ & $500-750^{\prime}$ & $750-1000^{\prime}$ & $1000-1250^{\prime}$ \\
\hline 0 & $161 \mathrm{~F}$ & $161 \mathrm{~F}$ & $161 \mathrm{~F}$ & $161 \mathrm{~F}$ & $161 \mathrm{~F}$ \\
\hline 5 & 141 & 157 & 161 & 161 & 161 \\
\hline 10 & 134 & 150 & 159 & 161 & 161 \\
\hline 15 & 132 & 144 & 156 & 160 & 161 \\
\hline 20 & 131 & 140 & 153 & 159 & 160 \\
\hline
\end{tabular}


The region around $\mathrm{CM}-2$ is calculated to decline from its original $158 \mathrm{~F}$ to $150 \mathrm{~F}$ after 20 years, due to injection in CM-1. No significant change to other wells is predicted to result from injection into VA-2 due to its low flowrate and distance from other wells. However, due to its proximity to the fault, injection in VA-2 could cause a reversal of the aquifer gradient locally and allow cooled injection fluid to enter the fault zone. The effect is.difficult to predict but it is unlikely that this flow could travel far from VA-2, except in the case of large connecting fractures, so as to pose a threat to the nearest production well, (i.e. VA-1).

A more likely scenario is that the natural gradient, estimated at 0.07-0.08 ft./ft., would sweep cooled injection fluid toward the southwest toward CM-2. This effect cannot be simulated in the TBLOCKS calculation. However, a pressure simulation including the gradient, was performed by Papadopulos Associates (Anderson and Kelly, 1983) to determine if a cooled plume from VA-2 would intersect $\mathrm{CM}-2$.

The Papadopulos calculations were run for eight scenarios of aquifer conditions. Average flowrates were estimated for VA-2 $(320 \mathrm{gpm})$ and $\mathrm{CM}-2(510 \mathrm{gpm})$. The results indicate that, for the scenarios under which interaction takes place, the decline in CM-2 flowing temperature would be less than $5 \mathrm{~F}$. 
The results of both $B G I$ and Papadopulos methods indicate that, under certain aquifer conditions, the temperature of CM-2 production could decline but such a decline would be gradual. Further, the potential for interference could be monitored with two monitoring wells placed between $C M-2$ and $V A-2$ and $C M-1$ and CM-2 (see recommendations). Monitoring data from these proposed wells could allow mitigation measures to be initiated before significant effects to production temperature occur.

Neither of the methods addresses the possibility of VA-2 injectate entering the fault zone as discussed above since that possibility would be very difficult to model with the data available to-date.

\section{Continued Production with Additional Injection}

The difference between this scenario and the previous calculations is the addition of a hypothetical BGL injection well. The choice of the injection well site is explained above (Section IV. 4.b) and the site was chosen primarily for modeling purposes.

The location of this hypothetical well (named BGL-I) is shown on Figure 36. It would be approximately $4000 \mathrm{ft}$. from CM-2 (down gradient) and would receive the total BGL heating system waste flow (estimated to average $325 \mathrm{gpm}$ at $110 \mathrm{~F}$ ).

The results of the TBLOCKS calculations are shown below. 
The initial temperature of the aquifer in that region is assumed to be $140 \mathrm{~F}$.

\begin{tabular}{llllll}
\multicolumn{5}{c}{ BGL-I } \\
Year & 250. & Distance \\
1900 & 750' & 1000: & 1250 \\
1990 & $140 \mathrm{~F}$ & $140 \mathrm{~F}$ & $140 \mathrm{~F}$ & $140 \mathrm{~F}$ & $140 \mathrm{~F}$ \\
1995 & 116 & 132 & 139 & 140 & 140 \\
2000 & 111 & 124 & 135 & 139 & 140 \\
2005 & 110 & 118 & 130 & 137 & 139 \\
2010 & 110 & 114 & 126 & 135 & 138
\end{tabular}

These results indicate there would be no threat to the nearest production well ( $\mathrm{CM}-2$ ) as a result of injection in the area of the BGL-I well. Cold water breakthrough is even less likely given the groundwater gradient which would tend to transport injected fluid to the southwest.

In addition, the results of the previous TBLOCKS calculation analysis apply regarding the interaction of $\mathrm{VA}-2, \mathrm{CM}-2$ and $\mathrm{CM}-1$ since those flowrates are assumed to be identical in this case. The injection at BGL-I is not likely to interfere with the pressure gradient in vicinity of the CM wells or the fault.

\section{5) Increased Production Without Additional Injection}

The scenario of future increased production were considered to be the same as for the pressure reponse calculations. It 
involved an increased flowrate of $50 \%$ over the average rate for each well. As for the previous TBLOCKS calculations, only injection is considered to potentially affect the temperature of the aquifer and production fluid temperature. If average production rates are increased $50 \%$ the following temperature declines near injection wells are calculated.

\section{CH-1}

Distance

\begin{tabular}{|c|c|c|c|c|c|}
\hline Year & $0-250^{\circ}$ & $250-500^{\prime}$ & 500-750' & $750-1000^{\prime}$ & $1000-1250^{\prime}$ \\
\hline 1990 & $126 \mathrm{~F}$ & $142 \mathrm{~F}$ & $154 \mathrm{~F}$ & $158 \mathrm{~F}$ & $158 \mathrm{~F}$ \\
\hline 1995 & 125 & 129 & 142 & 152 & 156 \\
\hline 2000 & 125 & 126 & 133 & 145 & 152 \\
\hline 2005 & 125 & 125 & 129 & 138 & 148 \\
\hline 2010 & 125 & 125 & 127 & 133 & 143 \\
\hline
\end{tabular}

The additional 50\% flow results in an additional $13 \mathrm{~F}$ drop compared to the average (no increased) flow rate case or a $21 \mathrm{~F}$ drop from original conclusions. For VA-2 the results are: 
VA-2

Distance

$\begin{array}{llccccc}\text { Year } & \frac{0-2501}{1990} & 161 \mathrm{~F} & 161 \mathrm{~F} & 161 \mathrm{~F} & 161 \mathrm{~F} & 161 \mathrm{~F} \\ 1995 & 137 & 153 & 160 & 150-10001 & \frac{1000-12501}{160} & 161 \\ 2000 & 132 & 144 & 156 & 159 & 161 \\ 2005 & 131 & 139 & 151 & 158 & 160 \\ 2010 & 131 & 135 & 147 & 156 & 159\end{array}$

\section{6) Increased Production with Additional Injection}

If it is assumed that a new injection well will be drilled to accomodate BGL flow as described above, then the following temperature declines in it would be expected for a $50 \%$ flowrate increase.

\section{BGL-I}

Distance

\begin{tabular}{|c|c|c|c|c|c|}
\hline Year & $\underline{0-250^{\prime}}$ & $250-500^{\prime}$ & $500-750^{\circ}$ & $750-1000$ & $1000-1250^{\prime}$ \\
\hline 1990 & $140 \mathrm{~F}$ & $140 \mathrm{~F}$ & $140 \mathrm{~F}$ & $140 \mathrm{~F}$ & $140 \mathrm{~F}$ \\
\hline 1995 & 114 & 128 & 137 & 139 & 140 \\
\hline 2000 & 110 & 118 & 130 & 137 & 139 \\
\hline 2005 & 110 & 113 & 124 & 133 & 138 \\
\hline 2010 & 110 & 111 & 119 & 129 & 136 \\
\hline
\end{tabular}


All input data except flowrates are the same as the previous BGL-I case. Again, much of the input data is estimated due to the lack of data on the aquifer from that region.

\section{7) Conclusions for Temperature Response Modeling}

These calculations give a rough idea of the effect of injection on the surrounding aquifer. However, there are a number of assumptions (see above) which significantly affect the results. Additional data on aquifer thermal properties, porosity and etc. are needed to enable more precise predictions. Also, the greatest obstacle to such modeling is the effect of the fracture network in the aquifer and its influence on the path taken by injected fluid. For this purpose, tracer tests are recommended. Tracer testing could be undertaken with a minimum of disturbance to normal operations. It is also recommended for any new injection wells.

Under the geologic and hydrologic conditions assumed for the area of the hypothetical BGL injection well used for this study, no significant threat of cooling of existing geothermal wells is likely. Those assumptions may allow relatively optimistic results, particularly if porosity is lower than $10 \%$. However, the groundwater gradient (roughly east to west) and density effects (that would allow cooled injectate to sink deeper than it is injected). Those factors may compensate for any error in 
the assumptions because injectate would be prevented from moving east toward any production well.

The results of this study and a previous study, described above (Anderson and Kelly, 1983) indicate that, at higher (winter) flow rates of the $V A$ and $C M$ wells, there is potential for breakthrough of injectate from VA-2 and CM-1 to CM-2. This potential exists if porosities are much lower than the $10 \%$ assumed for this study and/or a large fracture connection exists between $V A-2$ and $C M-2$ or $C M-1$ and $C M-2$. 


\section{RECOMMENDATIONS FOR DATA COLLECTION}

\section{1) Well Pressure/Hater Level Data}

In the past, the frequency of water level data collection has varied. Little useful data, particularly interference measurements, have been taken in areas away from the Boise Front Fault in the $C M$ well area. It has been difficult to establish the baseline water level (prior to CM start-up in 1982) and present static levels for many wells and areas. The BLM-VA monitoring data has served as the only continuous source of data for the entire BGL-CM-VA region.

More recently, monitoring of various wells in the BWSWD area (Kanta, Behrman, etc.) has allowed a record of water level declines in that area. However, some were not begun until after $C M$ and BGL start-up. Also, though continuous monitoring began to the north (Milstead and Gamble wells etc.) in 1988, this short-term data has been of little value for this study, particularly without flowrate data.

It is, of course, too late to compensate for the lack of background data, particularly for the BWSWD and CM wells. Fortunately, there are plans for a larger and more unified water level/ pressure monitoring network. Continuous computer logging systems for measuring pressure are planned or have recently been installed in; 1) Two private wells to the north (Terteling) 2) CM-2 3) VA-1 (Production) and 4) The Beard well. 
These should aid the accuracy of further modeling efforts considerably, particularly since little pressure/water level data had been available outside the main fault zone. The improved data from $\mathrm{CM}-2$ should significantly affect the level of understanding of the aquifer, away from the main fracture zone (Boise Front Fault).

Only a few weeks of monitoring data from the Beard well was available at the time of this writing and it is difficult to evaluate the contribution of the new system or recommend additional data collection, if necessary. However, even if good quality data is obtained from these new installations, there are some voids to fill.

Four or more slim hole observation wells would allow more effective modeling of both water level and temperature data. The water level data in the proposed observation wells can be taken by either mechanical water level recorder or a computer data logger, if it proves reliable and expedient.

Recommended locations are as follows: 1) Between CM-1 and CM-2 to monitor pressure and temperature effects, if any, resulting from interference. 2) Between $\mathrm{CM}-2$ and the main fault, approximately in the center of a triangle defined by CM-2, VA-2 and BLM. 3) Between $C M-1$ and BWSWD-3 off the main fault. 4) In the fault zone between VA-2 and the Edwards well. 5) Between $\mathrm{CM}-2$ and any new BGL injection well if near the Boise 
River (as assumed for this study).

Water level and temperature monitoring of the VA-Test well, could be very useful in determining the effect of injection there. Also, continuous monitoring the old statehouse well would provide some interference measurements for that area immediately without having to drill a new well. However, the condition of this old well, and whether it communicates with other wells, is not known.

The purpose for recommending additional monitoring wells is to be better able to understand the properties of the aquifer (especially outside the fault zone), the path and degree. of communication between the various areas and the effects of injection. The relationship of wells inside the fault zone to those outside has not been sufficiently explored through testing, particularly with regard to injection.

The degree of communication between the Geothermal Aquifer in the Boise city area and the Edwards, Milstead, Terteling wells area is also unknown due to the absence of data. The USGS has recently begun monitoring wells in that area. They show a pressure drawdown occuring due to pumping irrigation in the summer, with a rebound in the winter. This response indicates the pumping cycle in that area is opposite to central Boise geothermal wells. Flowrate data is needed to accompany the water level data so that it can be analyzed. So far there is no 
data available which can be used to link pumping in the northern area to the geothermal aquifer in central Boise. Conversely, there is no record of the effects of long-term geothermal production by BWSWD, CM, BGL or VA in the northern area.

Pressure measurements in production wells have not been sufficient to allow modeling of the effect on continued or increased production. This is true of both test data and data from normal operations.

As previously discussed, thermal effects make well head measurements of geothermal wells difficult to interpret. For this reason, there is no well test in which flowing well pressure could be used to distinguish wellbore effects from aquifer effects. Even if data collection in production wells during normal operations is improved, it may not be sufficient. The data required must come from controlled testing. Such testing must include precise downhole pressure at various stabilized flow rates. Pump tests are preferred over artesian flow test wherever possible.

\section{2) Temperature Data}

The temperature data is fairly sparse, consisting of recorded temperatures of flowing wells, static and non-static temperature profiles. The well head temperature data taken during normal operations of $\mathrm{CM}-2$ is suspect (see discussion in 
Section II.2. c.). Calibration of the installed thermometer and spot checks with an accurate, calibrated device should be performed at regular intervals year round.

The effects of injection should be better monitored by means of periodic temperature surveys in flowing and observation wells. The recommended observation well locations (see above) were chosen for the dual purpose of temperature and water level monitoring. The VA-Test well is ideally situated for both purposes since the potential for breakthrough of injection (from $V A-2)$ to the fault could pose a threat to other production wells.

Temperature effects should not be a problem in the Edwards-Milstead area since no injection takes place there but periodic static temperature surveys of one or two wells in the area would contribute to a better understanding of the system.

Since no injection takes place or is planned for the BWSWD area, periodic or continuous temperature data would be of littie value. Any effects of injection by wells in the BGL-CM-VA area moving toward the BWSWD area could be monitored by an observation well described above.

Periodic temperature surveys in the old Statehouse well are recommended. 


\section{3) Long-Term Flow Test}

As previously mentioned, long-term individual (1-2 months) constant rate well test data would have greatly assisted this study. In spite of the many practical constraints, it is strongly recommended that such tests be performed on major pumping wells (e.g. BGL-2 or $3,4, C M-2$, BWSWD 1 or 2 ) and any new wells drilled. Preferably, all other wells except the one tested should be shut in. This may be feasible for BGL or BWSWD in high summer with flow from the test well supplying the needs of both systems. Testing $\mathrm{CM}-2$ alone presents more difficult practical problems, but it may be possible to test $\mathrm{CM}-2$ at a high rate in summer with either BWSWD or BGL wells running at a low, carefully measured, constant rate. All available observation wells should be monitored during these tests.

The data from these tests would assist in defining reservoir parameters, long-term fracture flow behavior and wellbore effects of the wells tested. The wellbore parameters are necessary to distinguish between aquifer effects and wellbore effects. Most fracture models rely on flowing well drawdown data which must have wellbore effects removed for proper analysis of fracture flow behavior. 


\section{4) Geophysical Studies}

Other than the temperature surveys discussed above, there is no pressing need for any specific geophysical studies. Aquifer development is beyond the exploration phase and into the resevoir management phase. Also, there is probably too much cultural activity in Boise for most surface geophysical methods. A seismic reflection would have been helpful for determining whether significant offsets, which may affect groundwater flow, are present in the valley between the Boise Front Fault and the Boise River. Borehole geophysics could be examined as a method for mapping large fractures but is normally quite costly.

A good suite of geophysical logs (including resistivity, natural gamma, and caliper) are always recommended and should be performed on any new wells. A temperature log should be done on new wells as soon as they have stabilized after drilling.

\section{5) Elowrate Data}

One of the greatest obstacles to creating a model for the Boise Geothermal Aquifer is the flowrate data. The most significant problem is that flowrates are not measured or recorded over a reasonable average period but are usually determined from a single daily reading. This reading is usually taken in the morning. The data invariably reflects a higher flowrate than would be considered average for the day. Ideally, 
an average for the day should be calculated from an accurate total flow device read once daily.

Also important to such calculations is a precise record of any system down time. Specifically, when it began and ended and, if possible, any static well water level measurements or pressure measurements obtained while down. It is also important to record whether a well was shut-in or allowed to flow artesian during the (down) period.

Finaliy, the measurement instruments themselves, such as flow totalizers should be calibrated periodically (yearly ?). If they cannot be adjusted or replaced, estimates of their accuracy should be determined. Any well flow, whether pumped or artesian, is important. If a well flows artesian at a low rate (which may be below flow measurement accuracy) but does so for a month or more in summer, it could seriously affect the calculation.

An (inline) backup flow measurement device would be valuable for emergencies and spot checks of the primary instrument.

\section{6) Changes to Present Monitoring Metwork}

The present monitoring network consists of continuous water level recorders and periodic pressure or water level measurements in flowing wells. Because of the lack of data in many areas and the present transition to new methods and 
increased data collection, it is difficult to recommend reducing any present effort. If any reductions could be made, they would be in the area of the BWSWD wells.

The BWSWD area is likely to be more complex structurally than other areas along the fault as evidenced by fault mapping. However, the monitoring well response has been remarkably uniform. It probably is not necessary to continuously monitor the Behrman or Quarry View wells. Lack of well completion information and condition of the Behrman well make interpretation of its' response speculative. A static temperature profile of the Behrman well and Kanta well would be of interest.

Also, since there is no further development planned for this (BWSWD) area, the general water level trend and background have been established. One water-level monitoring well gives good control for the region.

No other reduction in monitoring can be recommended at this time.

\section{7) Geochenical Sanpling}

Regular geochemical sampling of geothermal wells is recommended. It would be ideal if the program begun by the USGS (Young, et al, 1988) could be continued on a yearly basis, at least for major pumping wells. This would allow continuity in 
methods and analysis which is critical to identification of minor geochemical trends. Changes in water chemistry, for a given well (particularly $(M-2)$, could provide evidence of cold water invasion prior to measureable temperature effects. The same is true of wells along the Boise Front Fault. Water chemistry changes along the fault may indicate intrusion by other waters outside the geothermal aquifer as a result of increased drawdown.

Tracer testing of injection wells is also recommended. This would take some of the guess work out estimating the potential for, and effects of, cool water breakthrough into CM-2. 


\section{References}

1) Anderson, J.E., 1979, Reconnaissance Geologic Investigation of the Geothermal Potential of the Capitol Mall Area, IDWR internal report.

2) J.E., 1981, Drilling and Completion Report Capitol Mall Geothermal Exploratory Well \#1, IDWR publication, $13 \mathrm{p}$.

3) Anderson and Kelly Consultants, 1981, Report on Capitol Mall Geothermal Well No.2, Prepared for CH2M Hill, $32 \mathrm{p}$.

4) , 1982, Flow Testing of Boise Geothermal Ltd. Wells No. 2 and 4., Prepared for CH2M/Hill, 25 p. plus appendices.

5) , 1983, Report of Drilling and Testing of Veterans Administration Medical Center Geothermal Production Well and Test Injection Well, Prepared for CH2M/Hill, 20 p. plus appendices.

6) , 1983, Report on Pump Test of Quarry View Well, Letter to City of Boise Parks Department, $5 \mathrm{p}$.

7) Berkeley Group Inc., 1981, Report to DOE-GLCP, Consulting Activities for the Boise, Idaho Low Temperature Geothermal Project, $10 \mathrm{p}$.

8) , 1985, Review of Boise District Heating Project, Monitoring Program. December 1983-February 1984, Berkeley Group Inc., Report for DOE, $16 \mathrm{p}$.

9) Bissell, R.R., 1980, Geothermal Water Disposal City of Boise and Boise Warm Springs Water District Geothermal District Heating Systems: CH2M Hill Document prepared for DOE, $42 \mathrm{p}$.

10) Bodvarsson, G.S., Benson, S.M., Witherspoon, P.A., 1982, Theory of the Development of Geothermal Systems Charged by Vertical Faults, Journal of Geophysical Reseach, Vol. 87, No. B11, p. 9317-9328.

11) Boise Warm Springs Water District, 1989, Geothermal Production, 1977-1989. Prepared by R.H. Griffiths, Consultant.

12) Brott, C.A., Blackwell, D.D., and Mitchell, J.C., 1978, Tectonic Implications of Heat Flow of the Western Snake River Plain, Idaho: Geological Society of America Bulletin, v.89, p. 1697-1707. 
Figures 


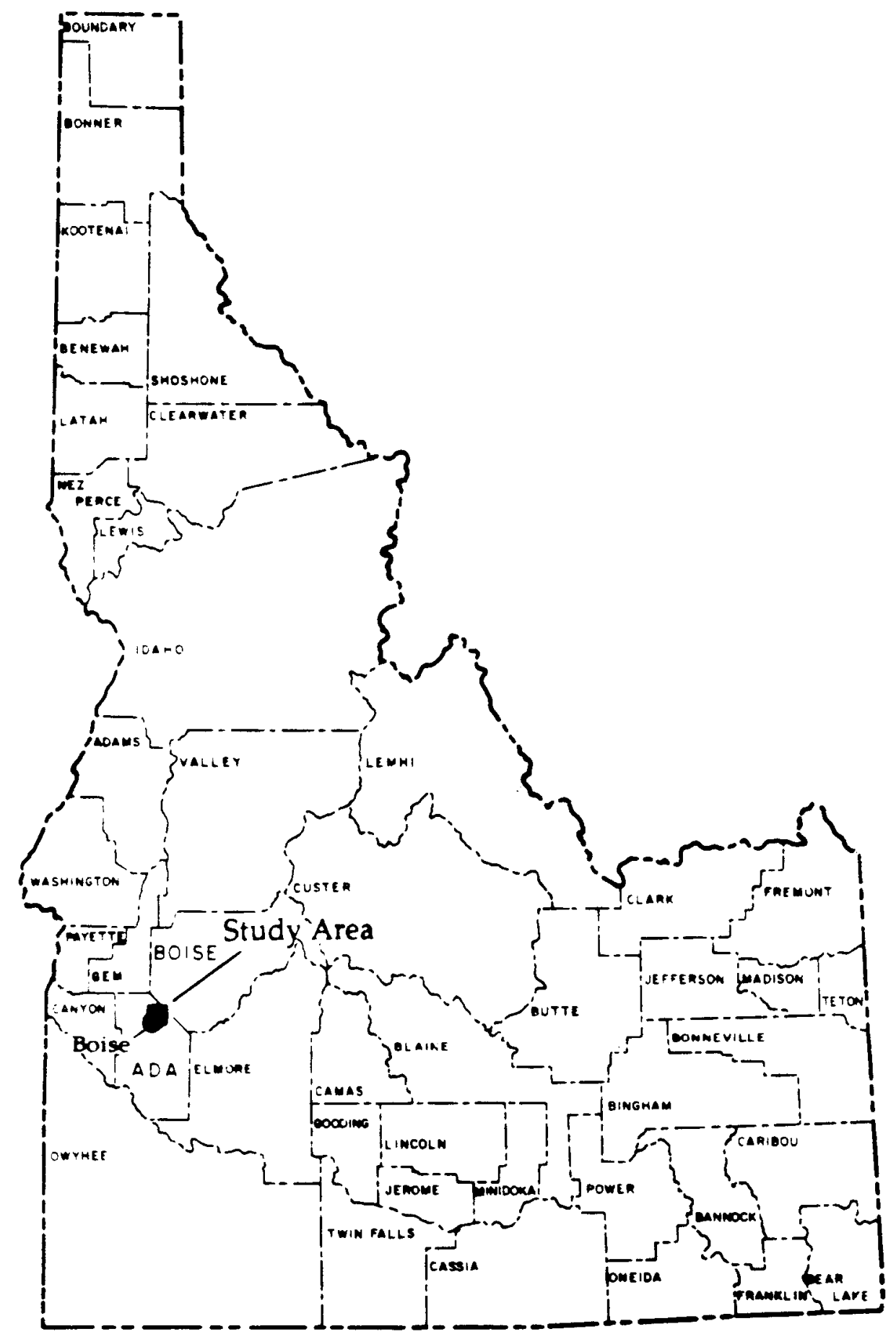

(from Young, 1988)

Figure 1. Location of study area in Idaho. 


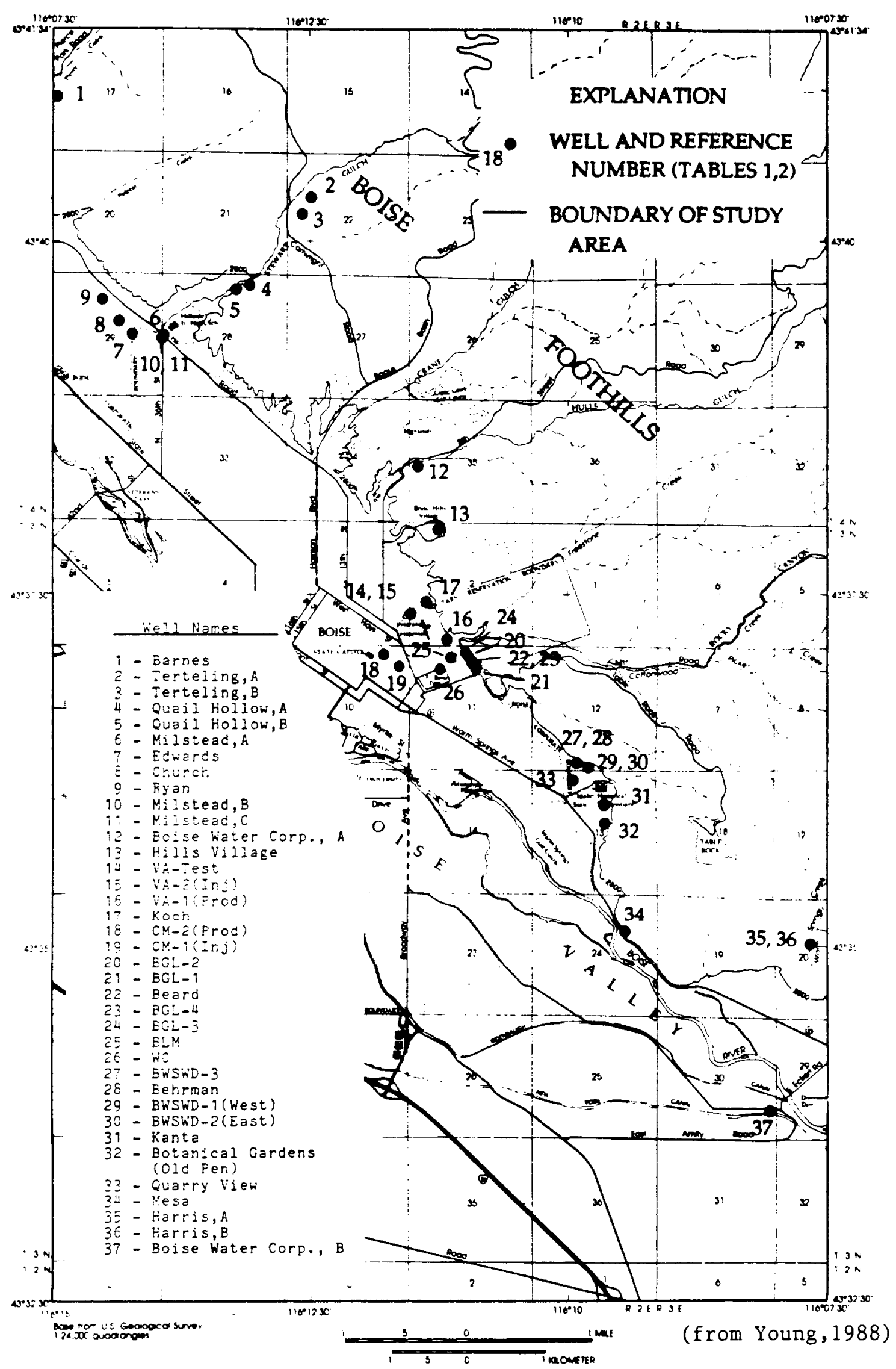

Figure 2. Location of geothermal wells. 


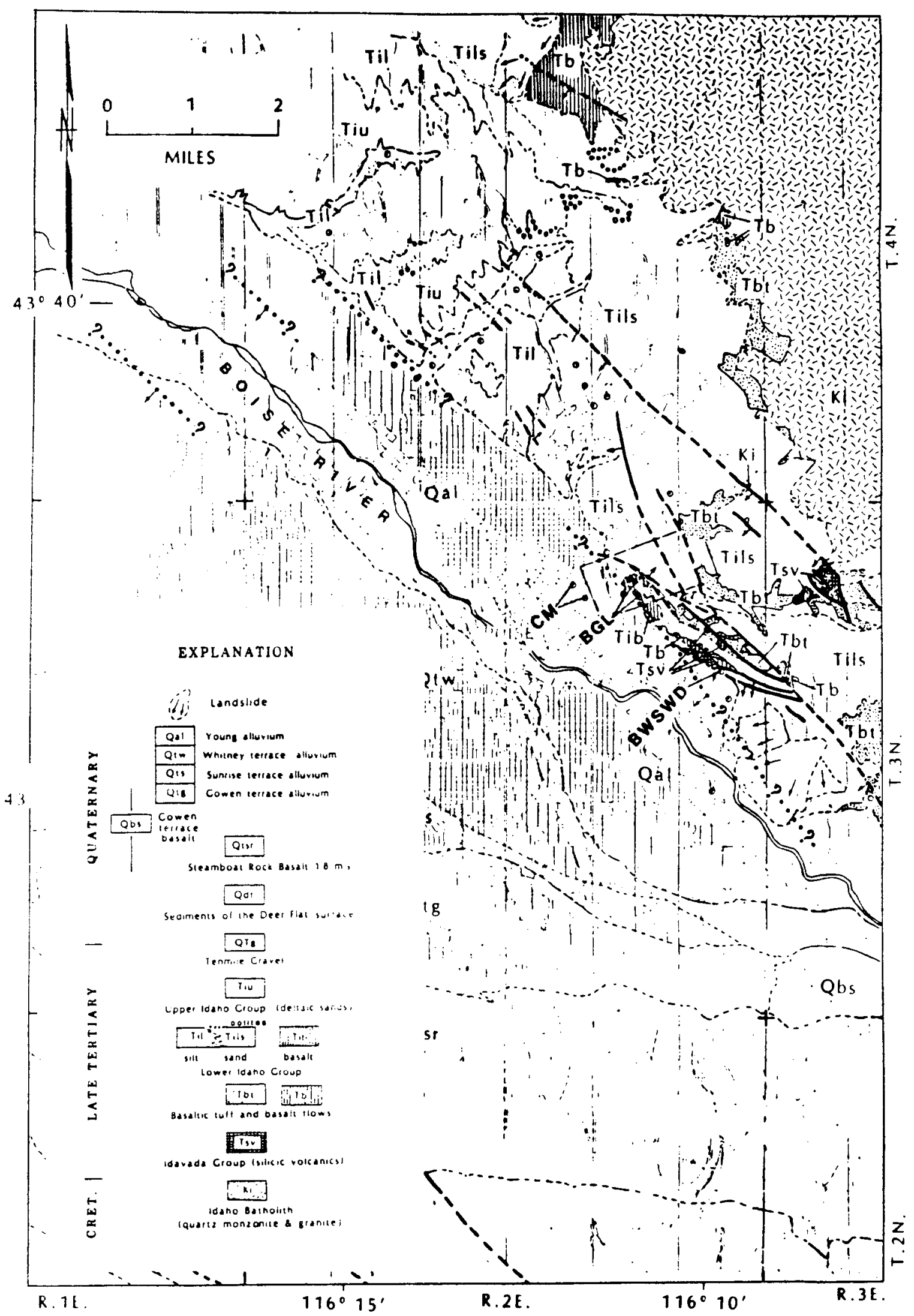

(from Wood and Burnham, j983)

Figure 3. Geologic map of the Boise area. 


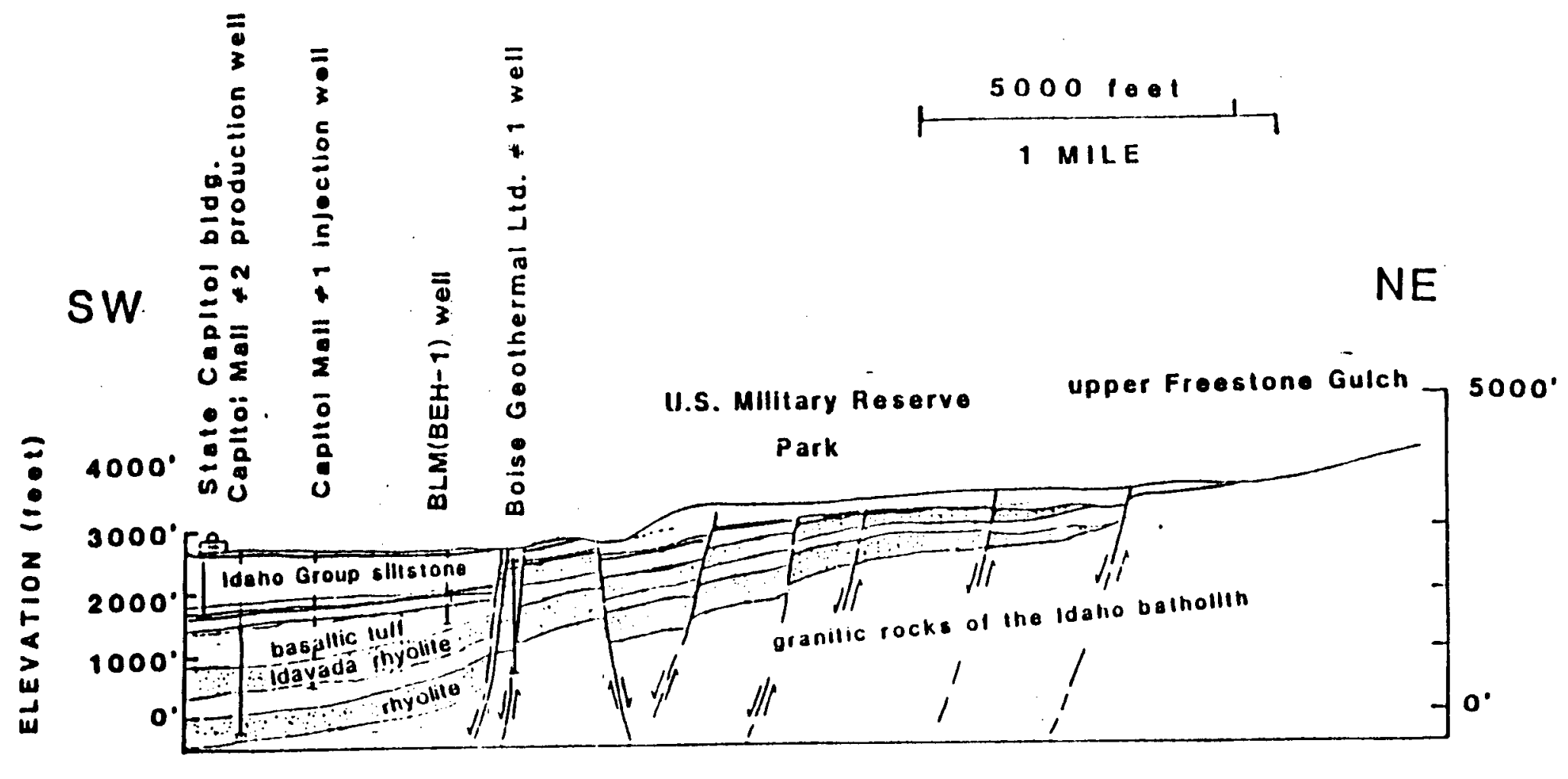

(from Waag and Wood, 1987)

Figure 4. Geologic cross-section through the Capitol Mall and BGL We1ls. 


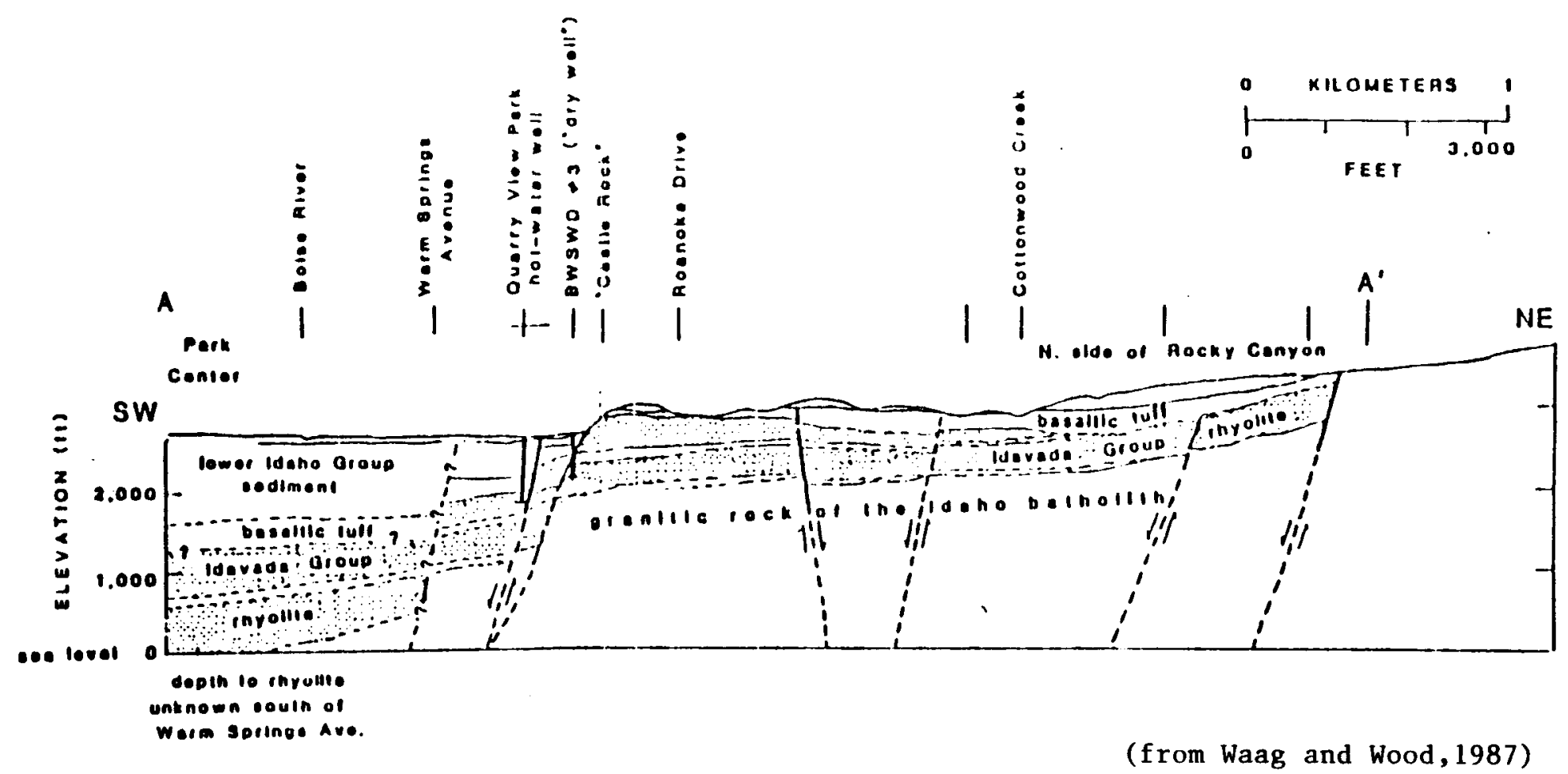

Figure 5. Geologic Cross-section through the area of the BWSWD We11s. 


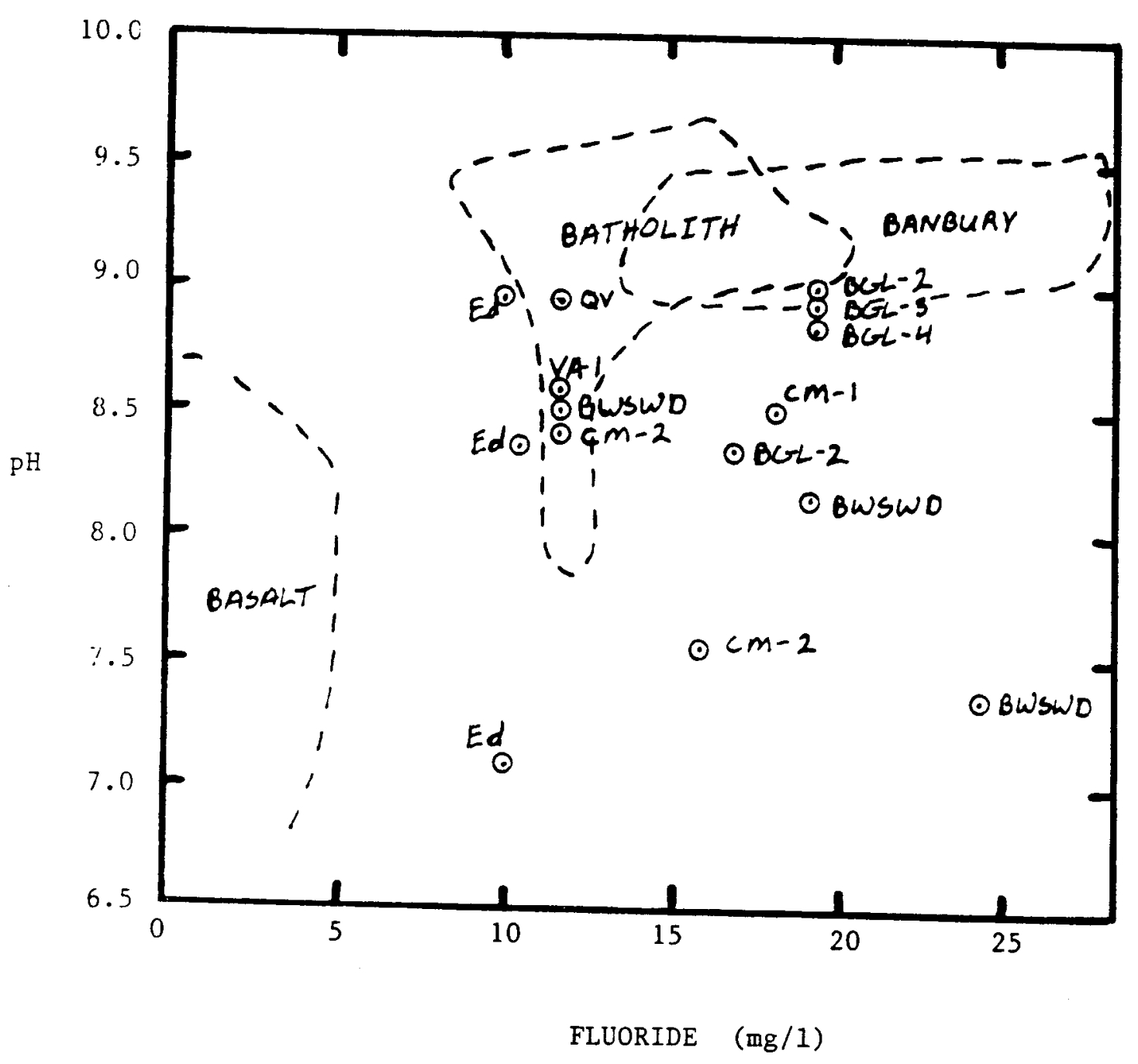

Figure 6. Plot of fluoride-ion vs. $\mathrm{pH}$ for selected regions in Idaho and Boise area wells.

(Modified from Waag and Wood,1987b) 


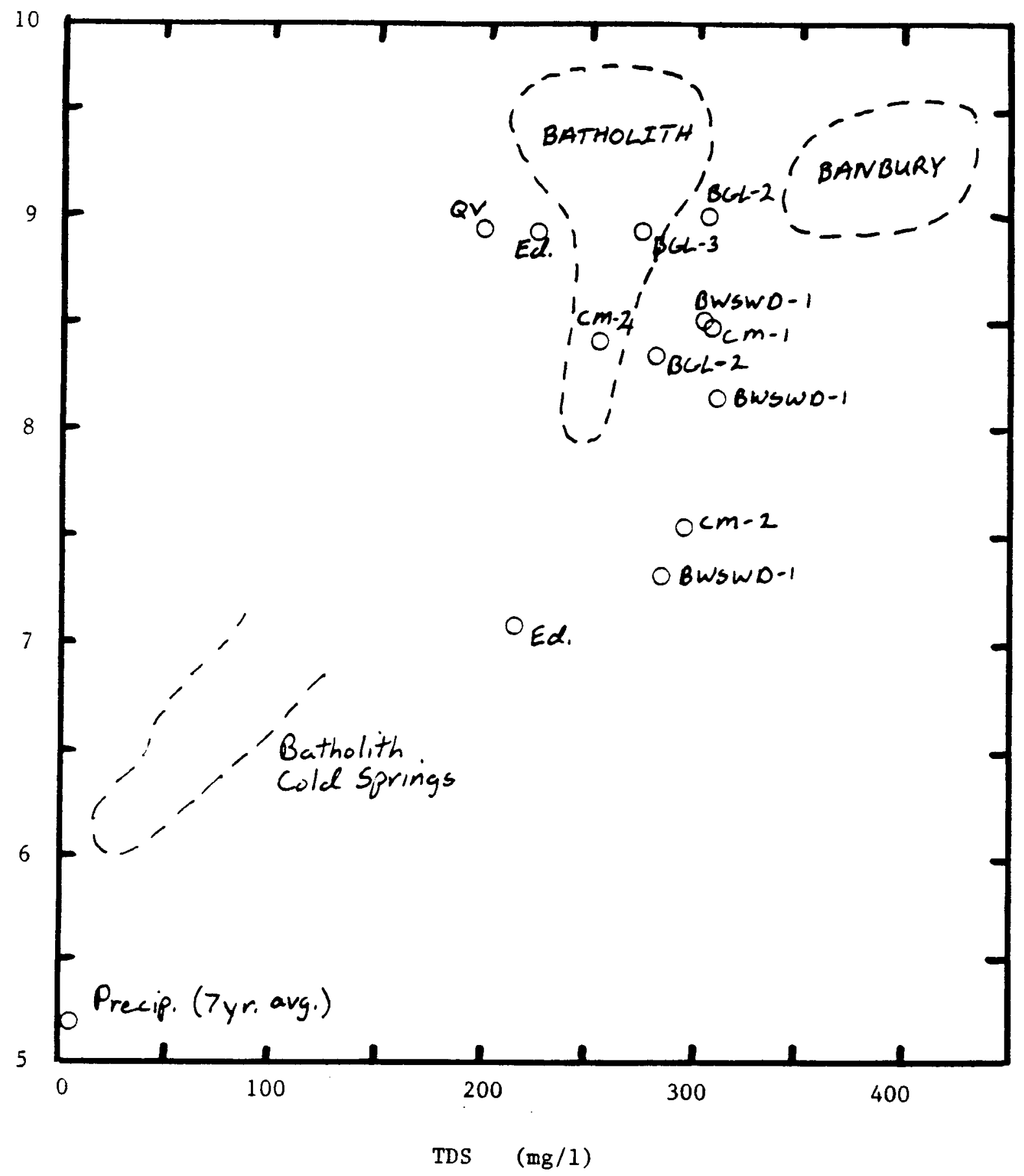

Figure 7. Plot of total dissolved solids vs. $\mathrm{pH}$ for selected waters of Idaho and Boise area wells. (modified after Waag and Wood, 1987b) 


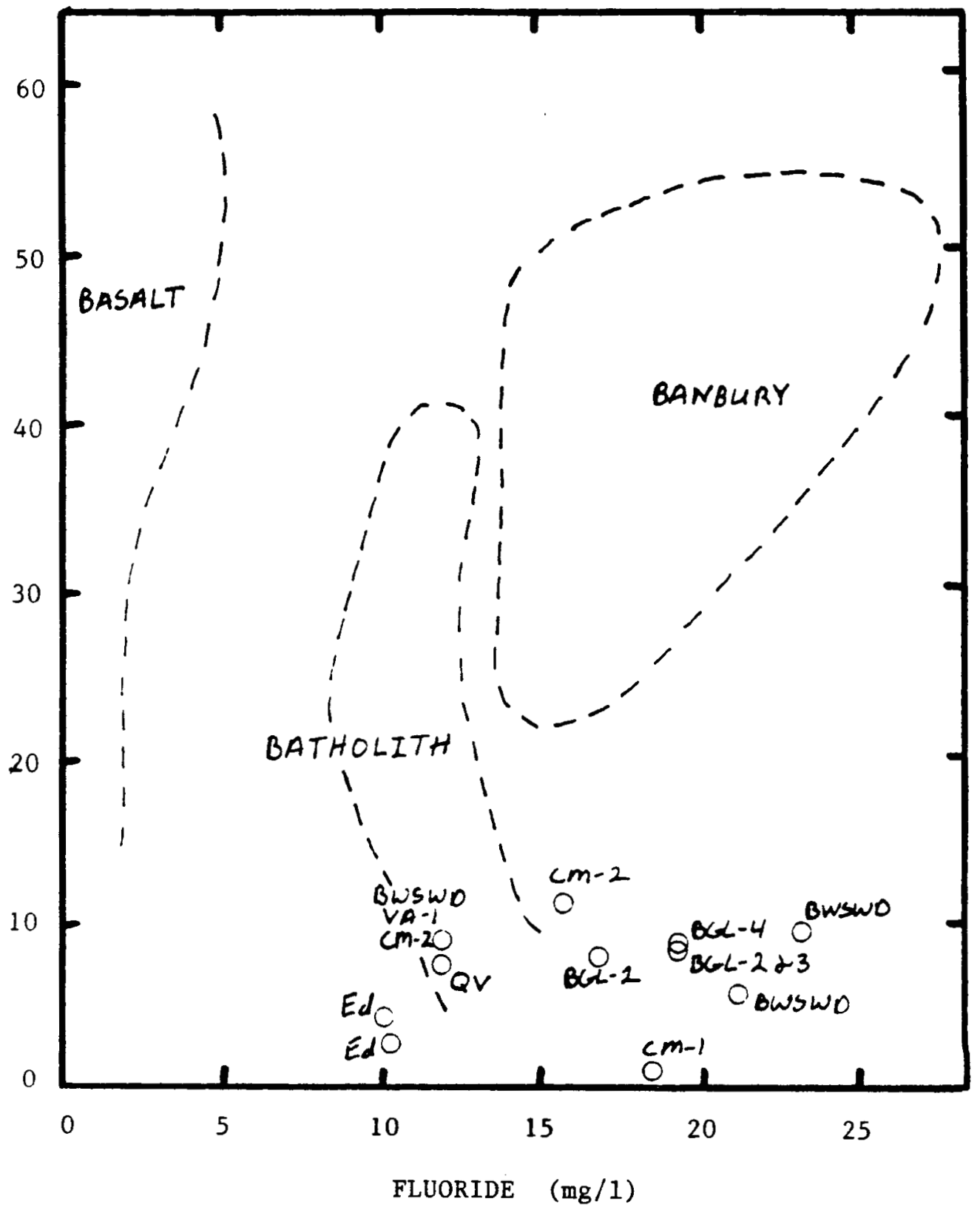

Figure 8. Plot of fluoride-ion concentration vs. chloride-ion concentration for selected waters of Idaho and Boise area wells.

(modified after Waag and Wood, 1987b) 


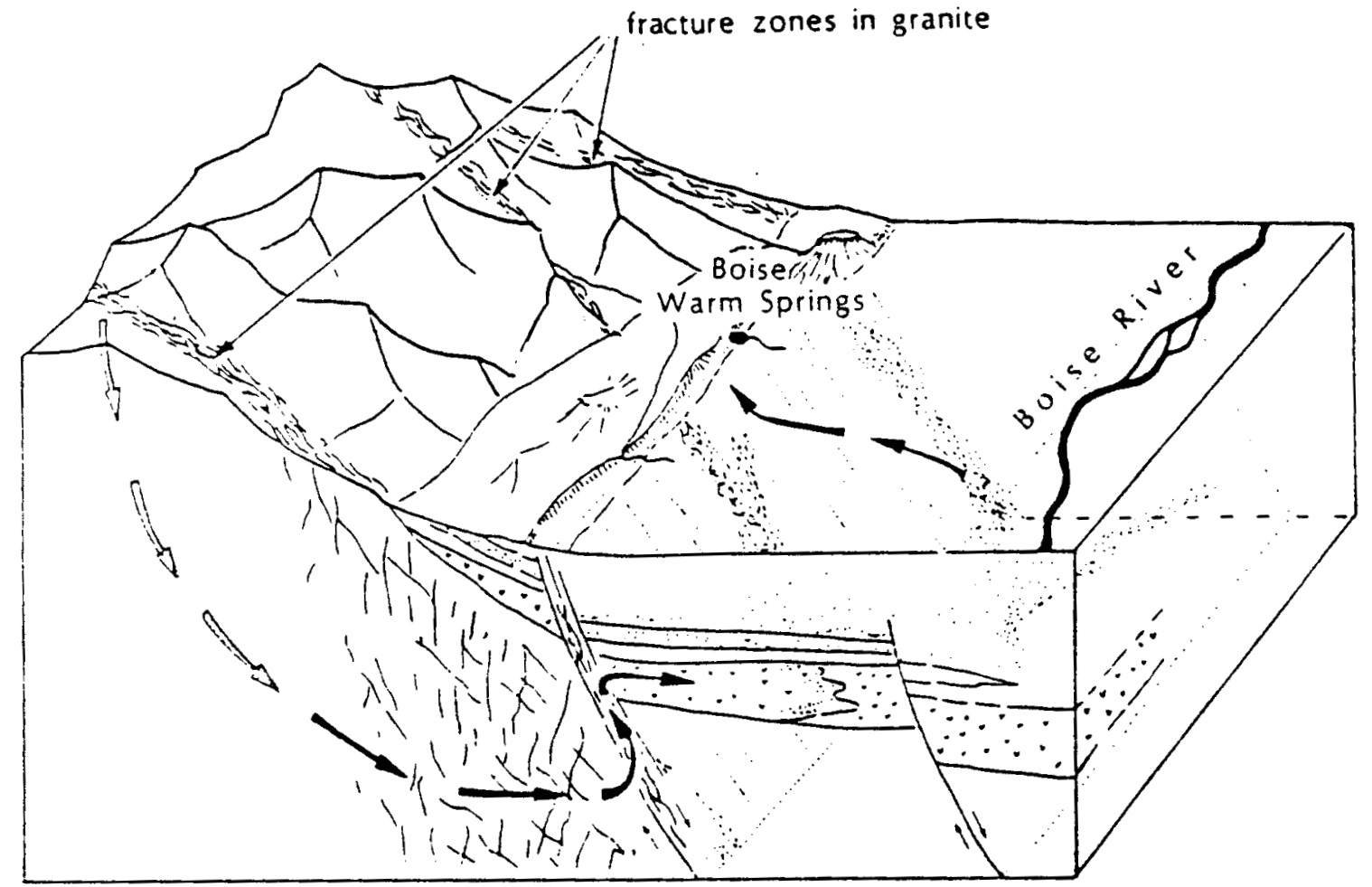

Figure 9. Conceptual model of the geothermal groundwater circulation system through fractured granite to the discharge area along the foothills fault zone of Boise and into the permeable rhyolite aquifers beneath the north-eastern part of the city. (Adopted from Wood and Burnham, 1987) 


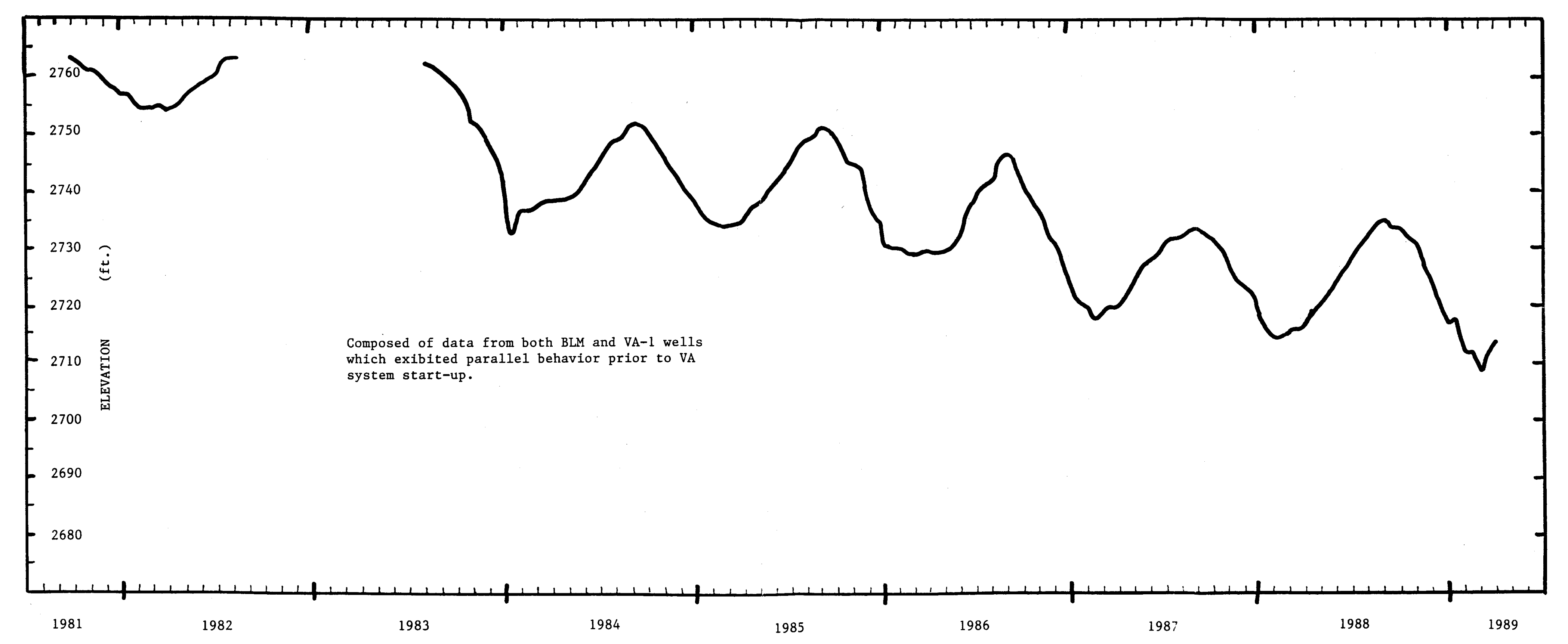

Figure 10. Hydrograph of the BLM well.

(after Waag and Wood,1987 and Waag, 1989) 
y



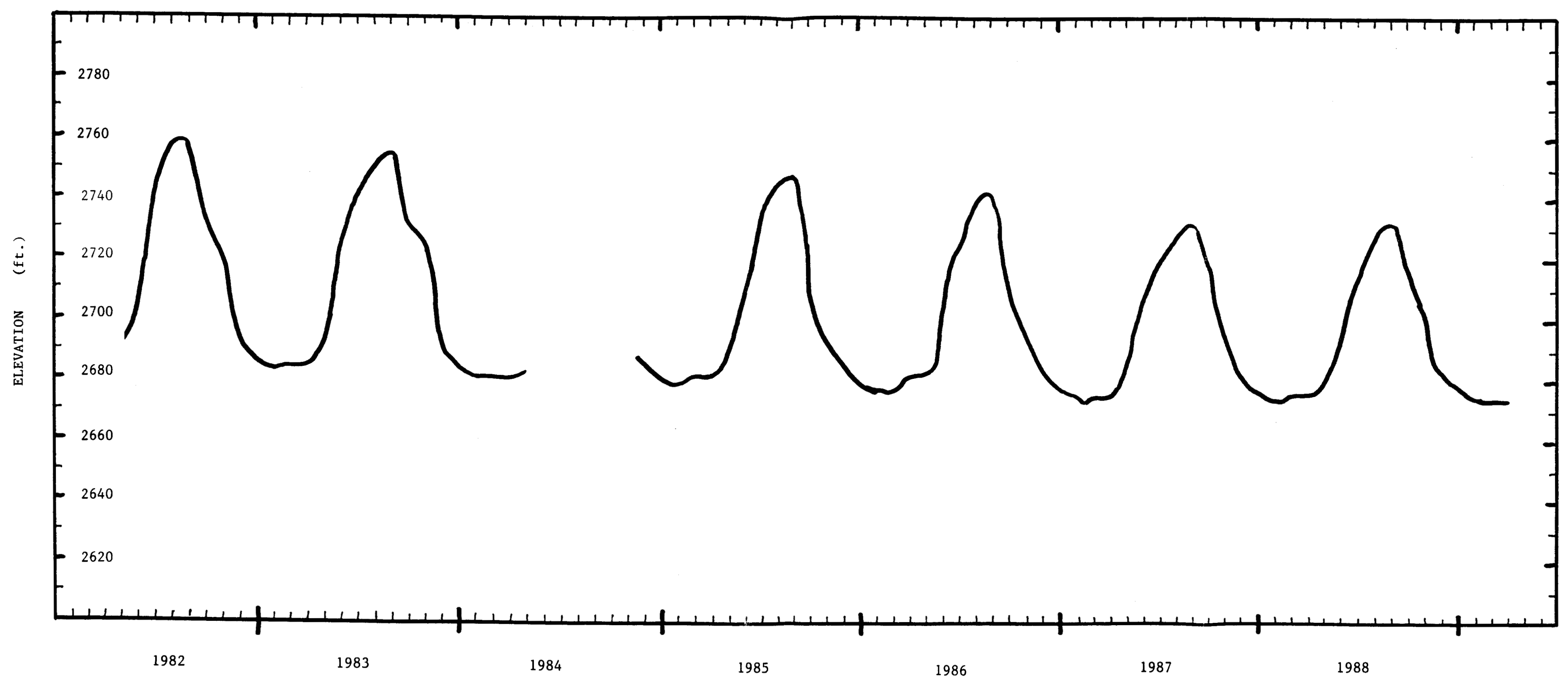

Figure 13. Hydrograph of BWSWD-3. (after Waag, 1989) 


$$
\mathrm{mm}
$$




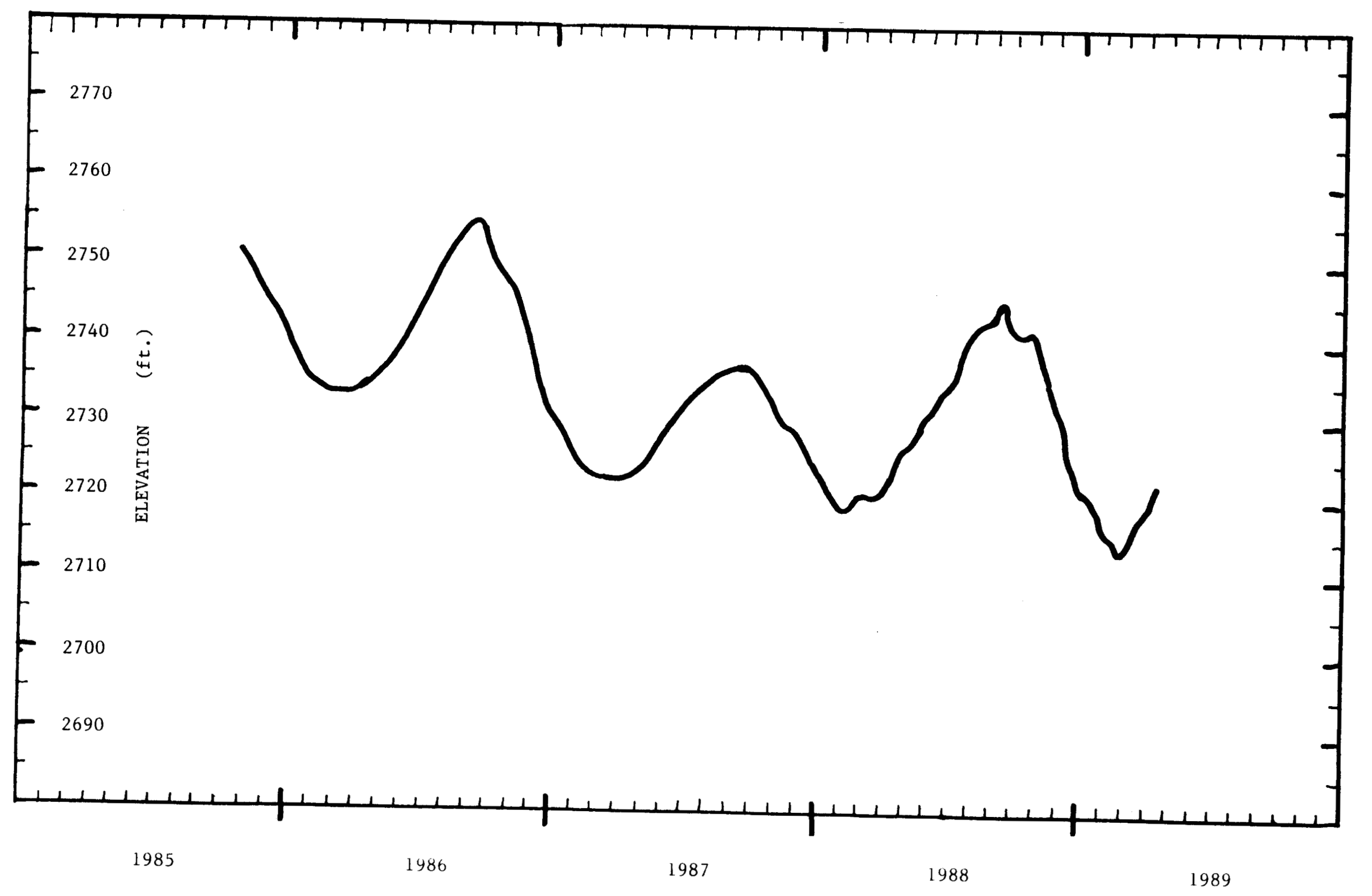

Figure 15. Hydrograph of the Behrman well.

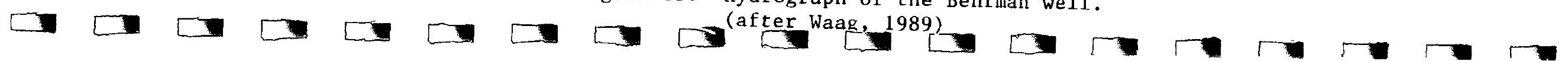




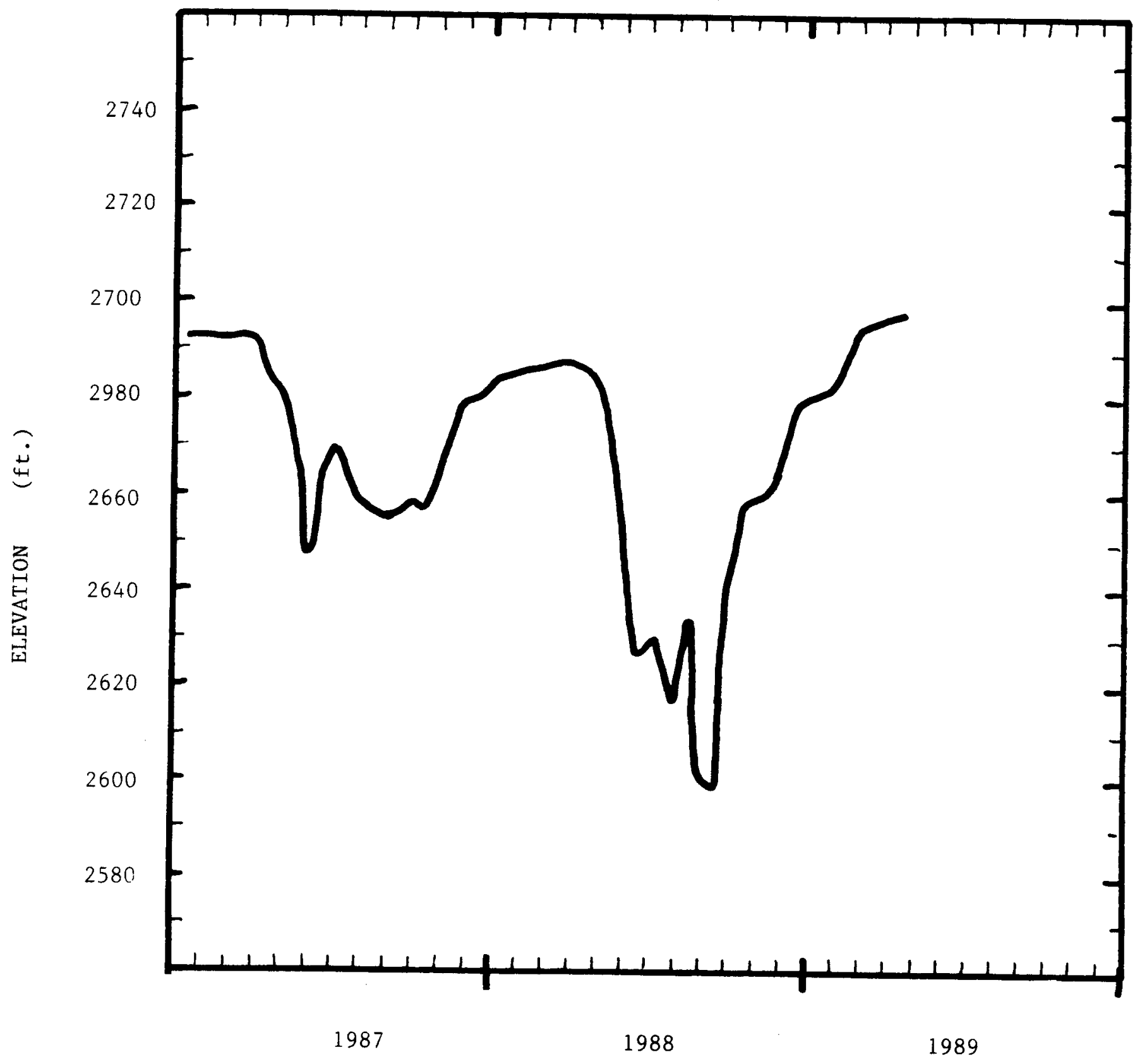

Figure 16. Hydrograph of the Quarry View well. (after Waag, 1989) 


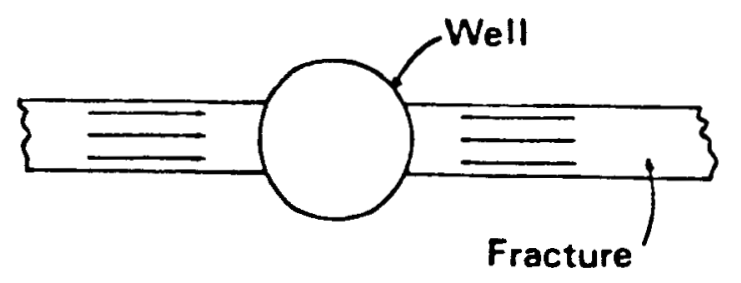

(a)

FRACTURE LINEAR FLOW

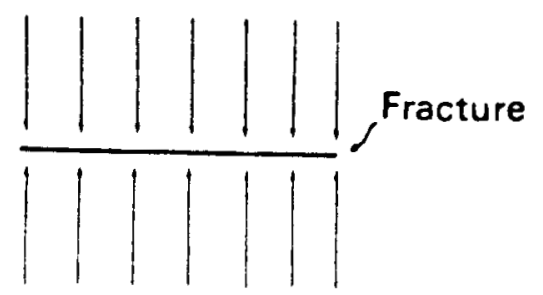

(c)

FORMATION LINEAR FLOW

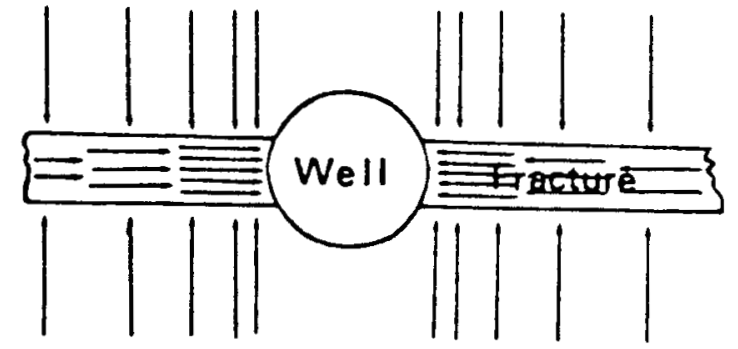

(b)

BILINEAR FLOW

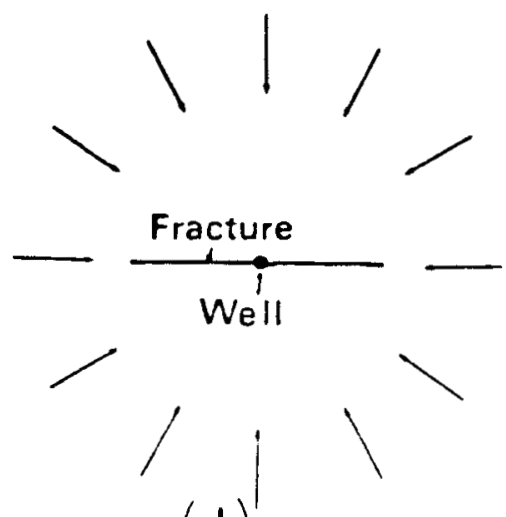

(d)

PSEUDO-RADIAL FLOW

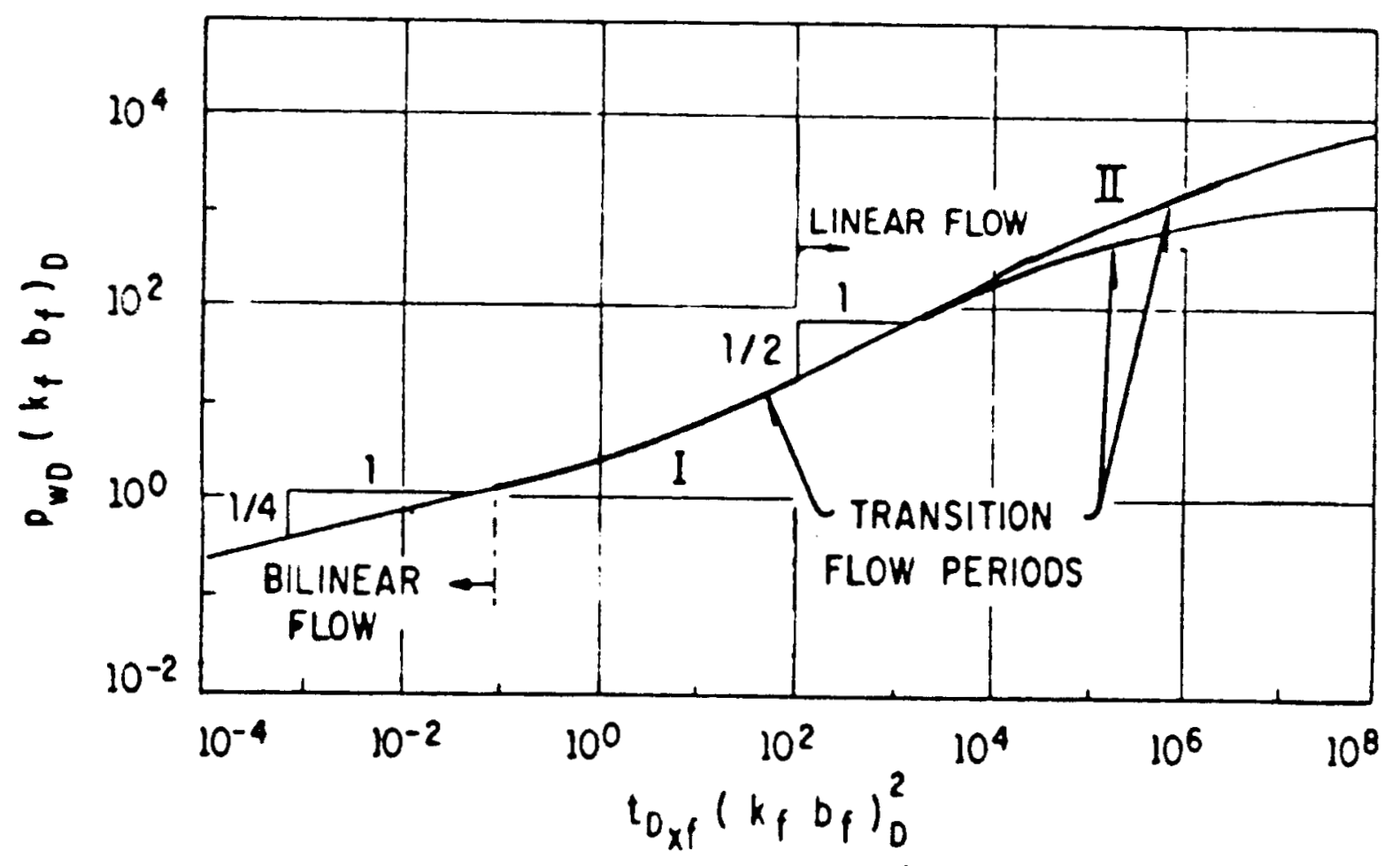

Figure 17. Schematic diagram and plot of fracture flow behavior. 


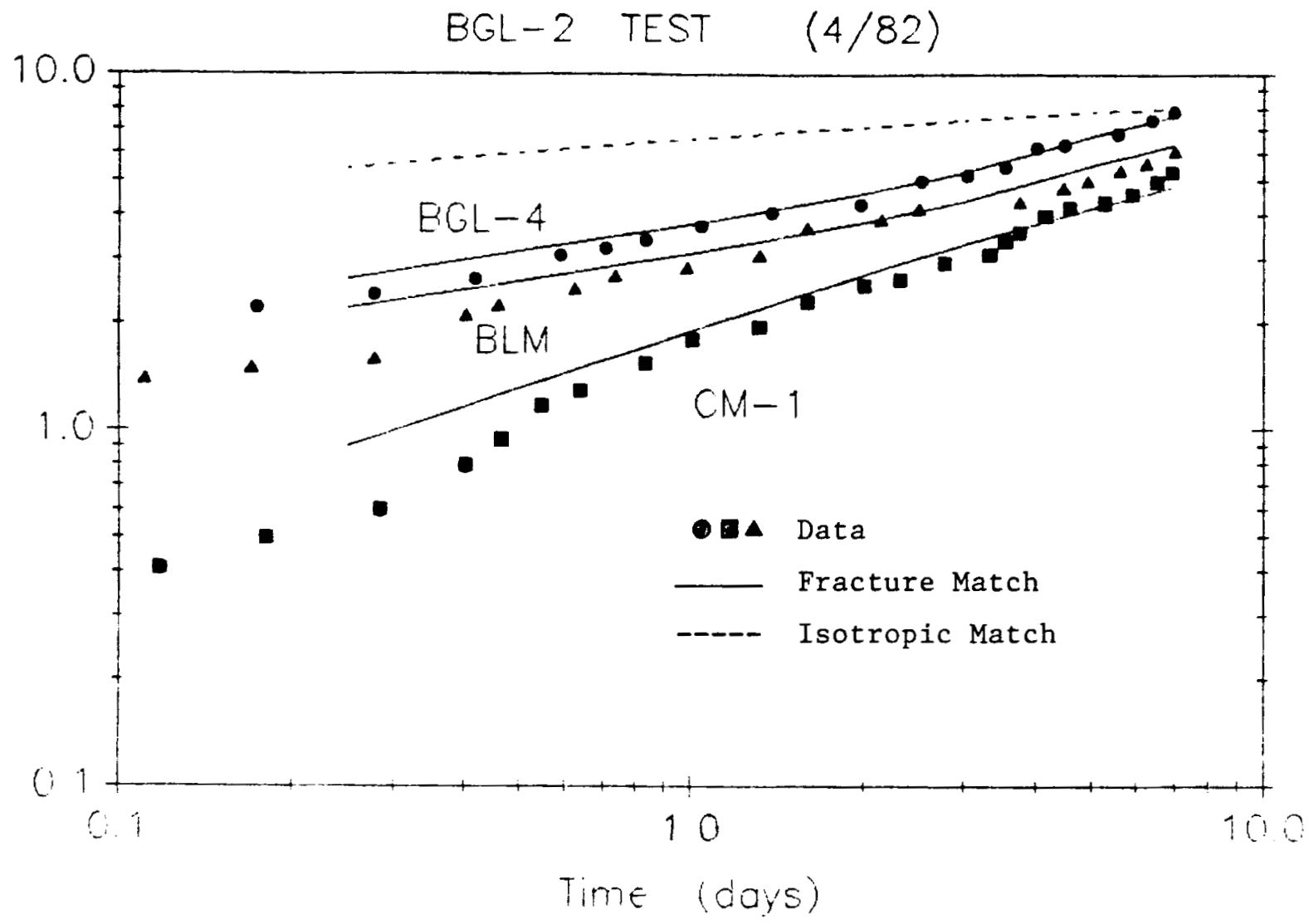

Figure 18a. Log-Log plot of BGL-2 Test data and calculated match.

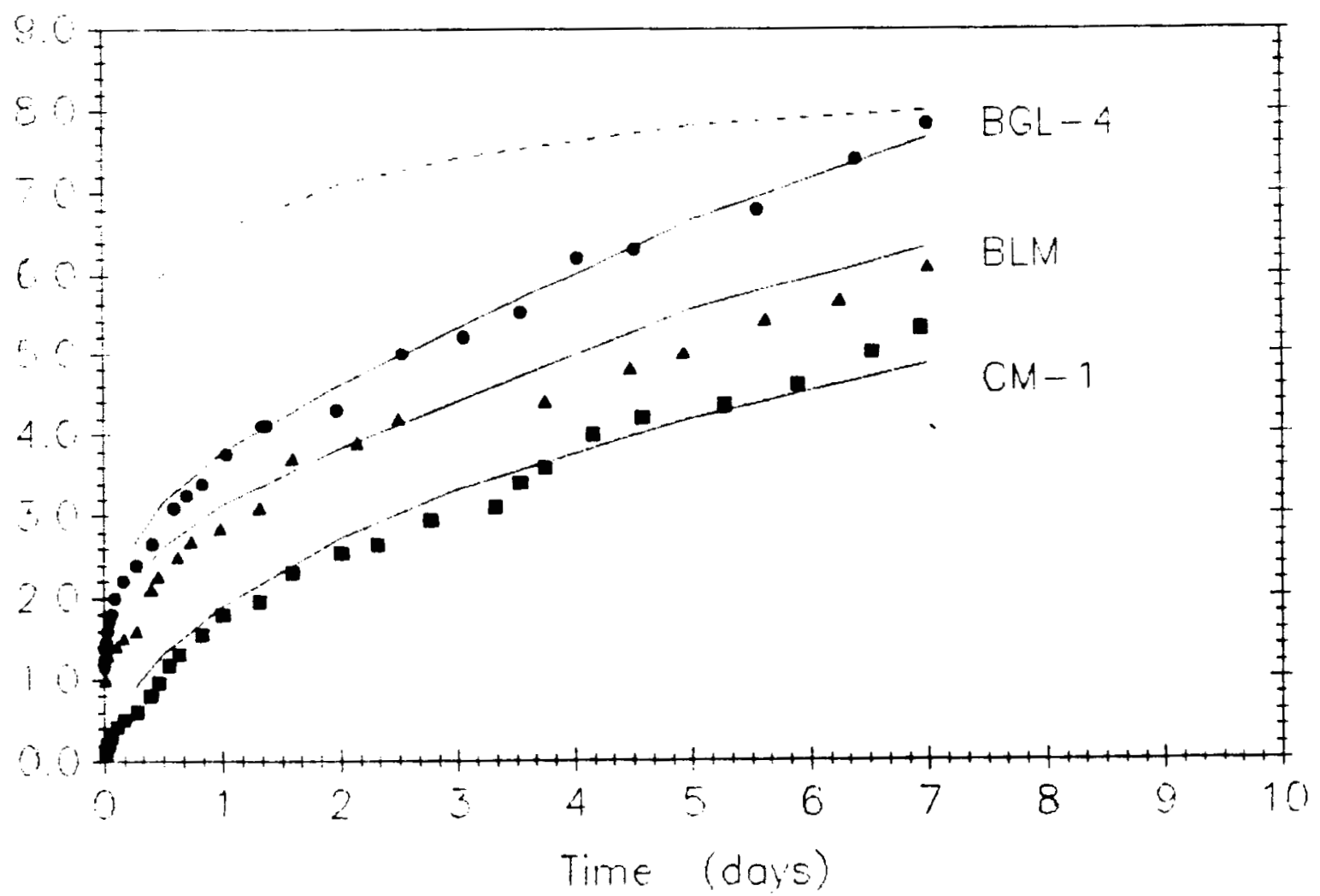

Figure 18b. Linear plot of BGL-2 Test data and calculated match. 


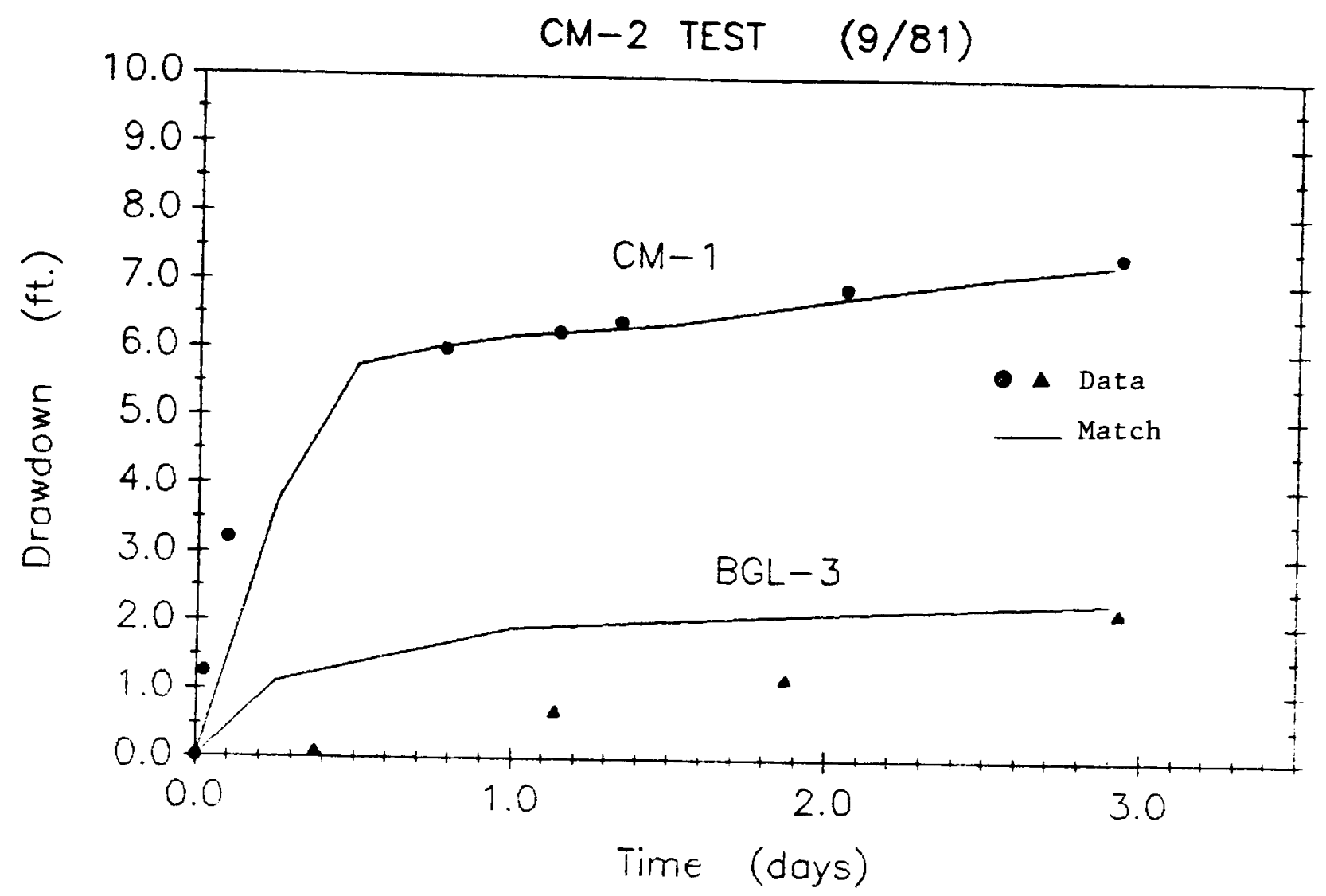

Figure 19a. Linear plot of the CM-2 Test with the calculated match.

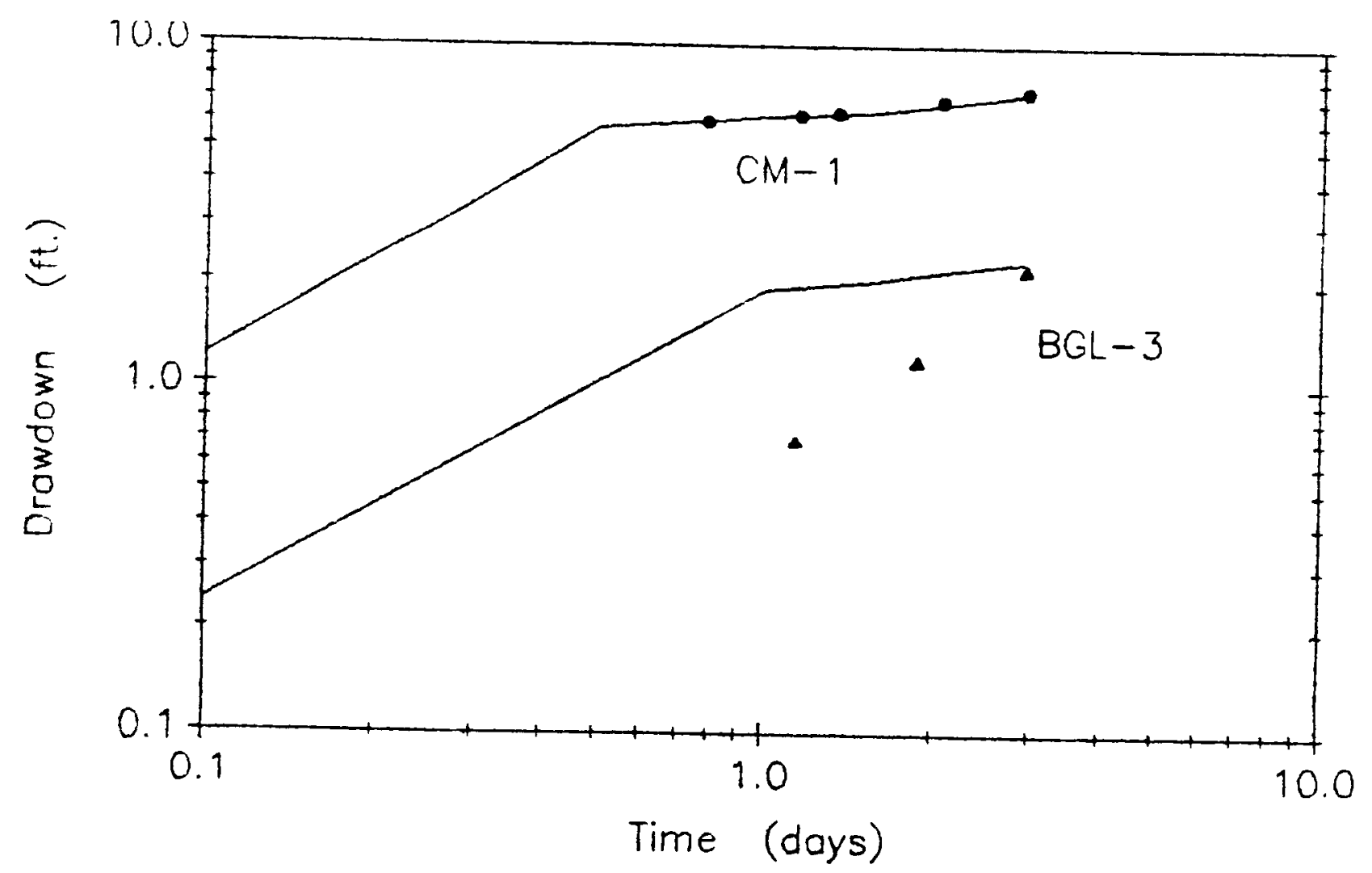

Figure 19b. Log-Log plot of the CM-2 Test. 


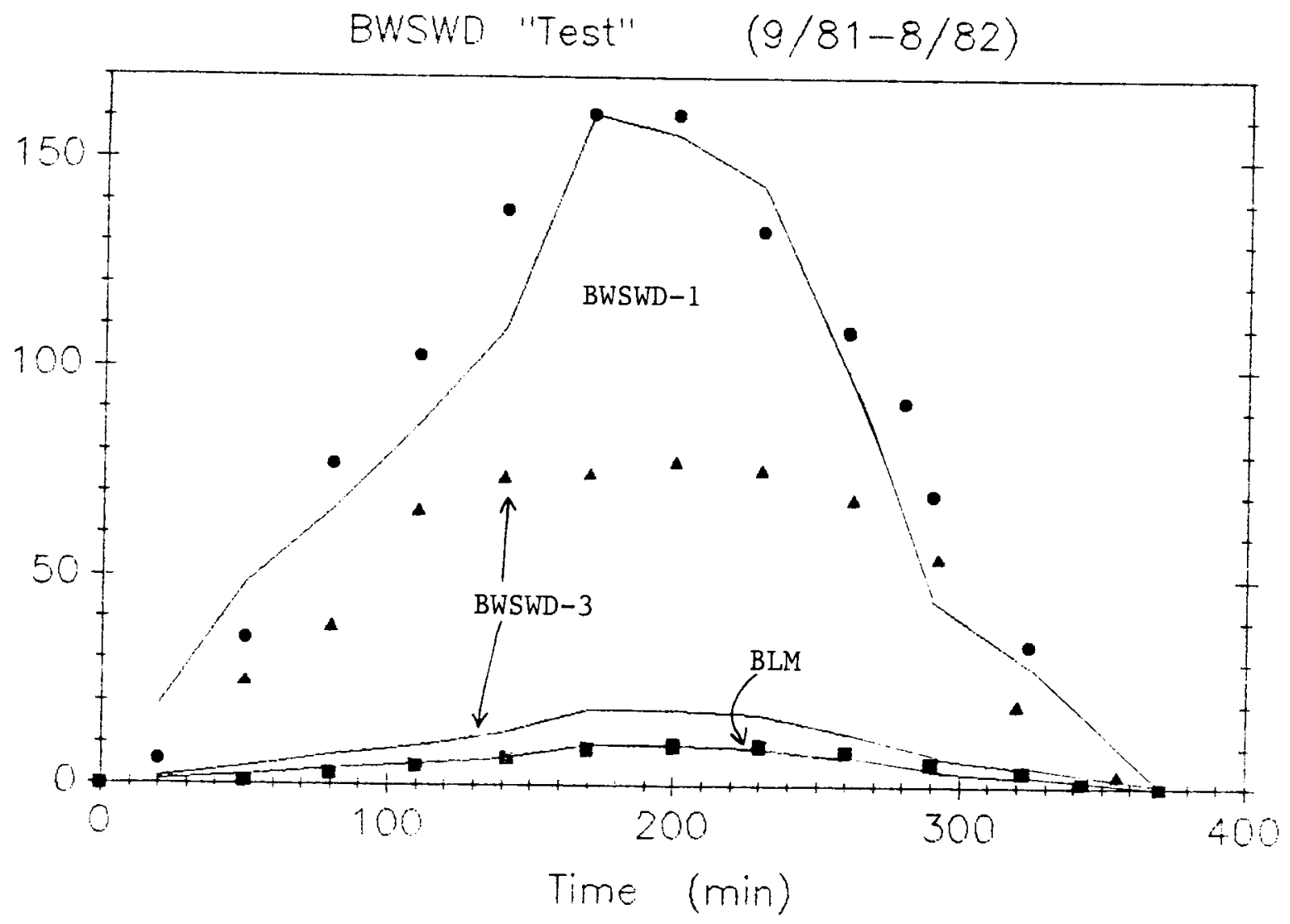

Figure 20. Data and calculated match for the BWSWD-1\&2 history match "test" for one year of normal operation.

- D Data

_ Match 


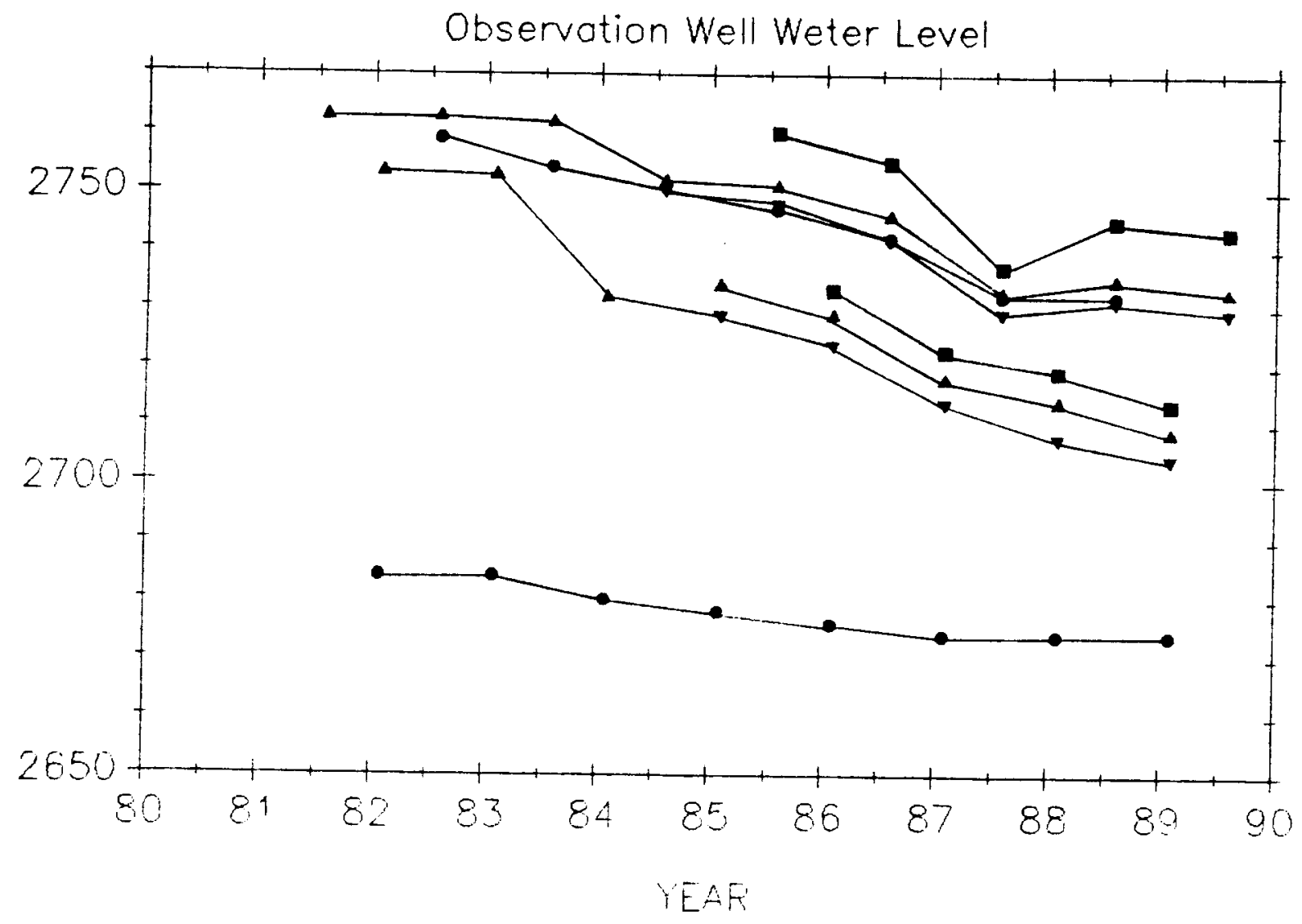

$\begin{array}{ll}\text { BWSWD-3 } & \bullet \\ \text { BLM } & \mathbf{\Delta} \\ \text { Behrman } & \boldsymbol{\bullet} \\ \text { Kanta } & \nabla\end{array}$

Figure 21. Observation well water level data taken from water level recorder measurments and plotted as high and low values for each year. 


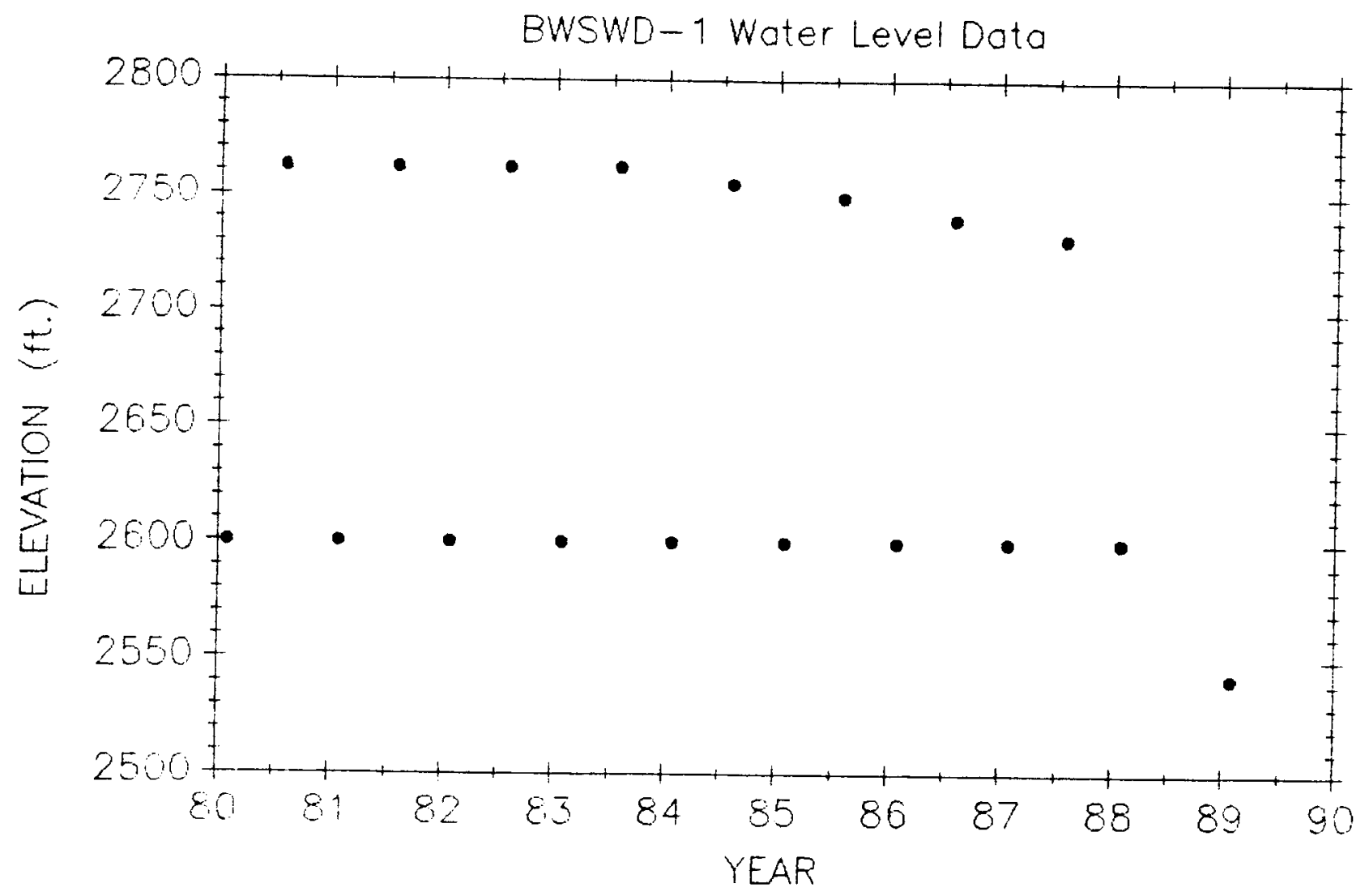

Figure 22. High and low water level data in BWSWD-1. 


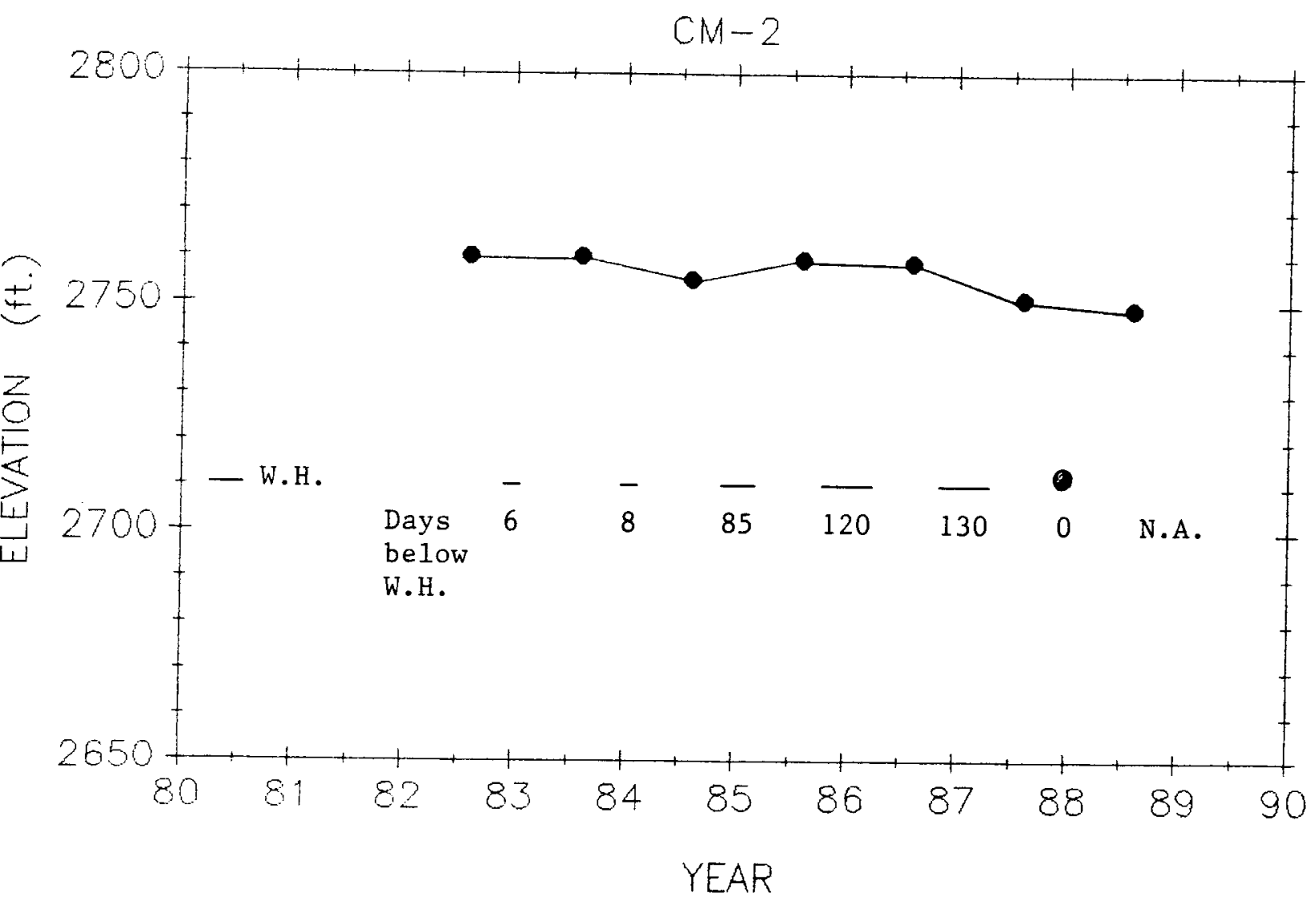

Figure 23. Capitol Mall - 2 well head pressure (yearly maximum), converted to approximate (hot) water level elevation. Well head elevation and number of days water level dropped below the well head in winter is also noted. 


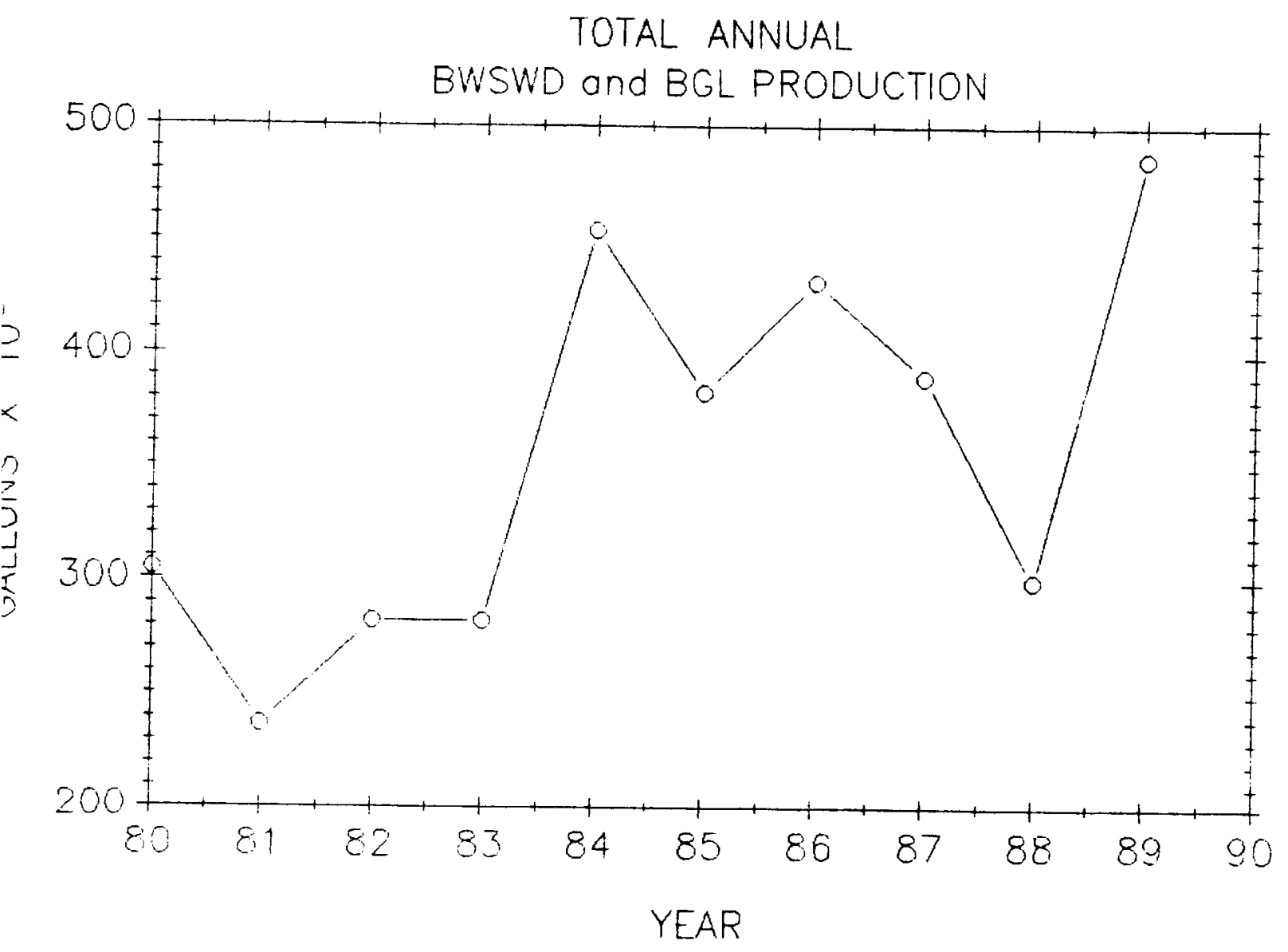

Figure 24. BWSWD and BGL annual geothermal production.

(after Waag, 1987) 


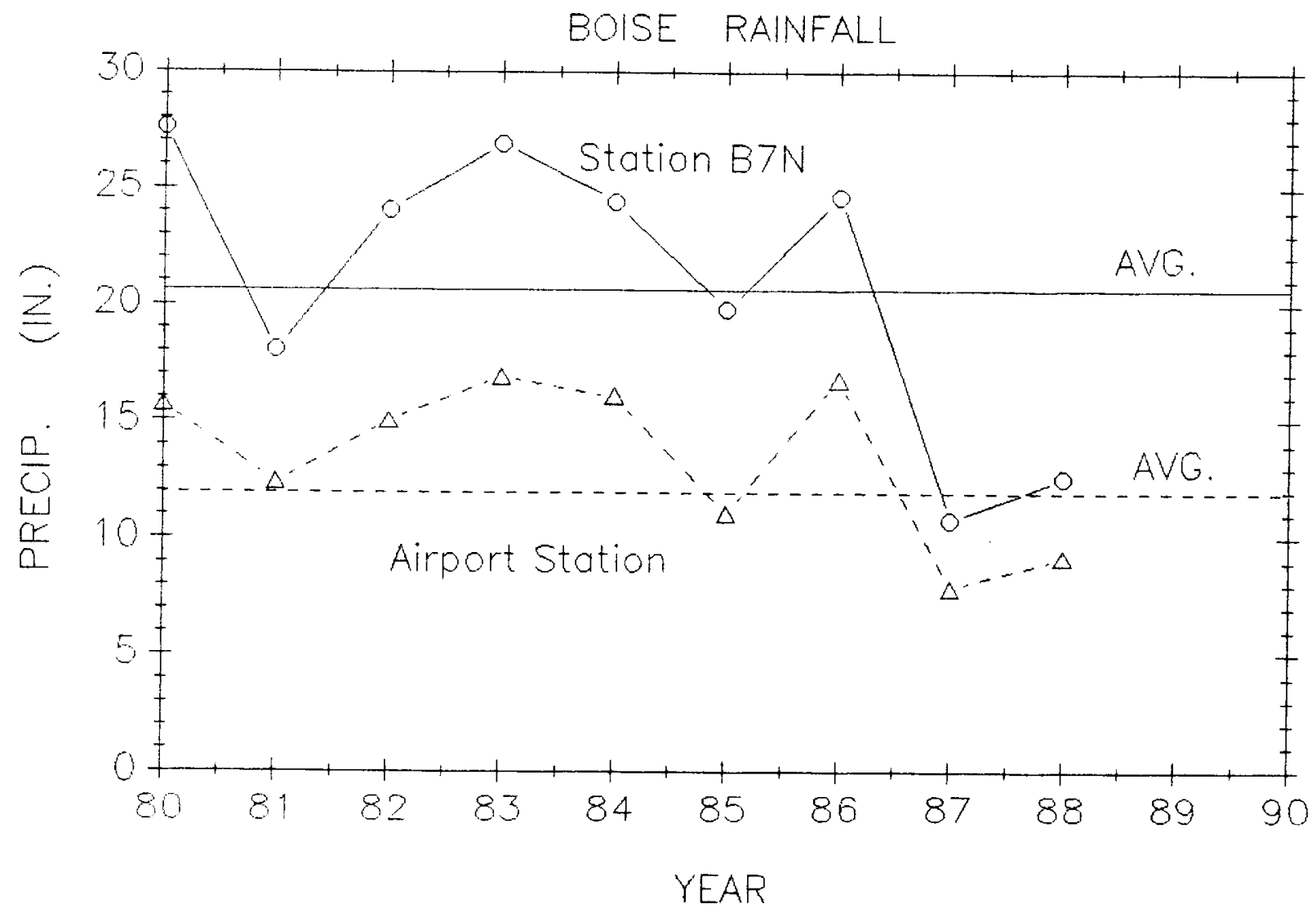

Figure 25. Boise area precipitation and historical average. 


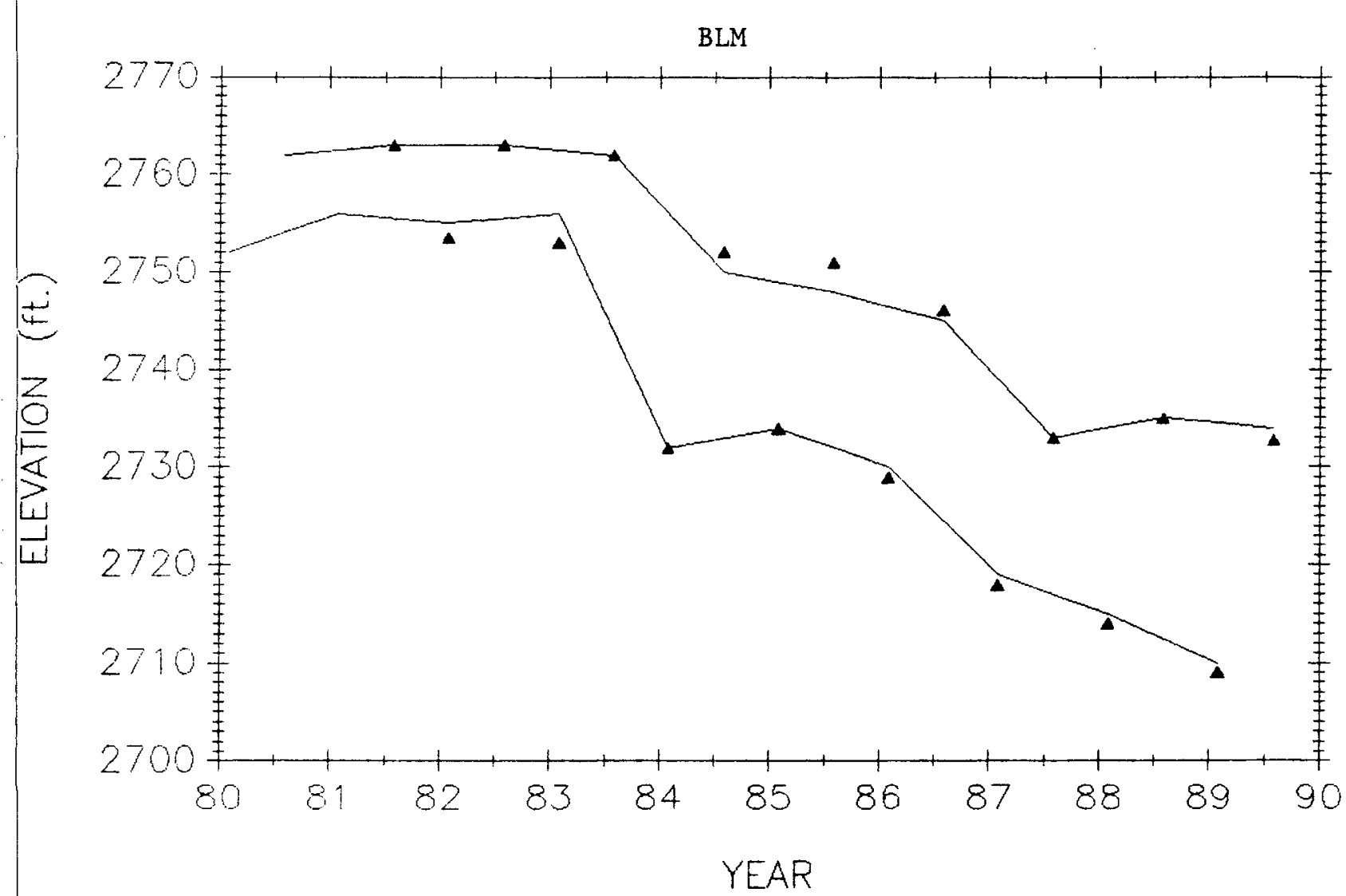

Figure 26. BLM data (points) and history match (lines). 


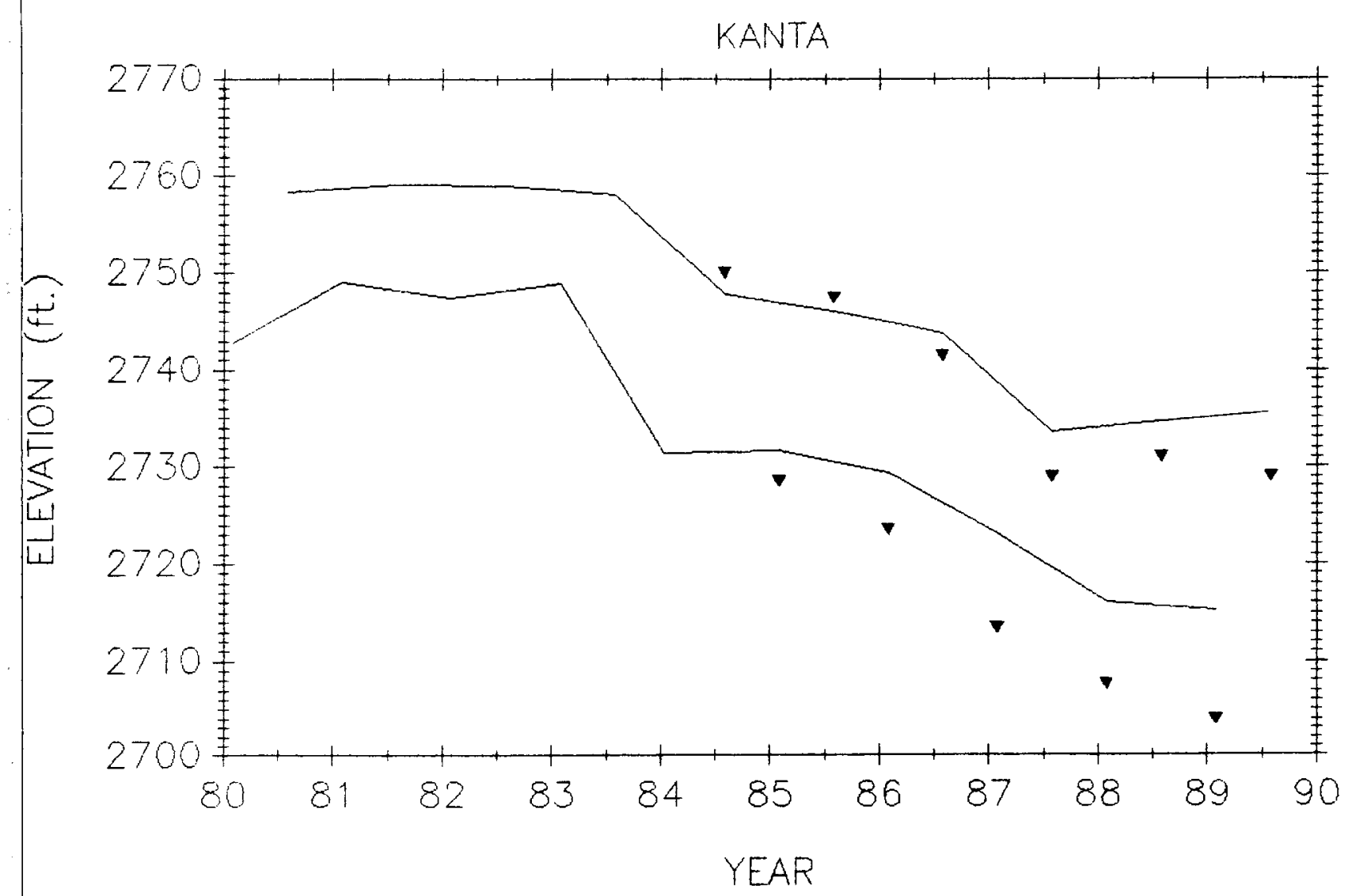

Figure 27. Kanta well data (points) and history match (1ines). 


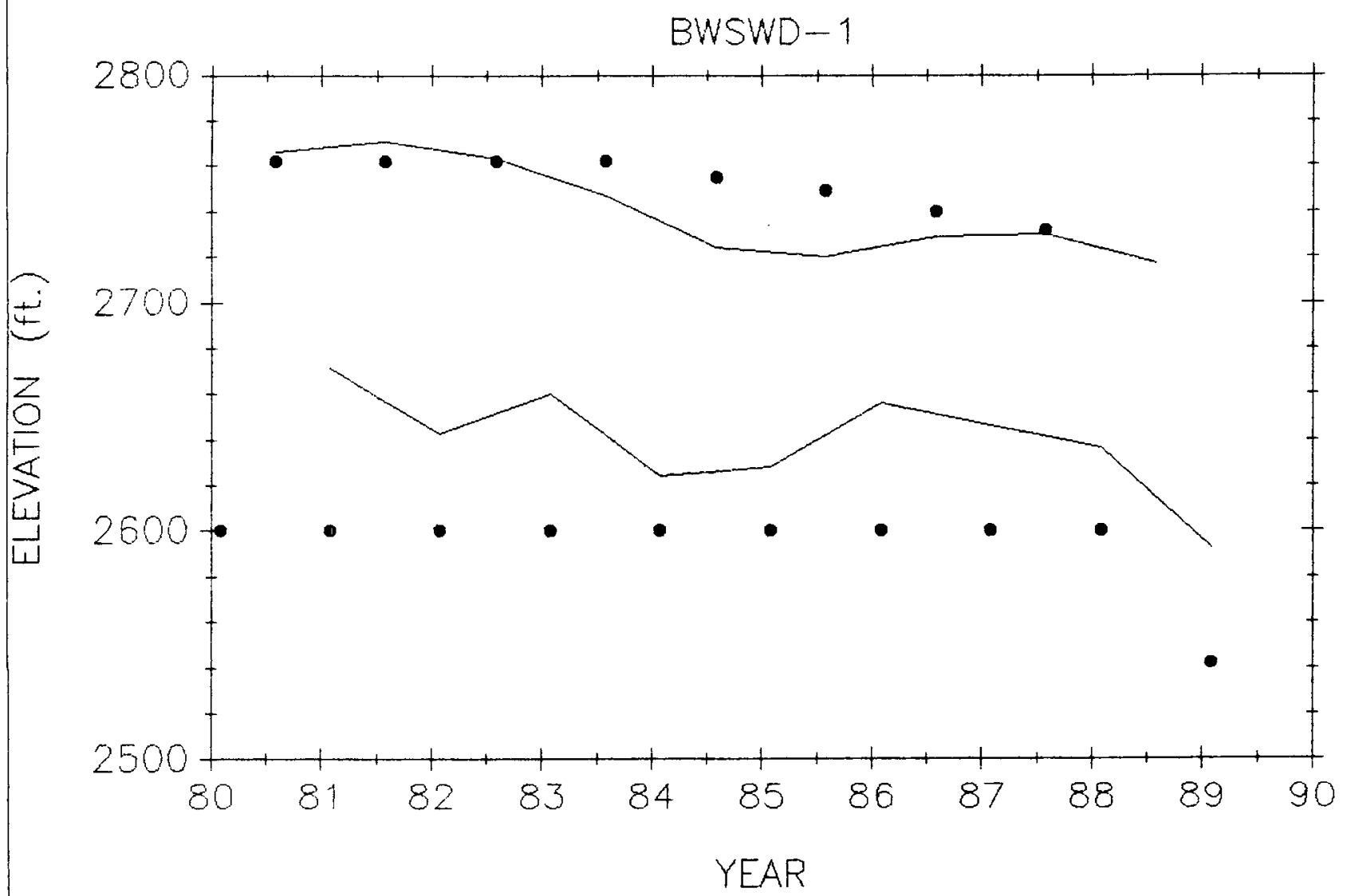

Figure 28. BWSWD-1 data (points) and history match (1ines). 


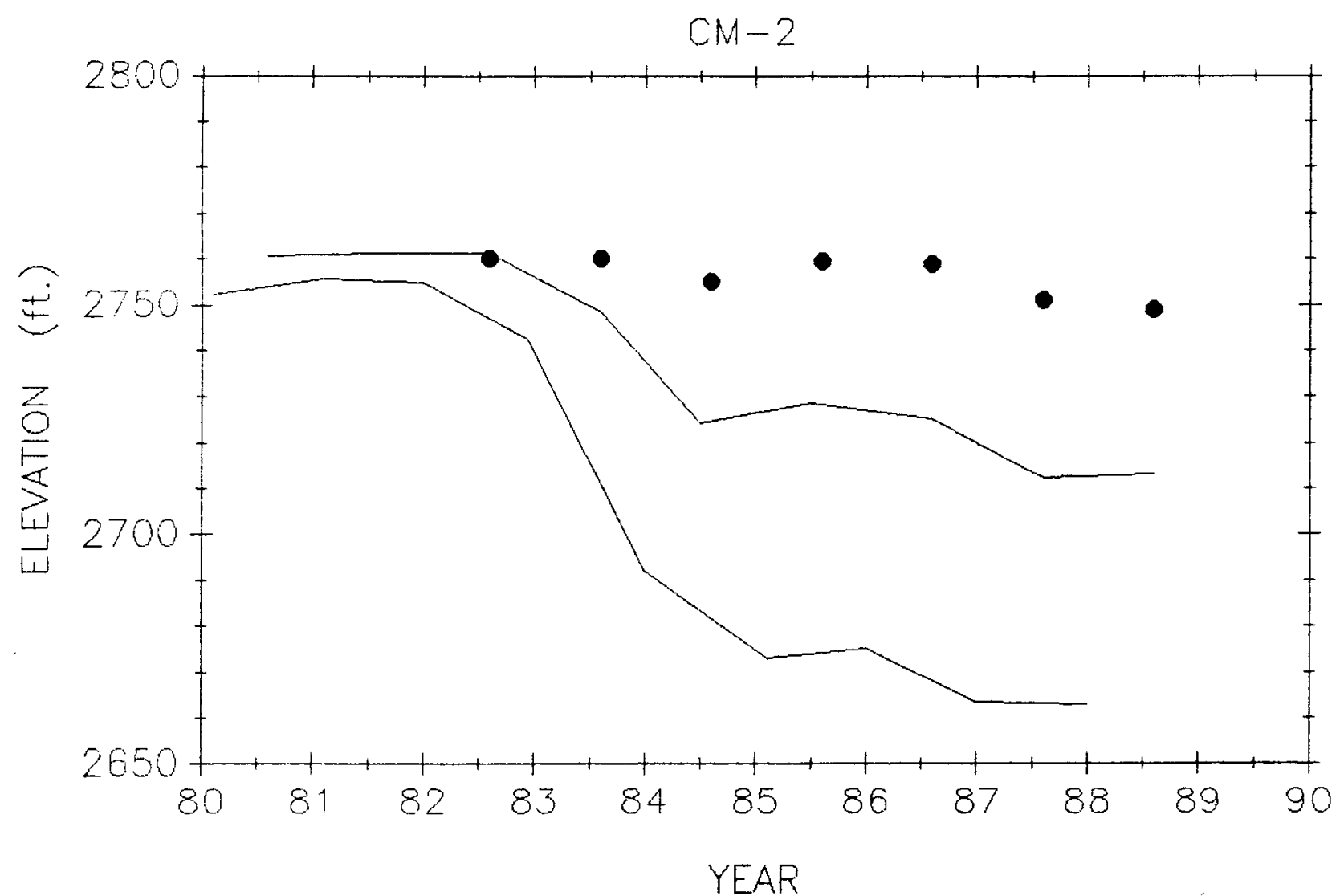

Figure 29. CM-2 data (points) and history match(lines). 


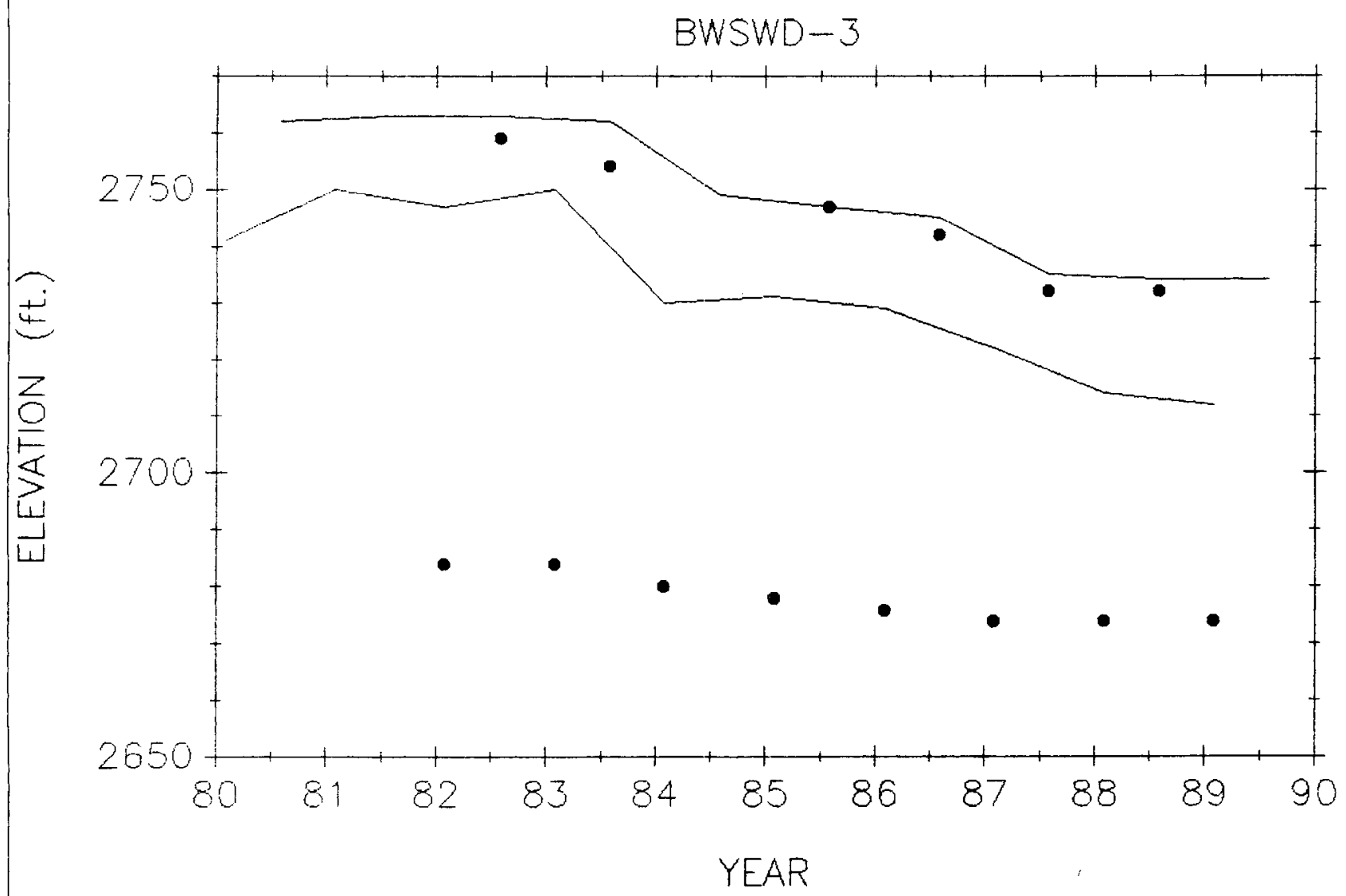

Figure 30. BWSWD-3 data (points) and calculated history match(lines). 


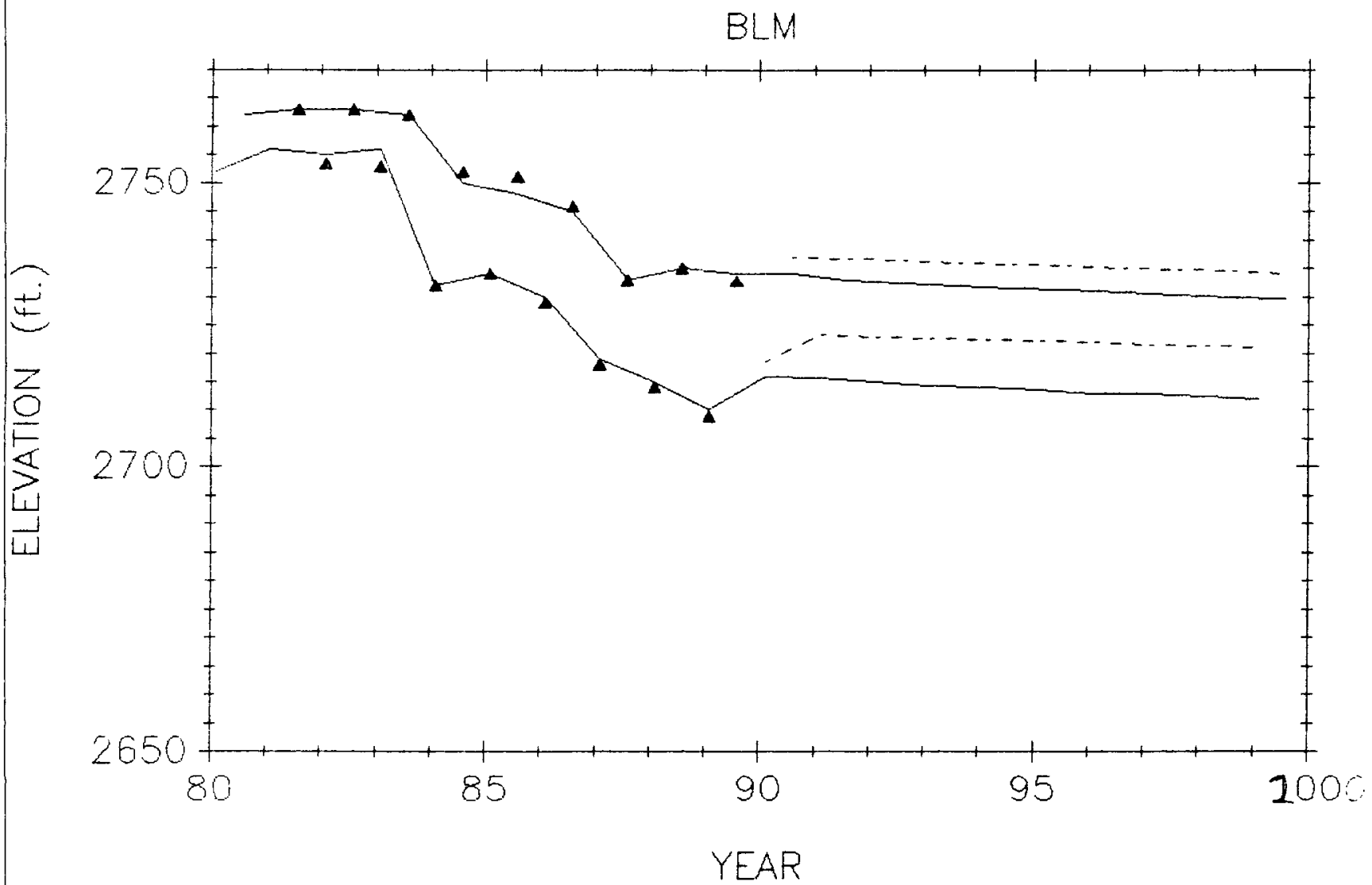

Figure 31. BLM well data and calculated drawdown from year 1990 to 2000. Assuming no additional production. Dotted line is the calculated values assuming BGL injection occurs. 


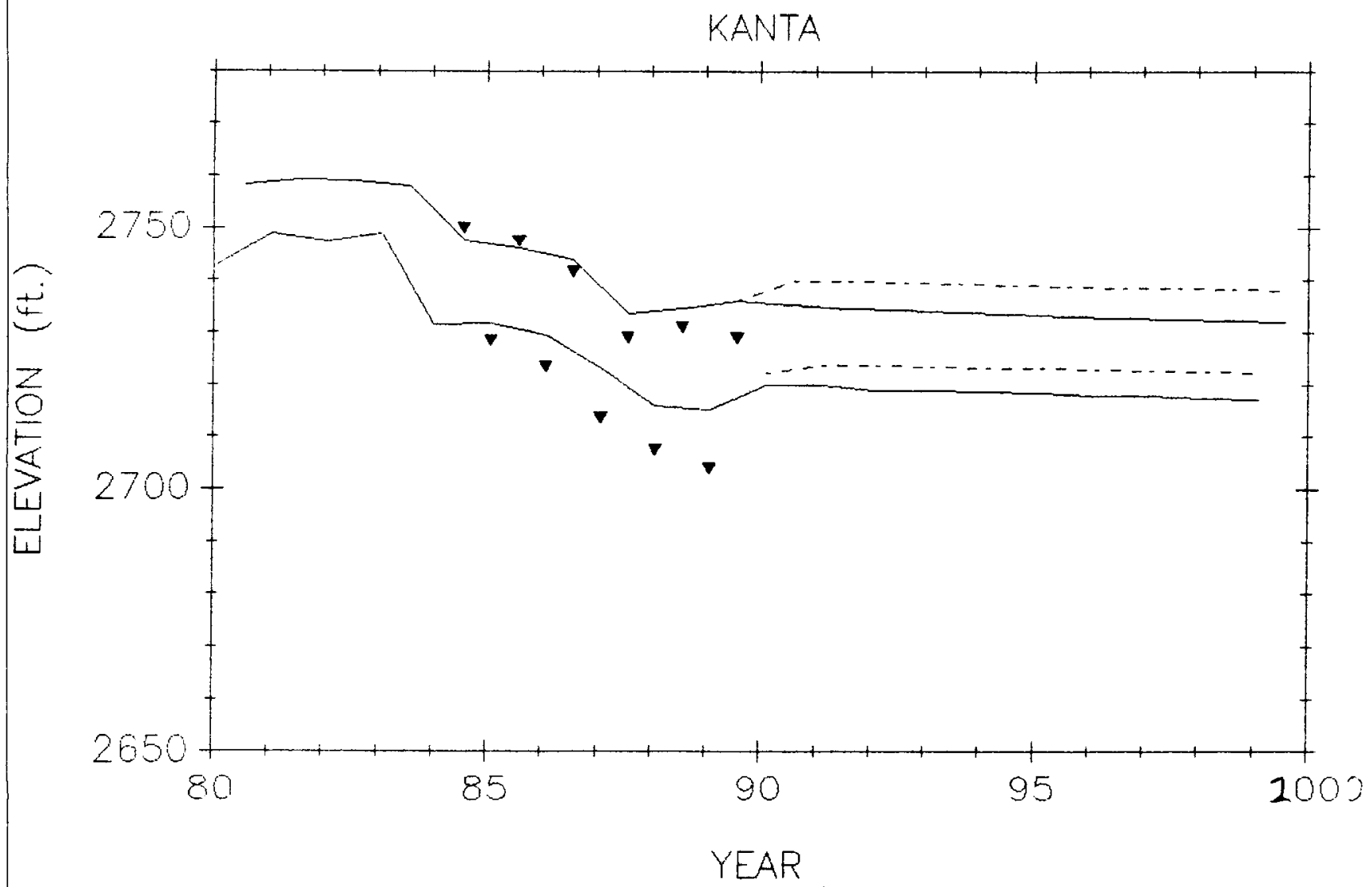

Figure 32. Kanta well data and calculated drawdown from year 1990 to 2000. Assuming no additional production. Dotted line is with BGL injection. 
BLM

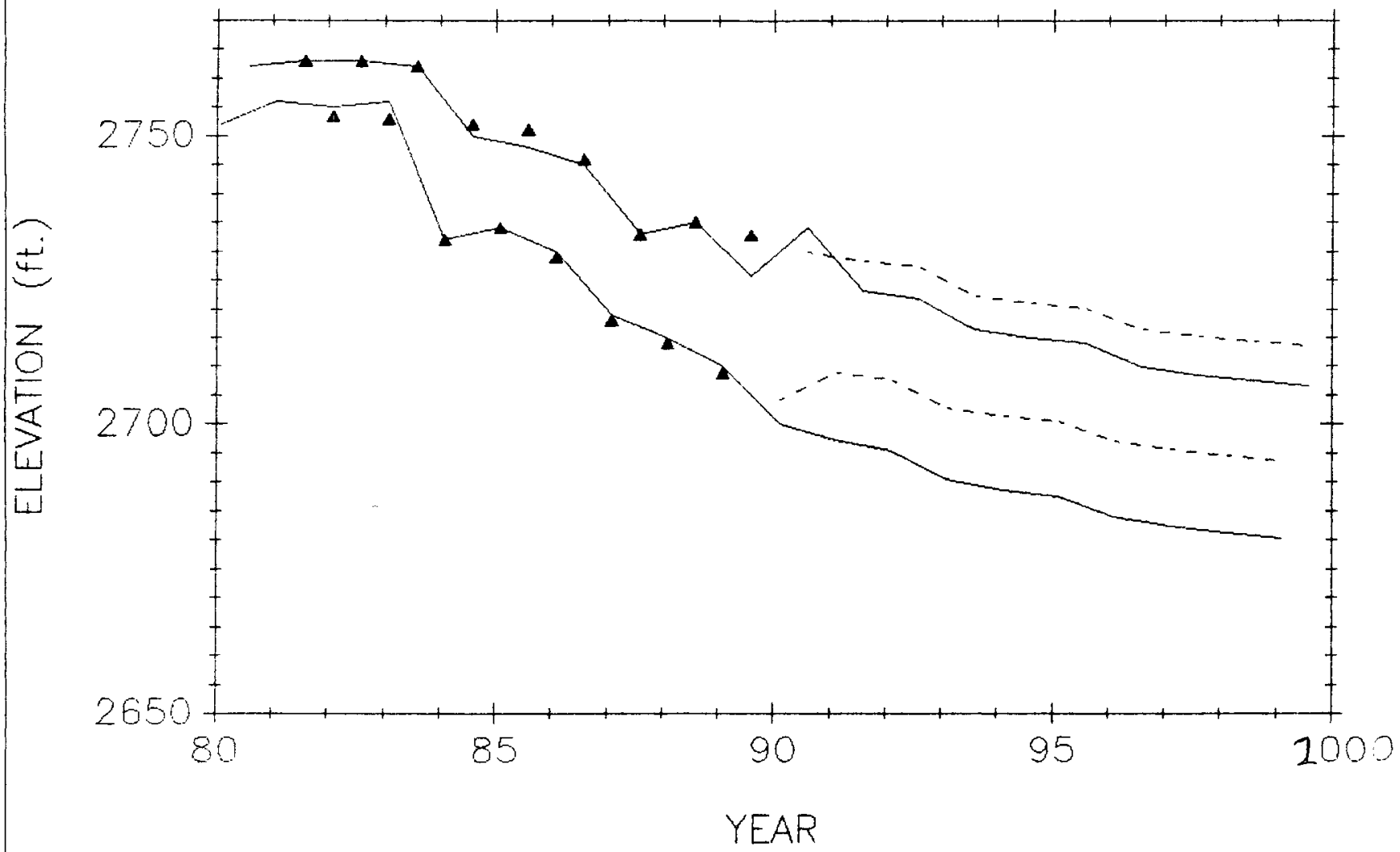

Figure 33. BLM calculated drawdown assuming $50 \%$ additional production. Dotted line is with BGL injection. 


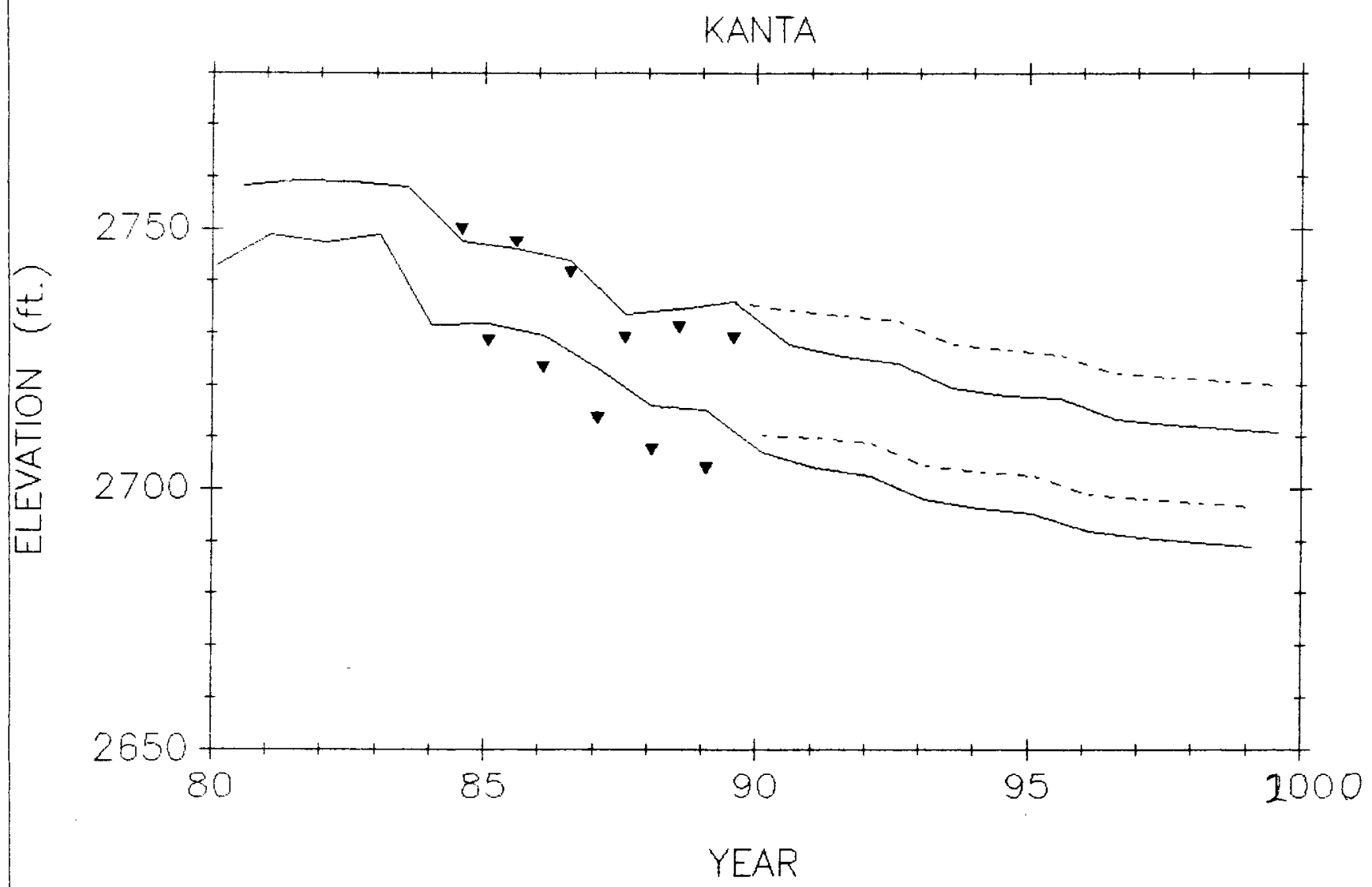

Figure 34. Kanta well calculated drawdown assuming $50 \%$ additional production. Dotted line is with BGL injection. 


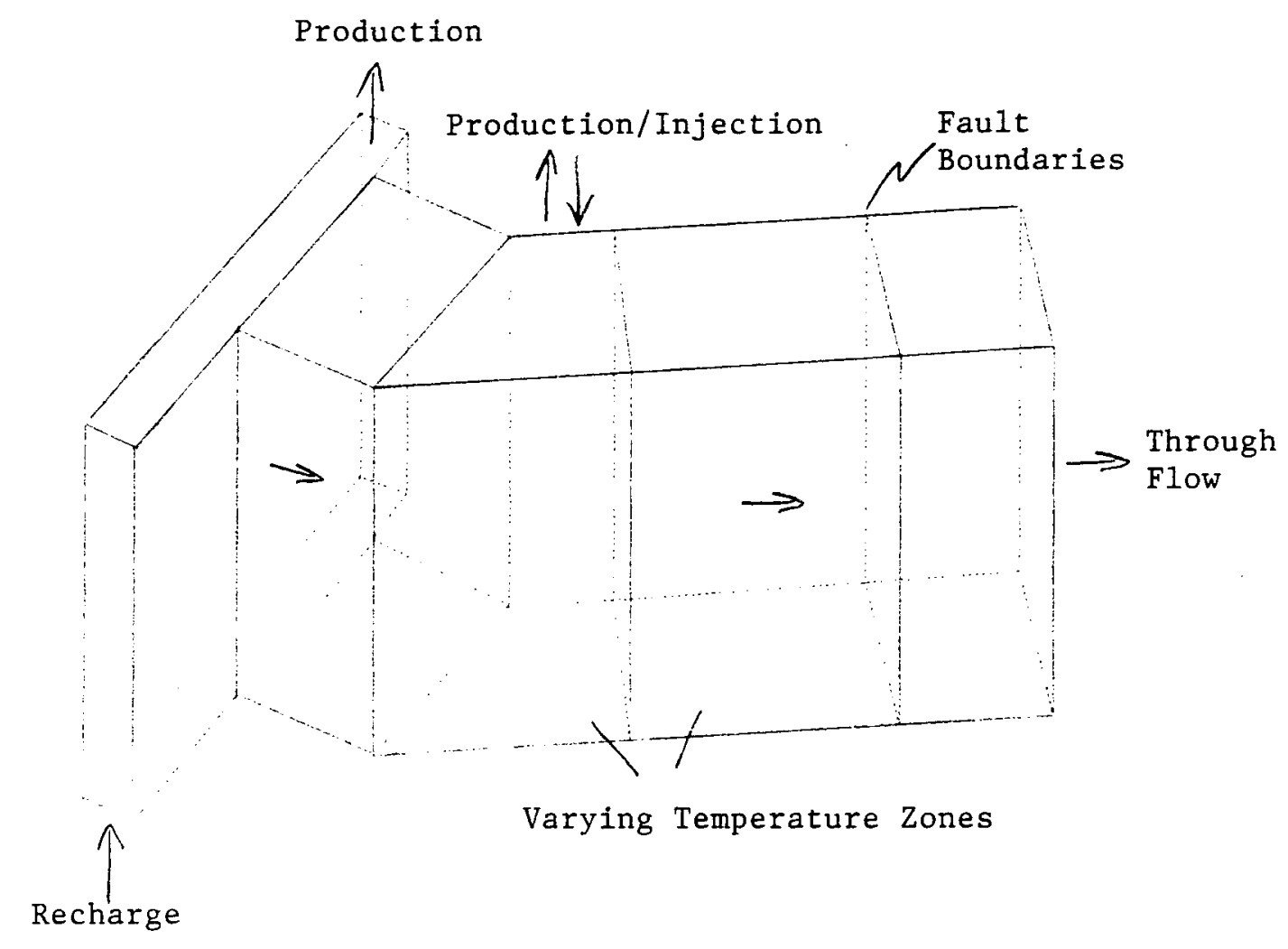

Figure 35a. Sample TBLOCKS model.

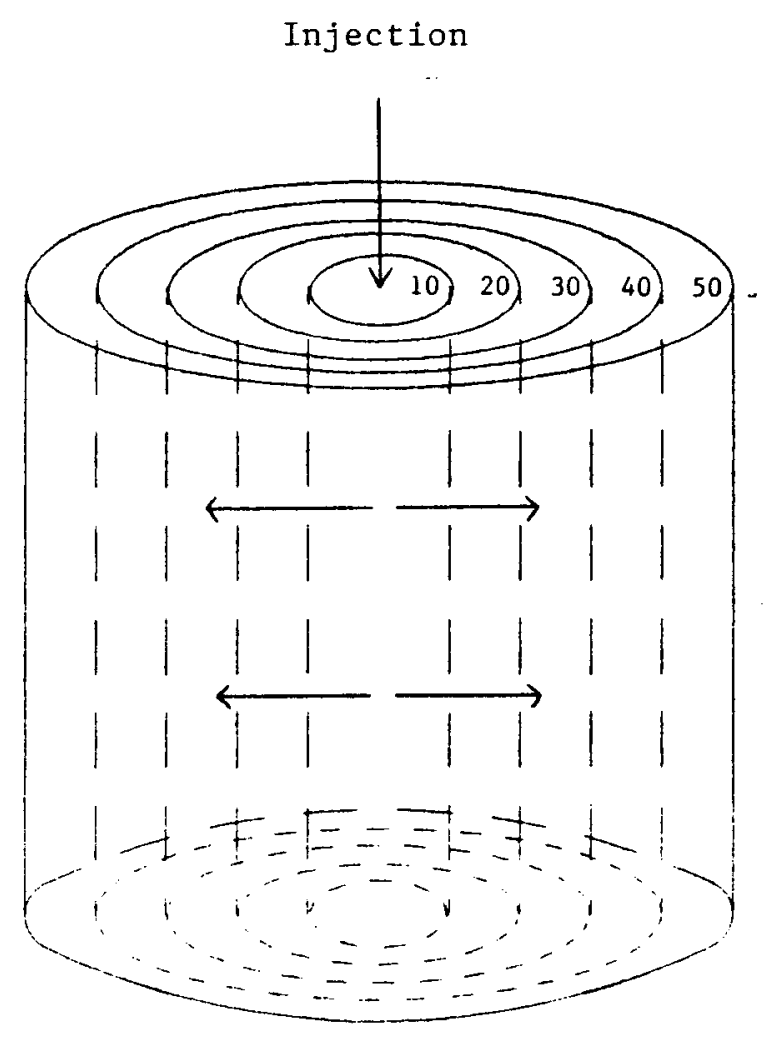

Figure 35b. Schematic diagram of injection with a cylindrical model. 


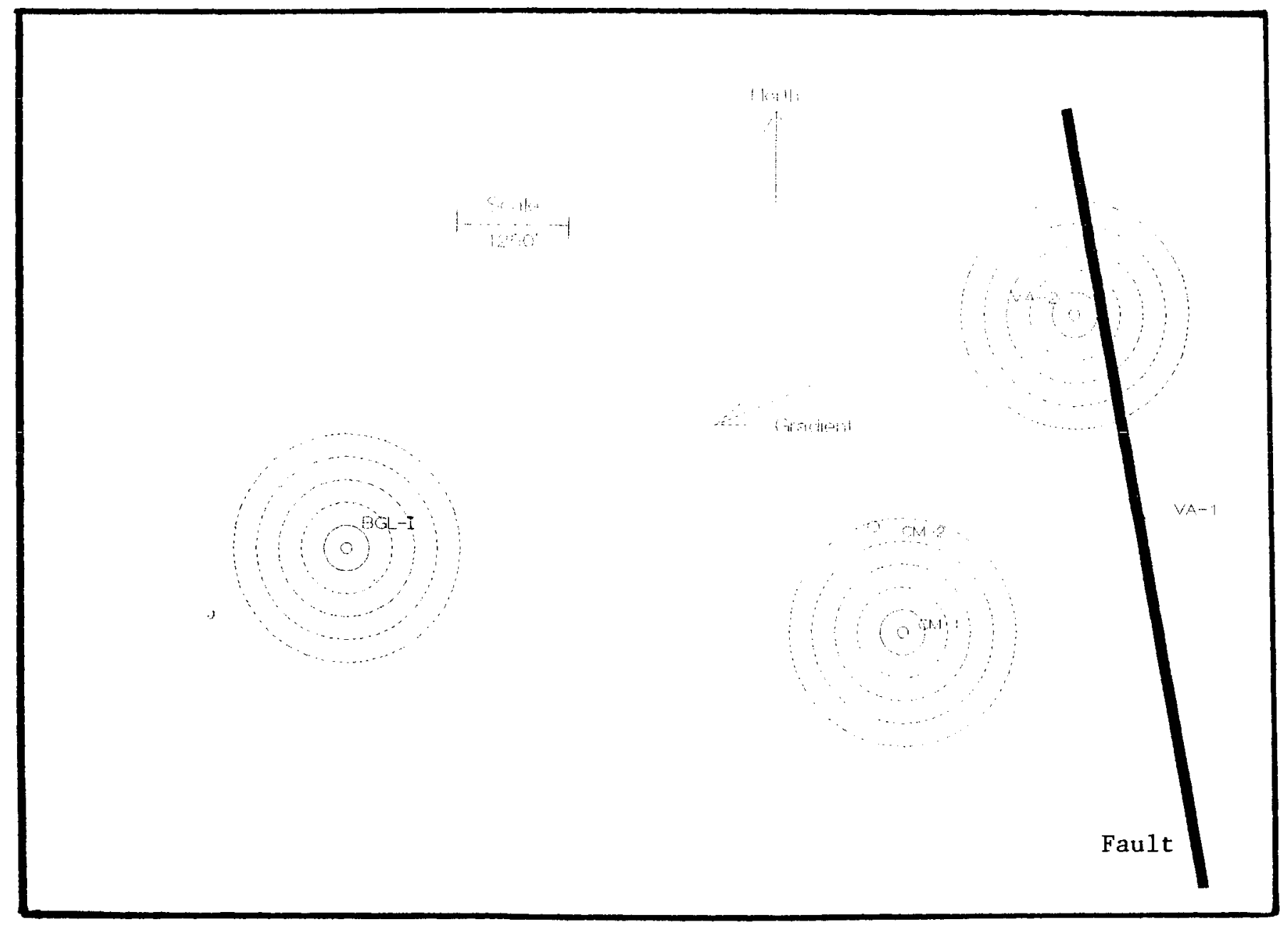

Figure 36. Schematic illustration of injected fluid distribution around injection wells, including the relative location of a hypothetical BGL injection well (BGL-I). 


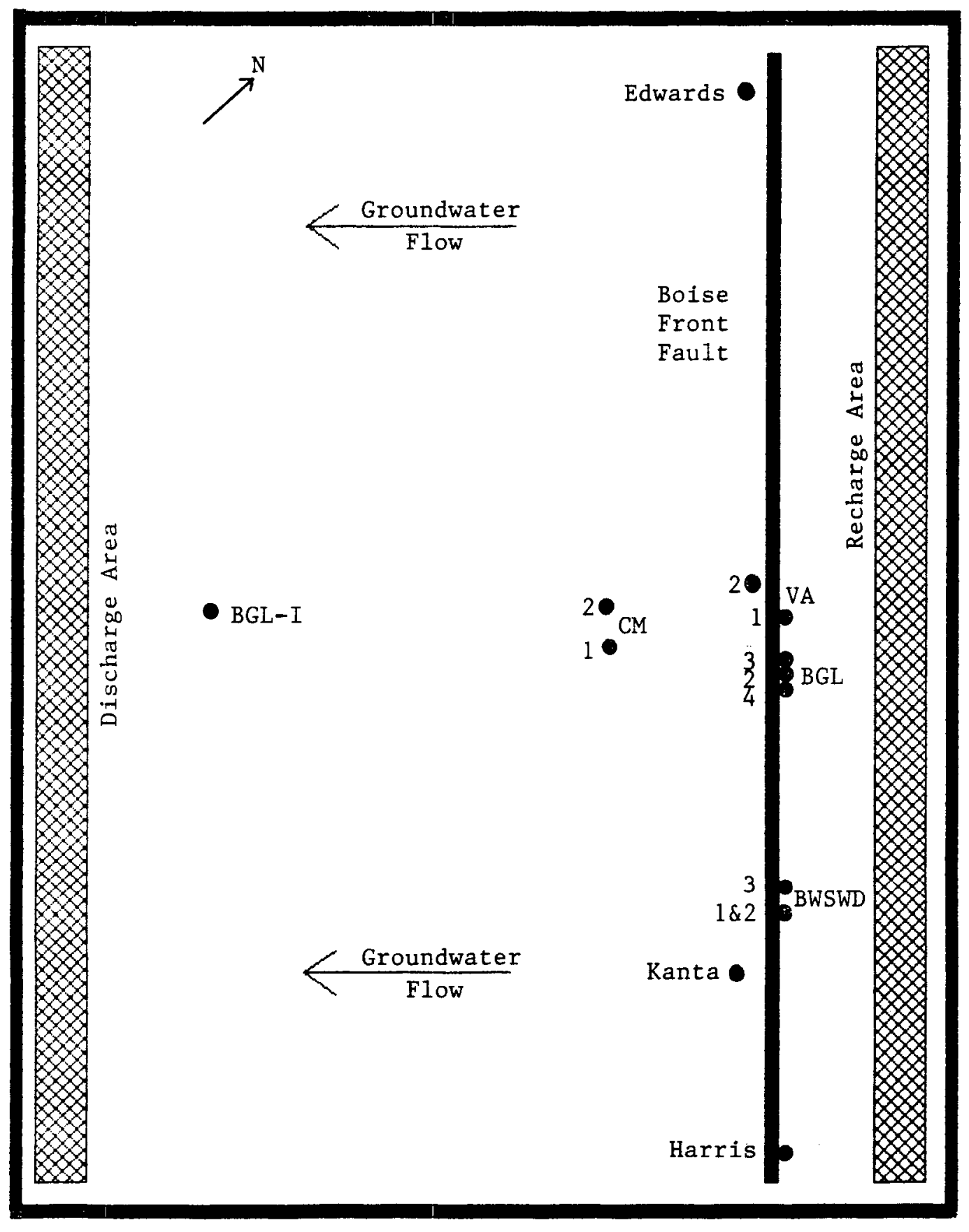

\footnotetext{
Figure 37. Schematic diagram of the pressure response model. Note: The BGL-I well is a hypothetical well used for modeling purposes on1y.
} 


\section{Appendix A}

\section{Available Well Temperature Profiles}




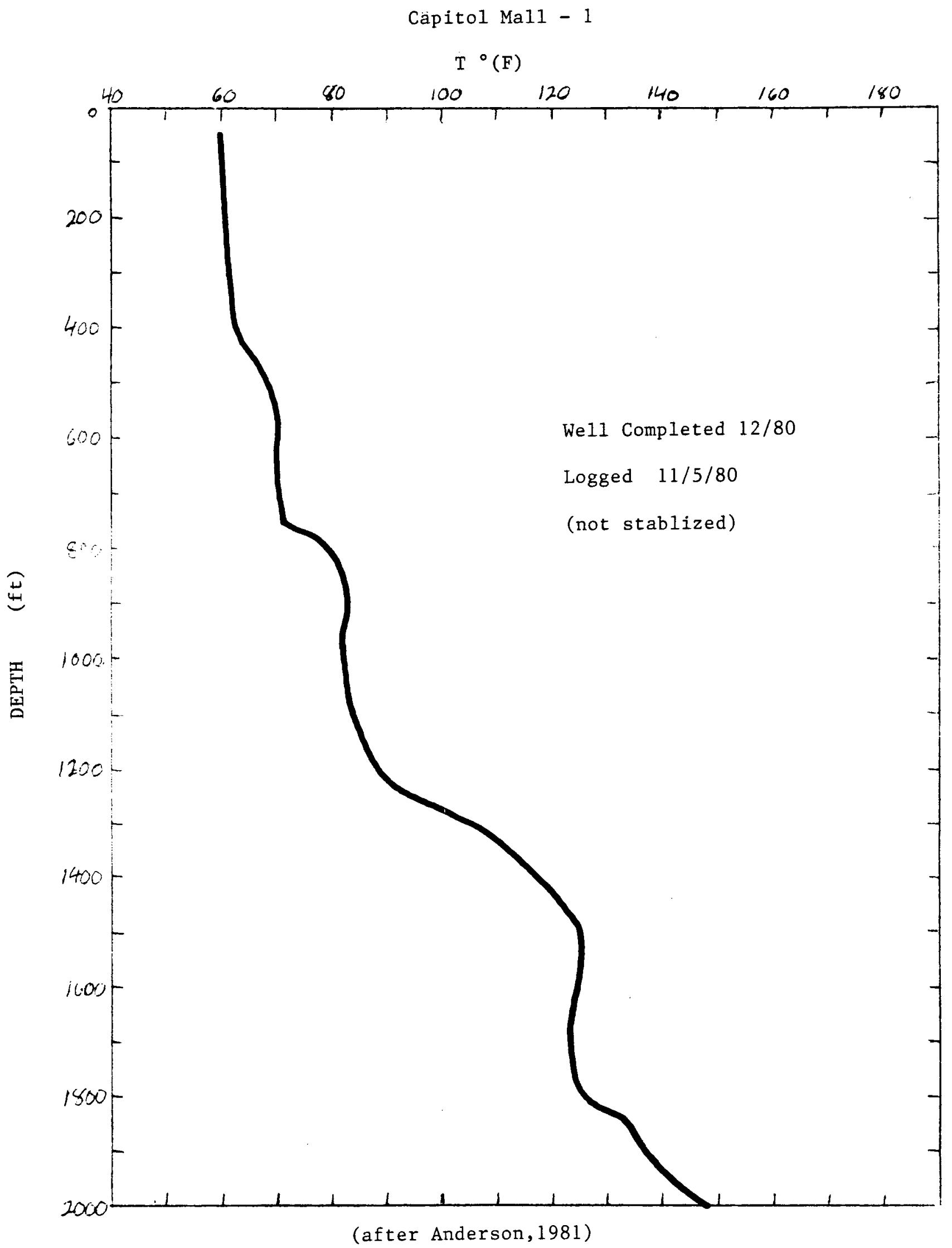




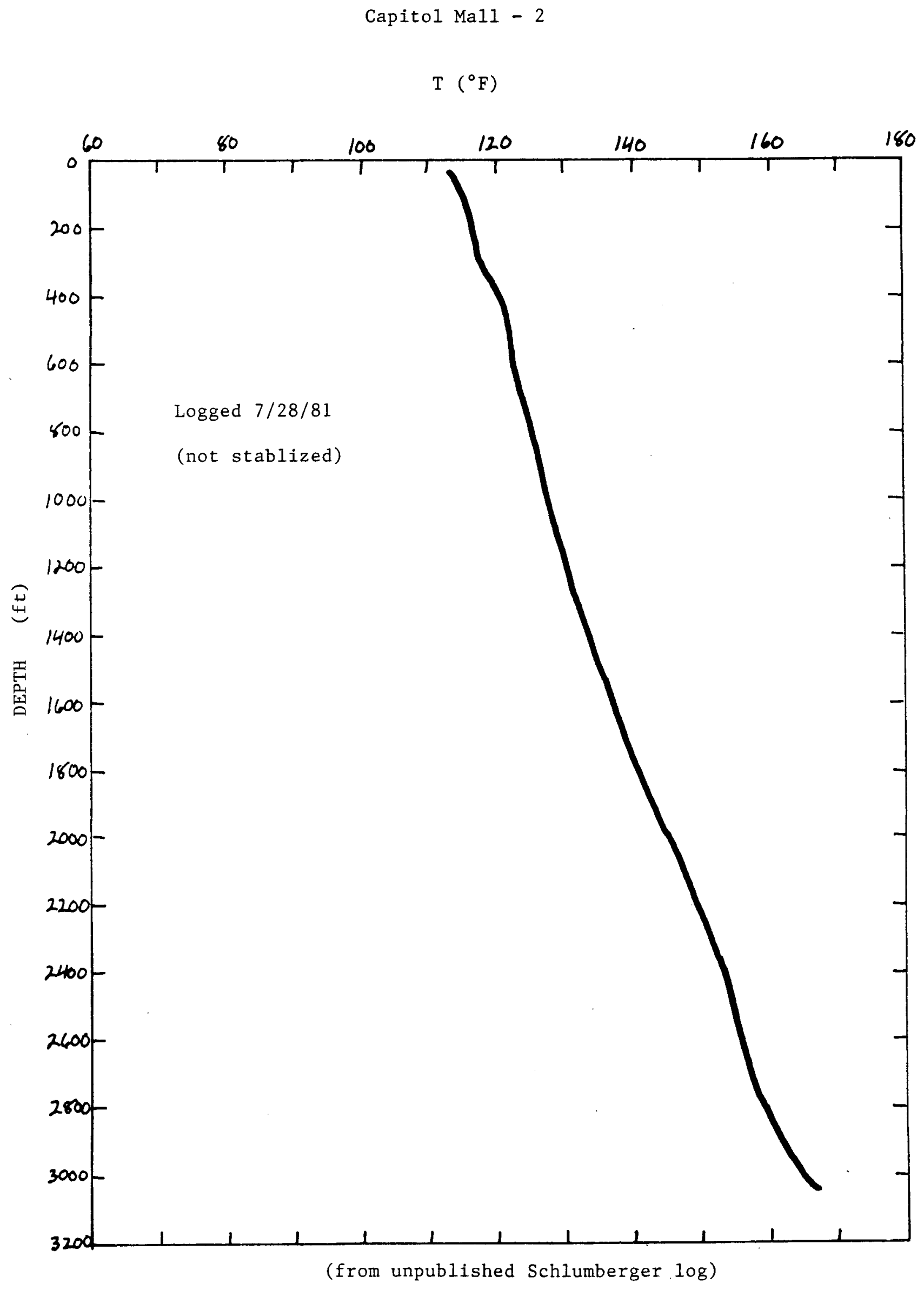




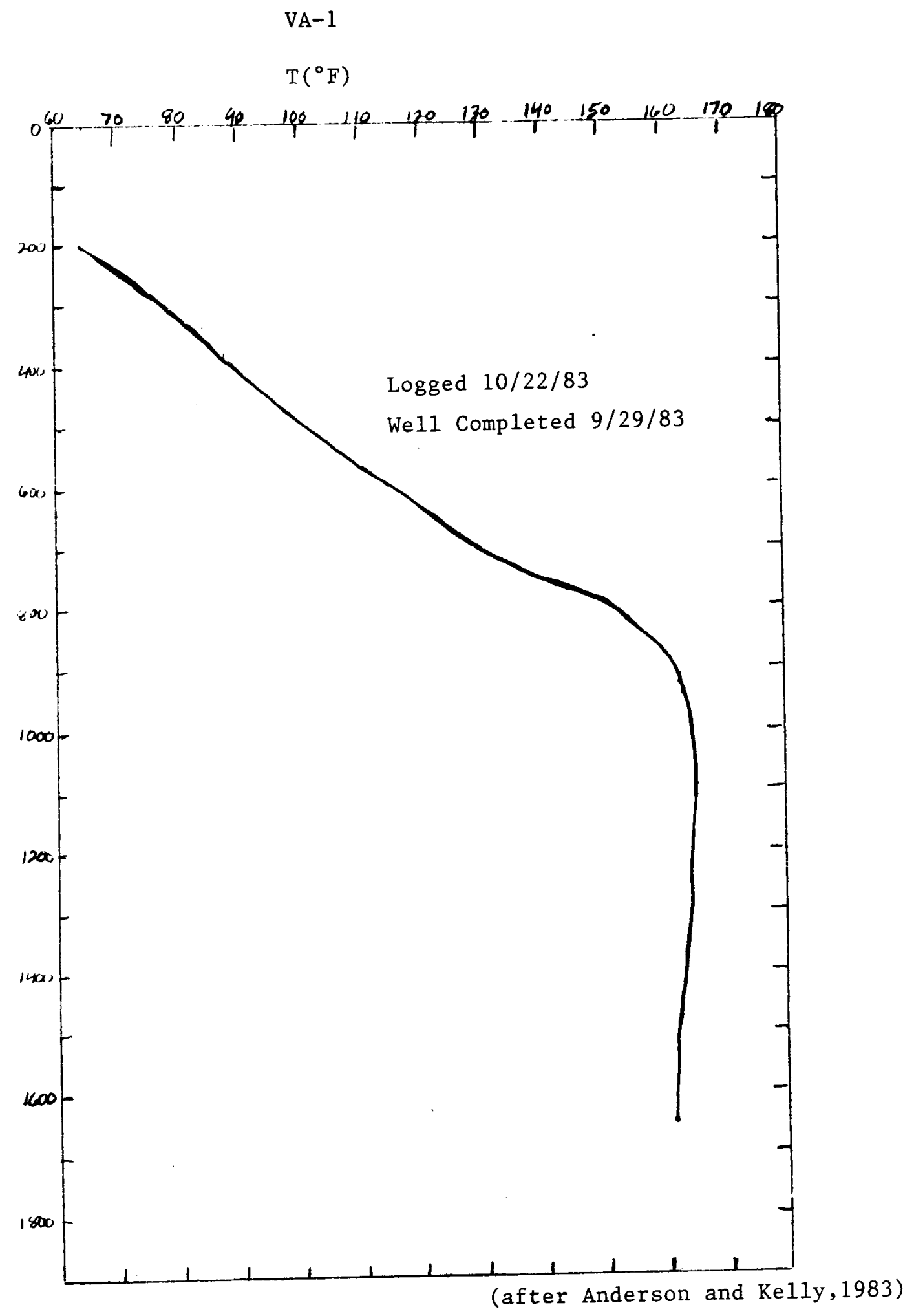




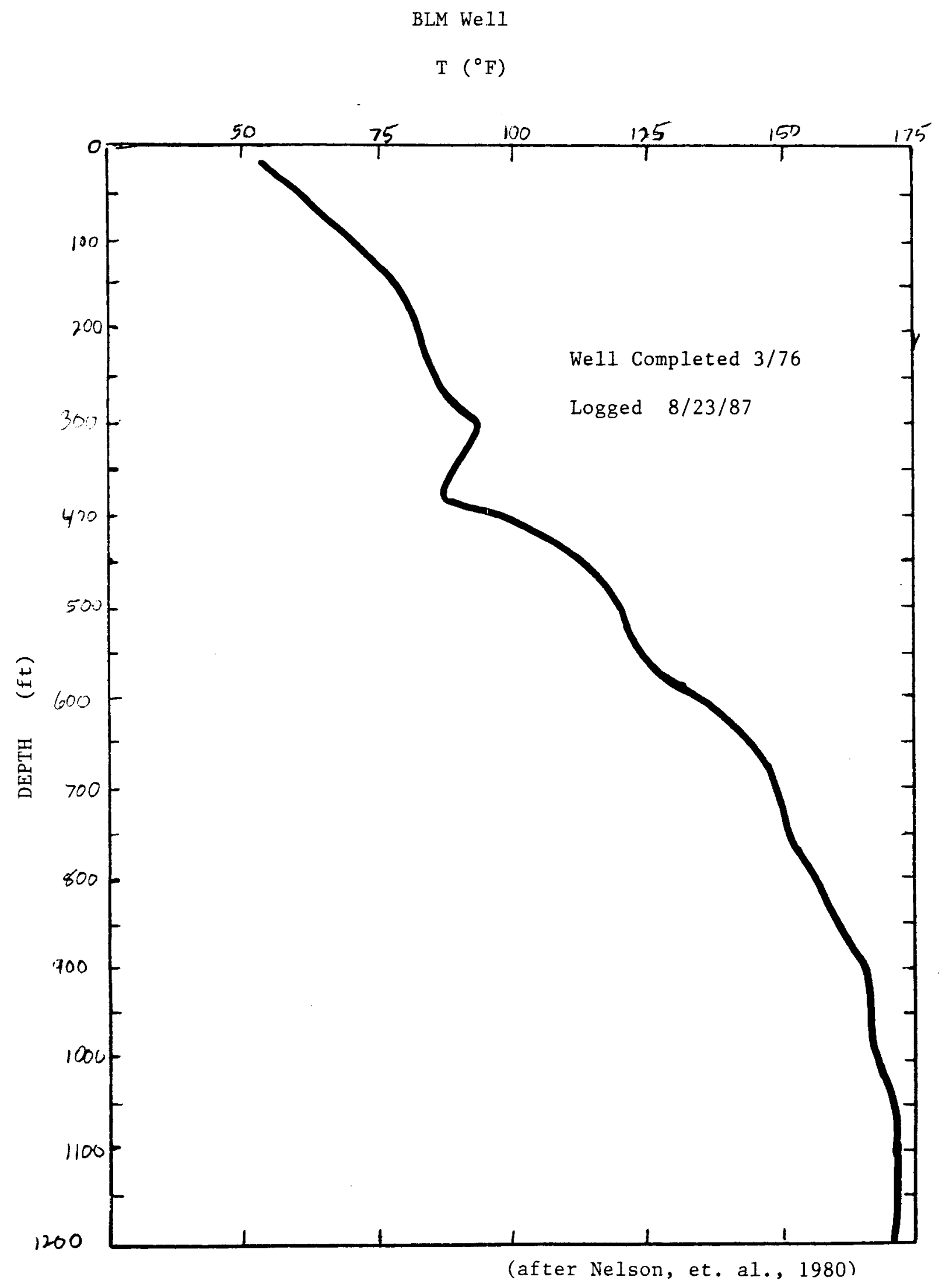




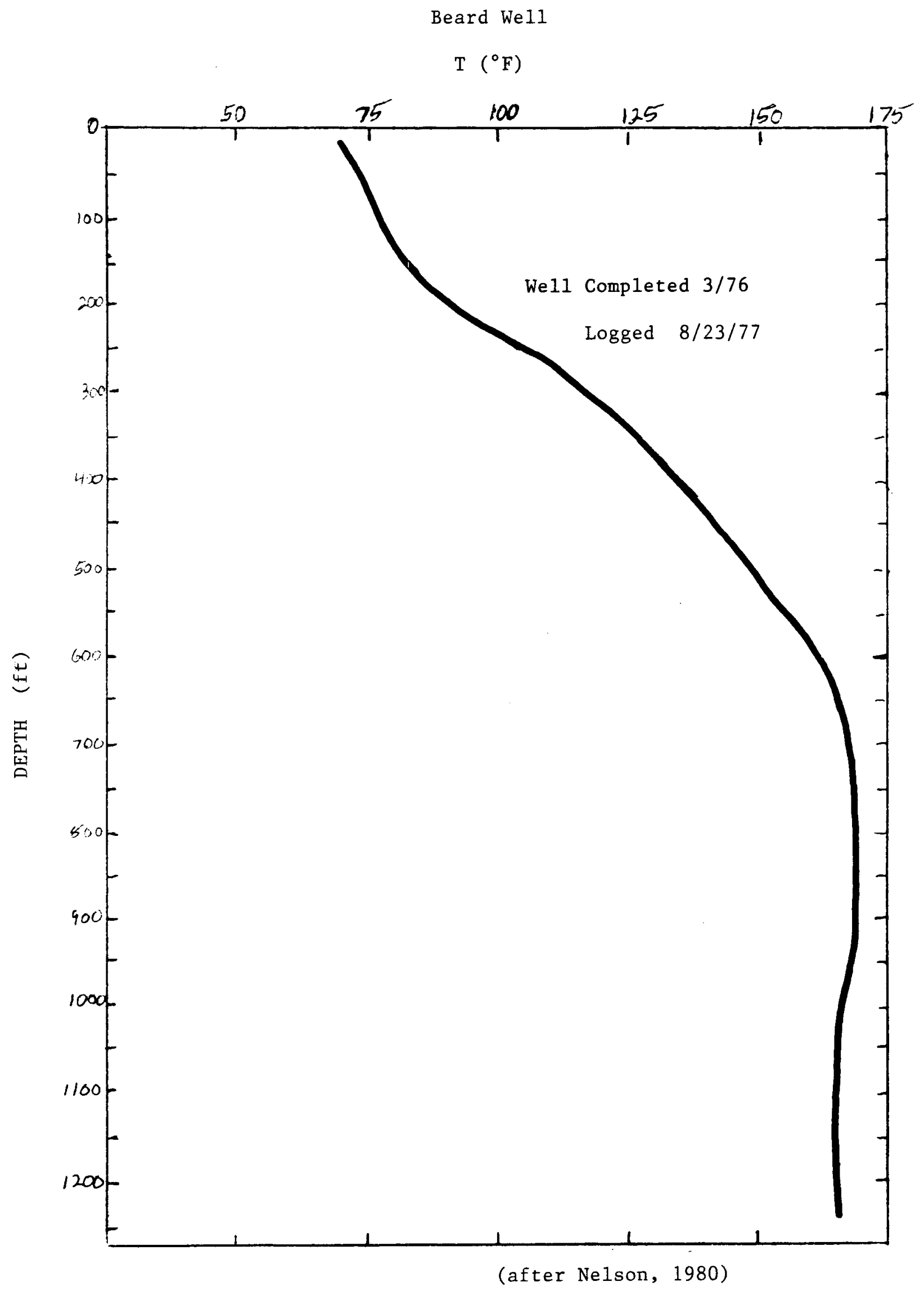


BGL 1 and 2

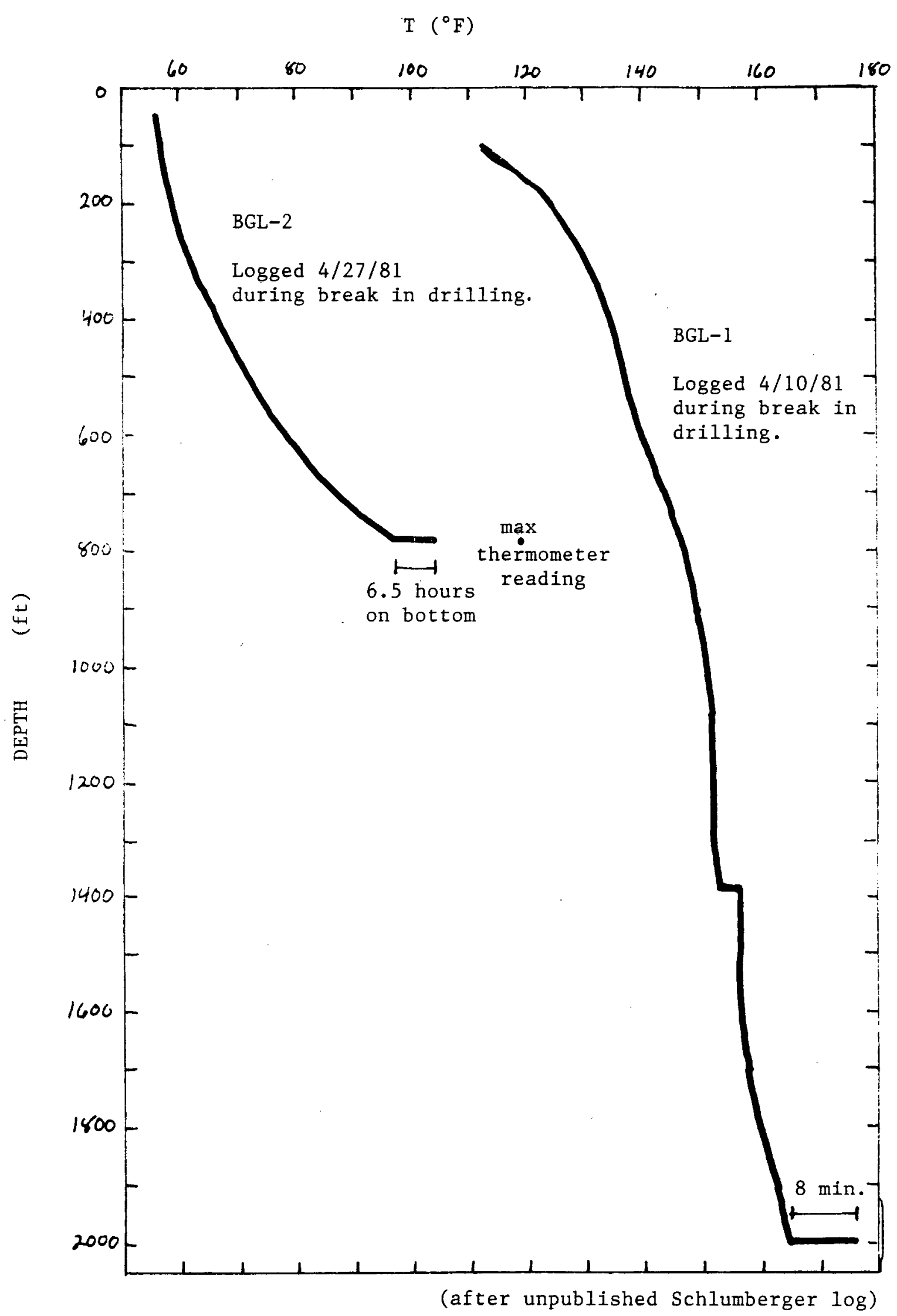


BWSWD - 1

$T\left({ }^{\circ} \mathrm{F}\right)$

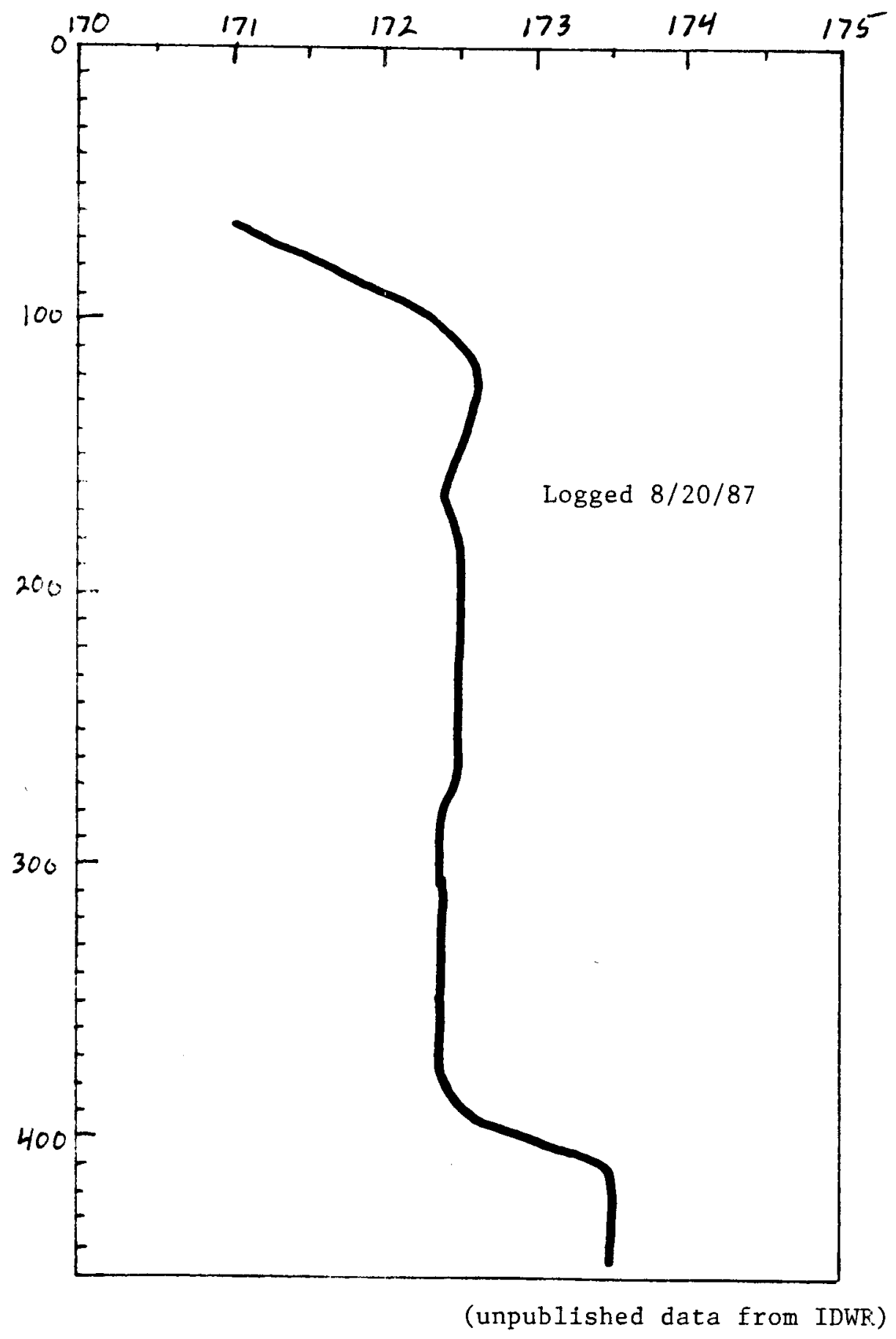


BWSWD - 2

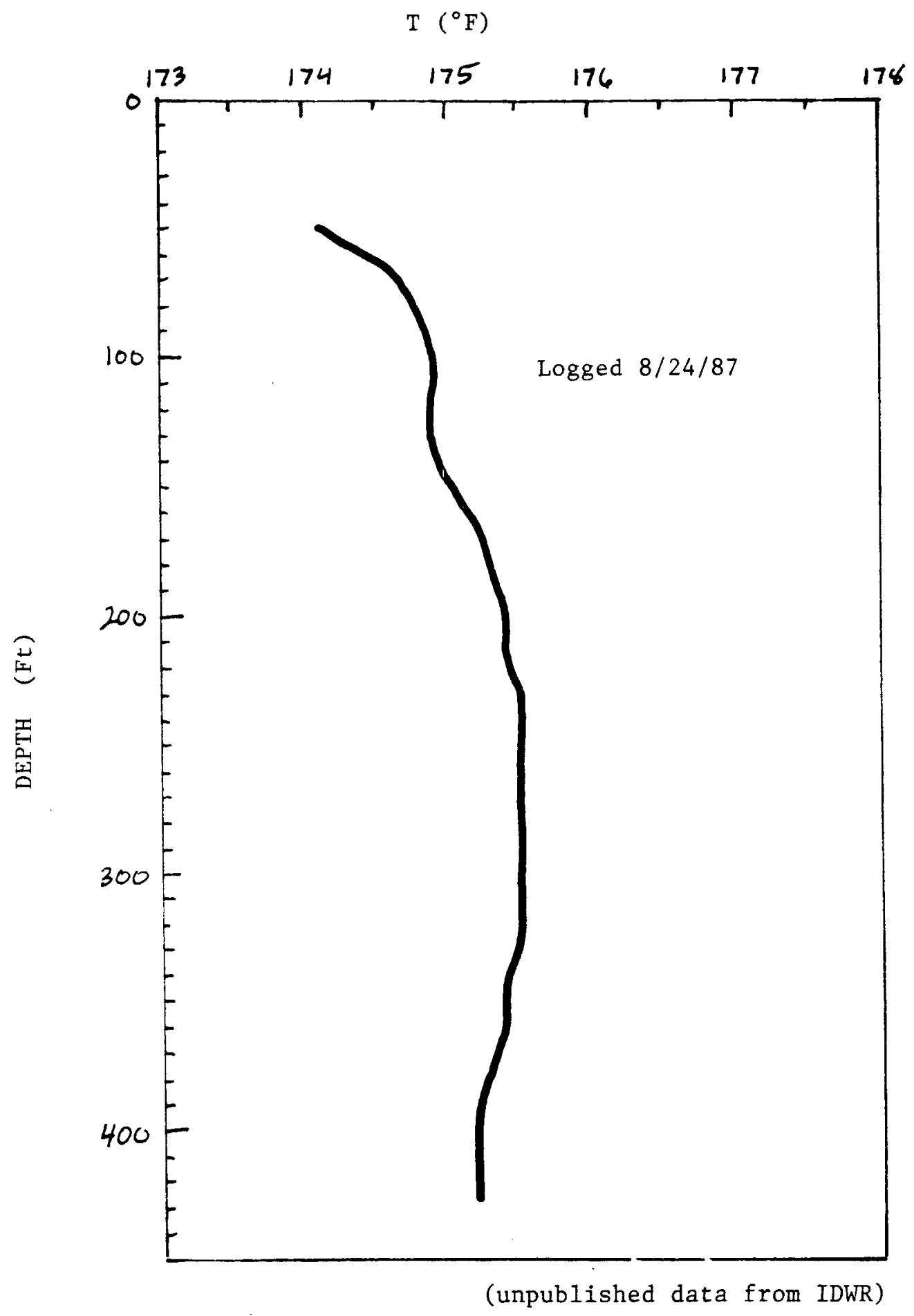




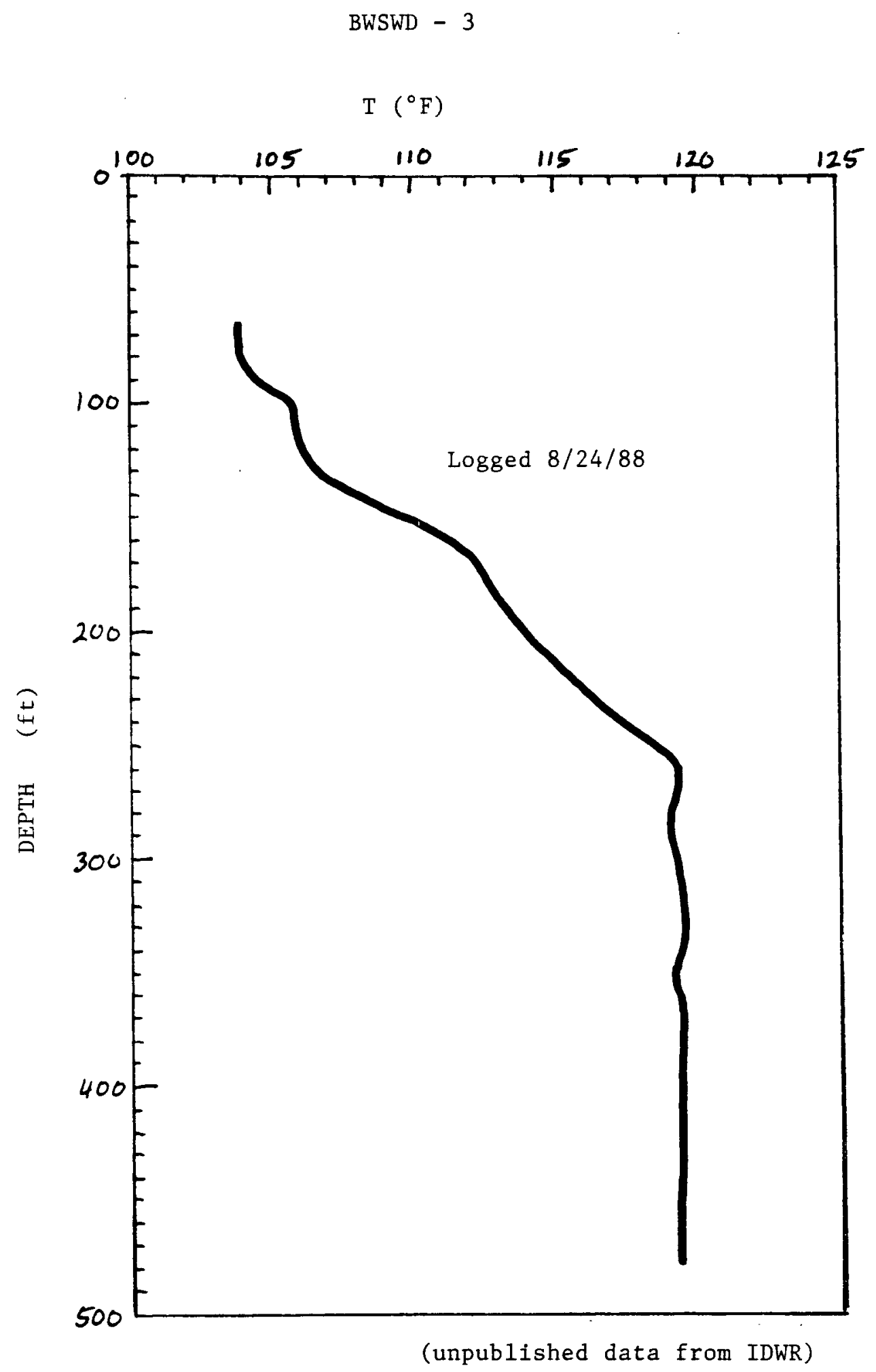




\section{Harris We11}

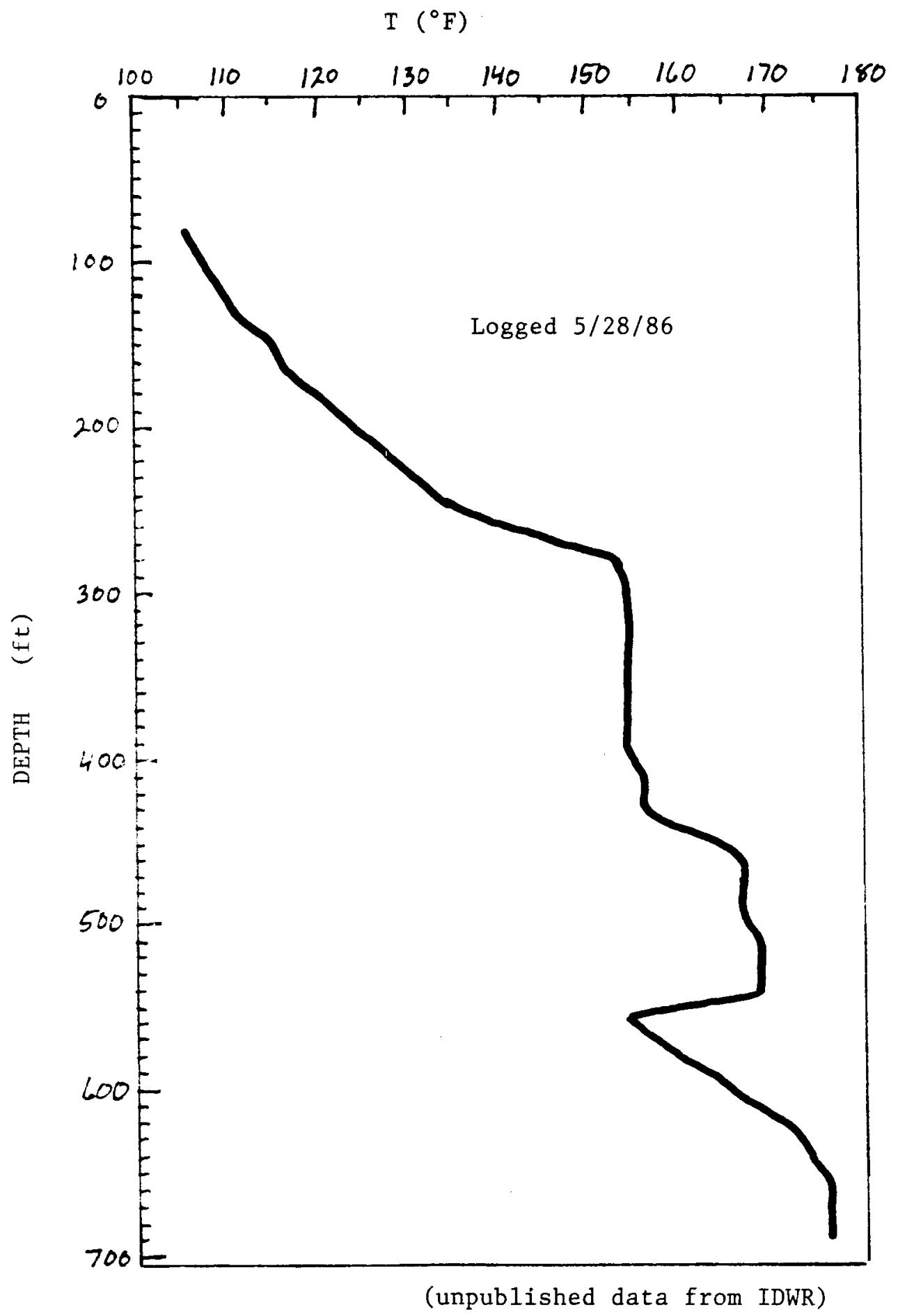


Appendix B

Individual Well Data from Young et. al., 1988

report nomad and pouted pepratily 


\section{Appendix C}

\section{Available Well Completions/Lithologies}


BLM Wel1

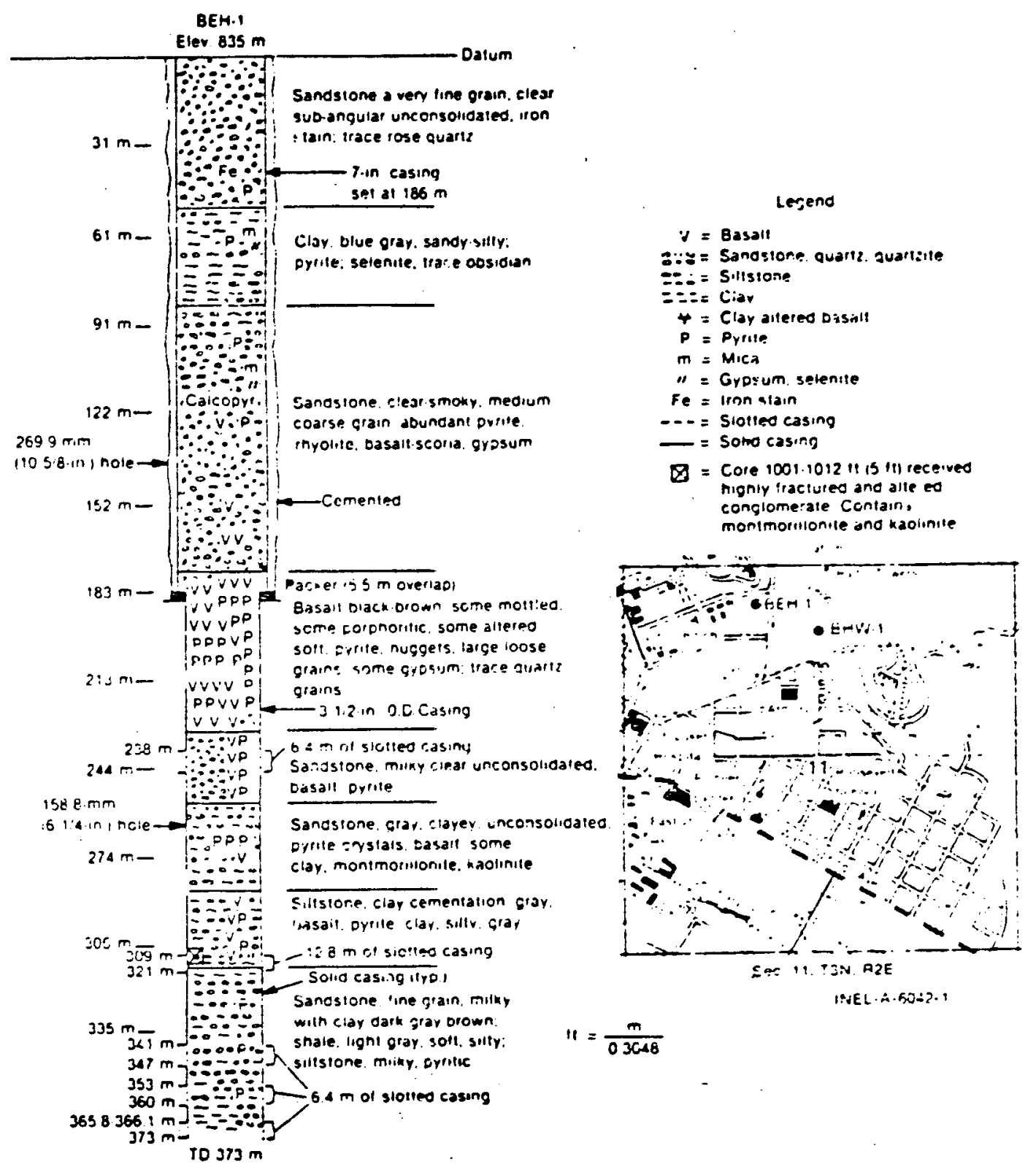

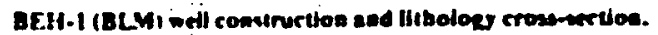

(from Nelson, 1980) 
Beard Well

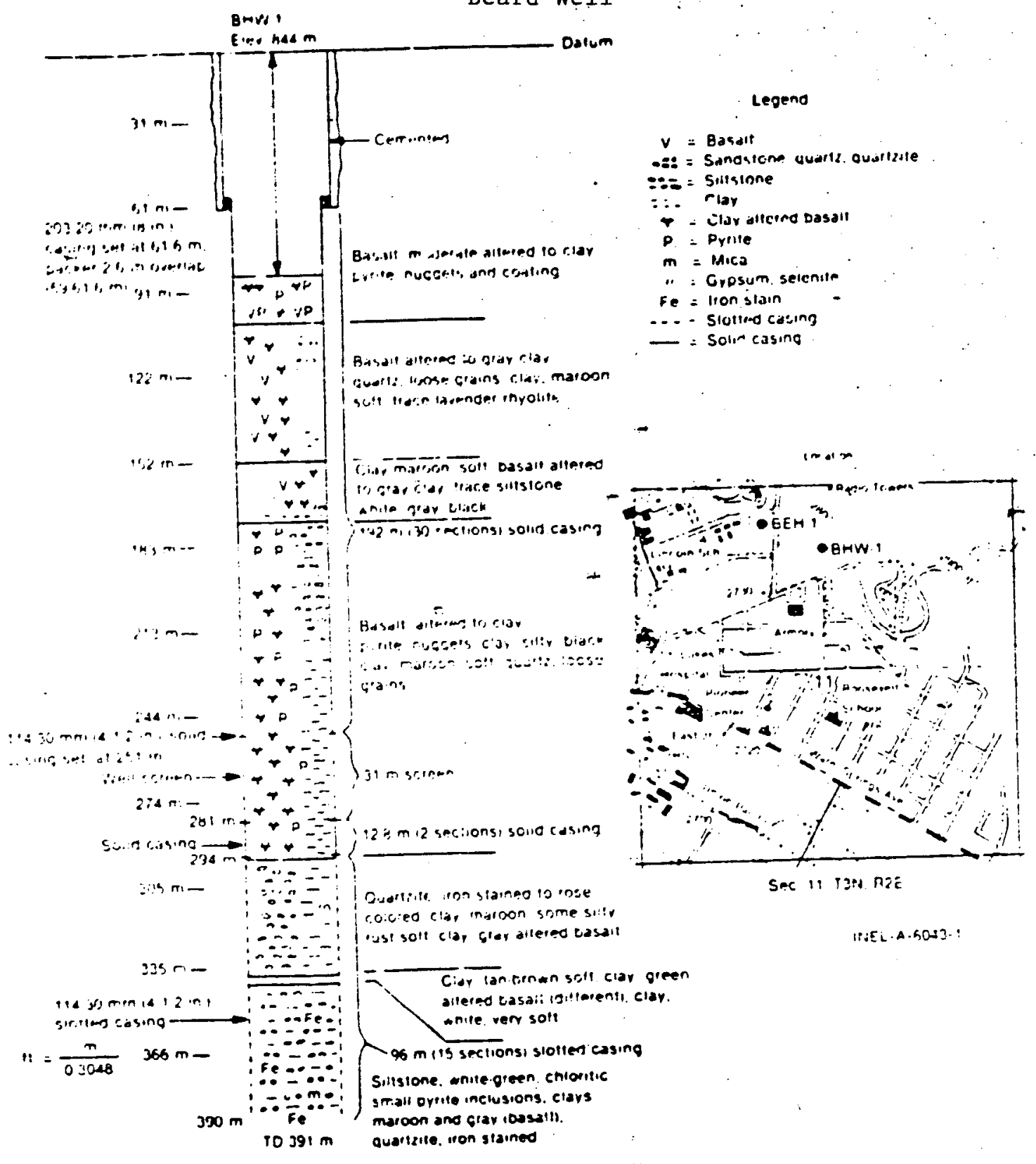

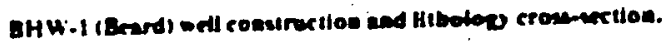

( after Nelson, 1980) 
CM-1

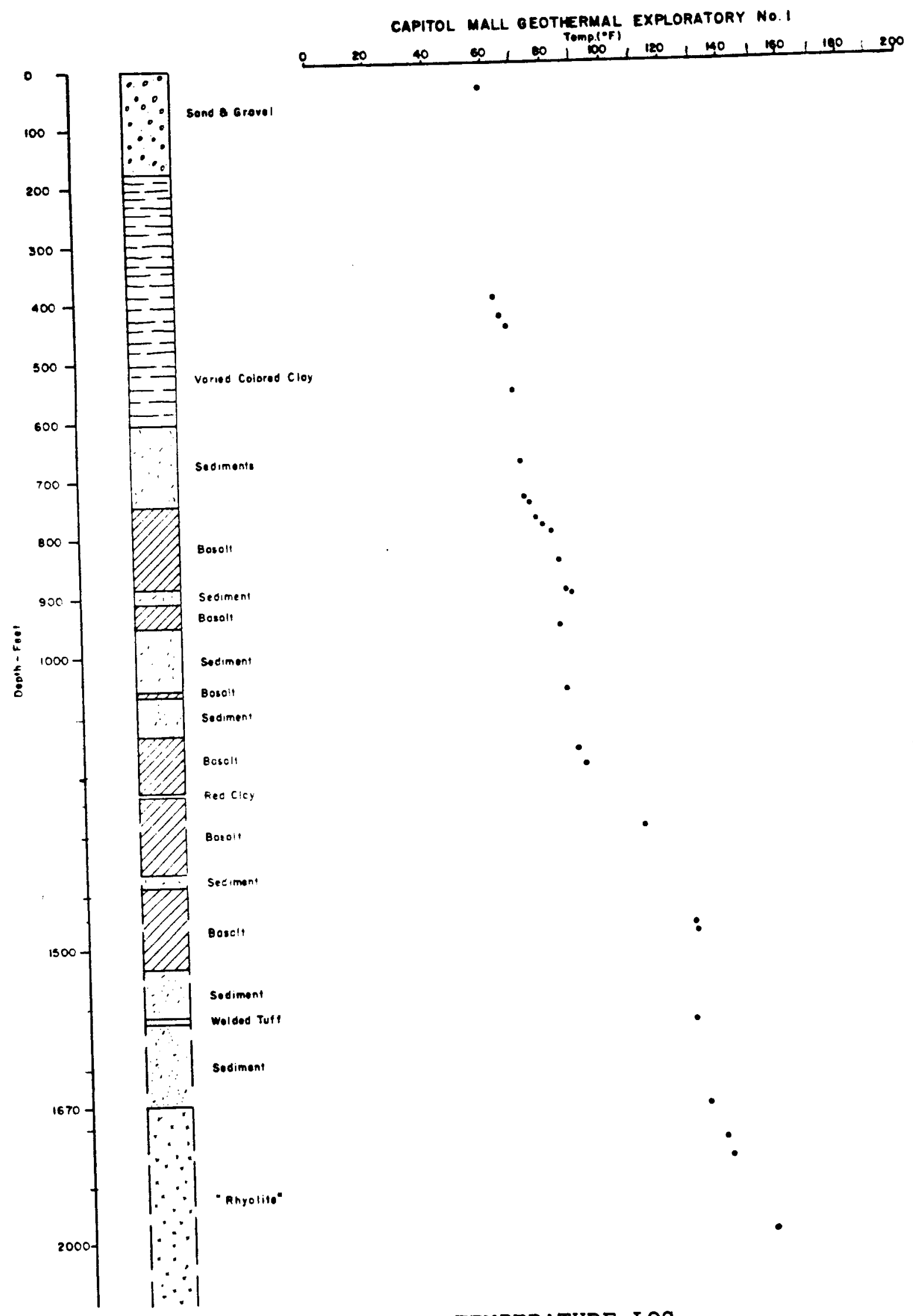

TEMPERATURE LOG

(from Anderson, 1981) 
CM-1

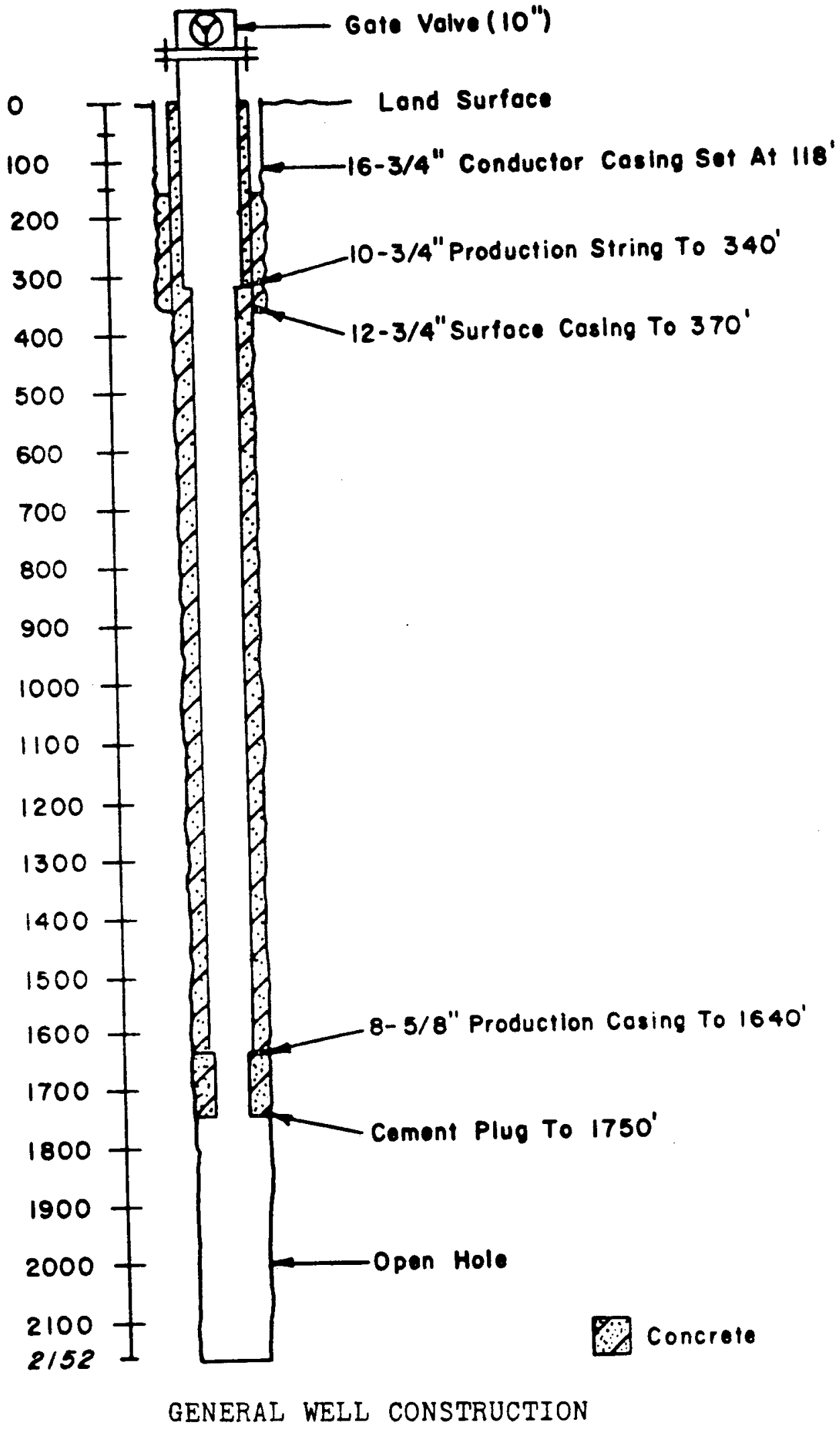

(from Anderson, 1981) 


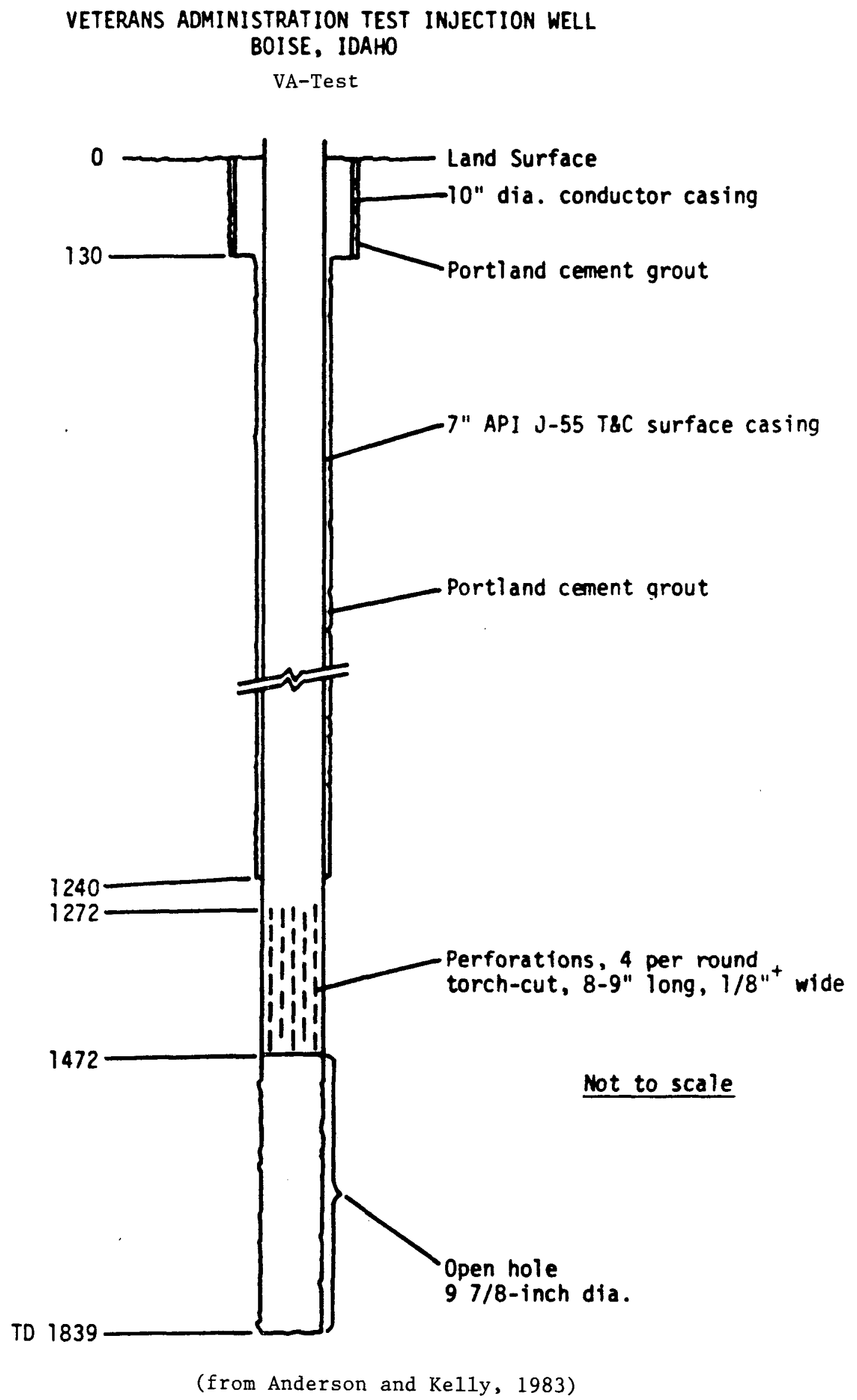


VETERANS ADMINISTRATION GEOTHERMAL PRODUCTION WELL BOISE, IDAHO

VA-1

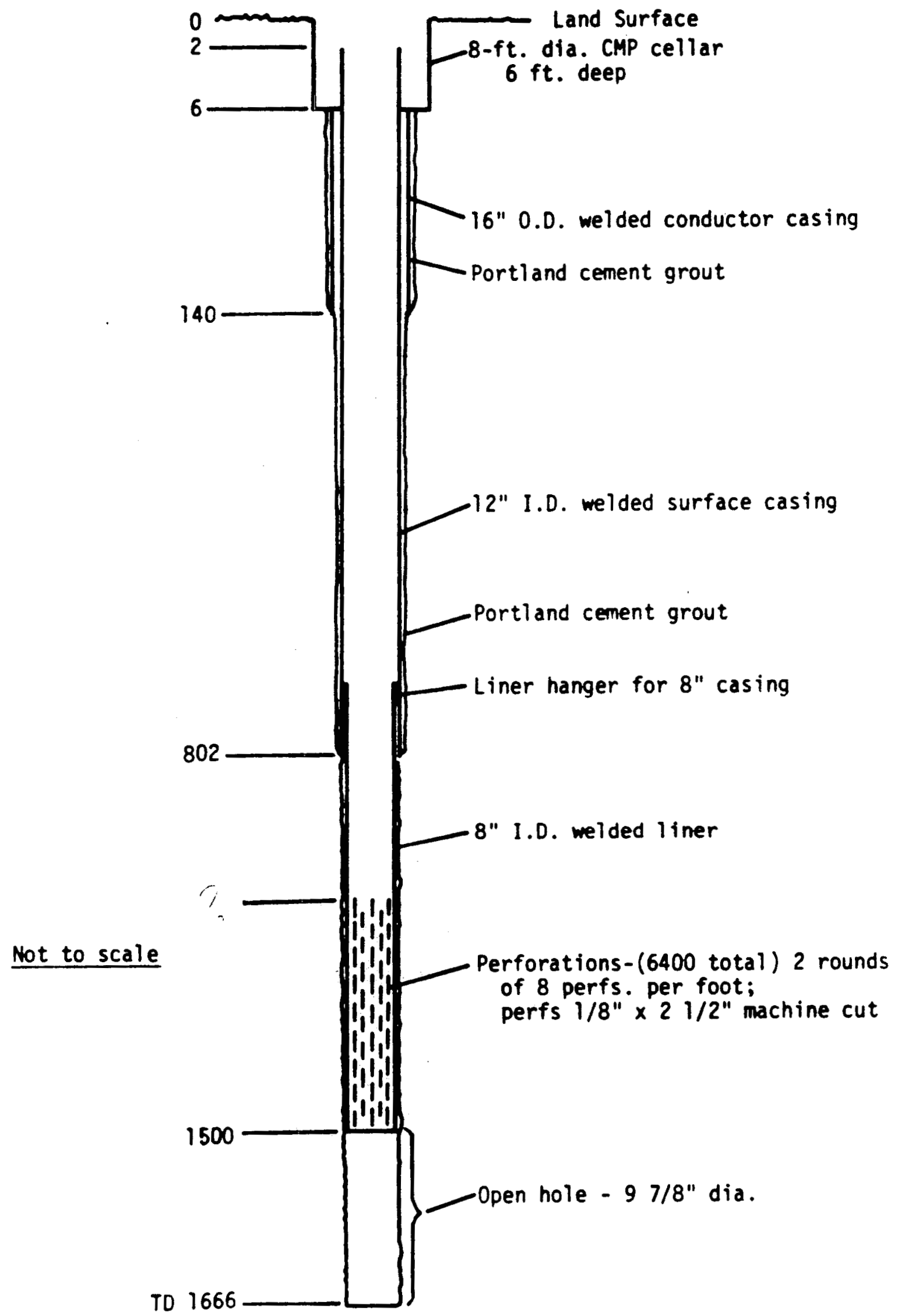

(Anderson and KeIly, 1983) 


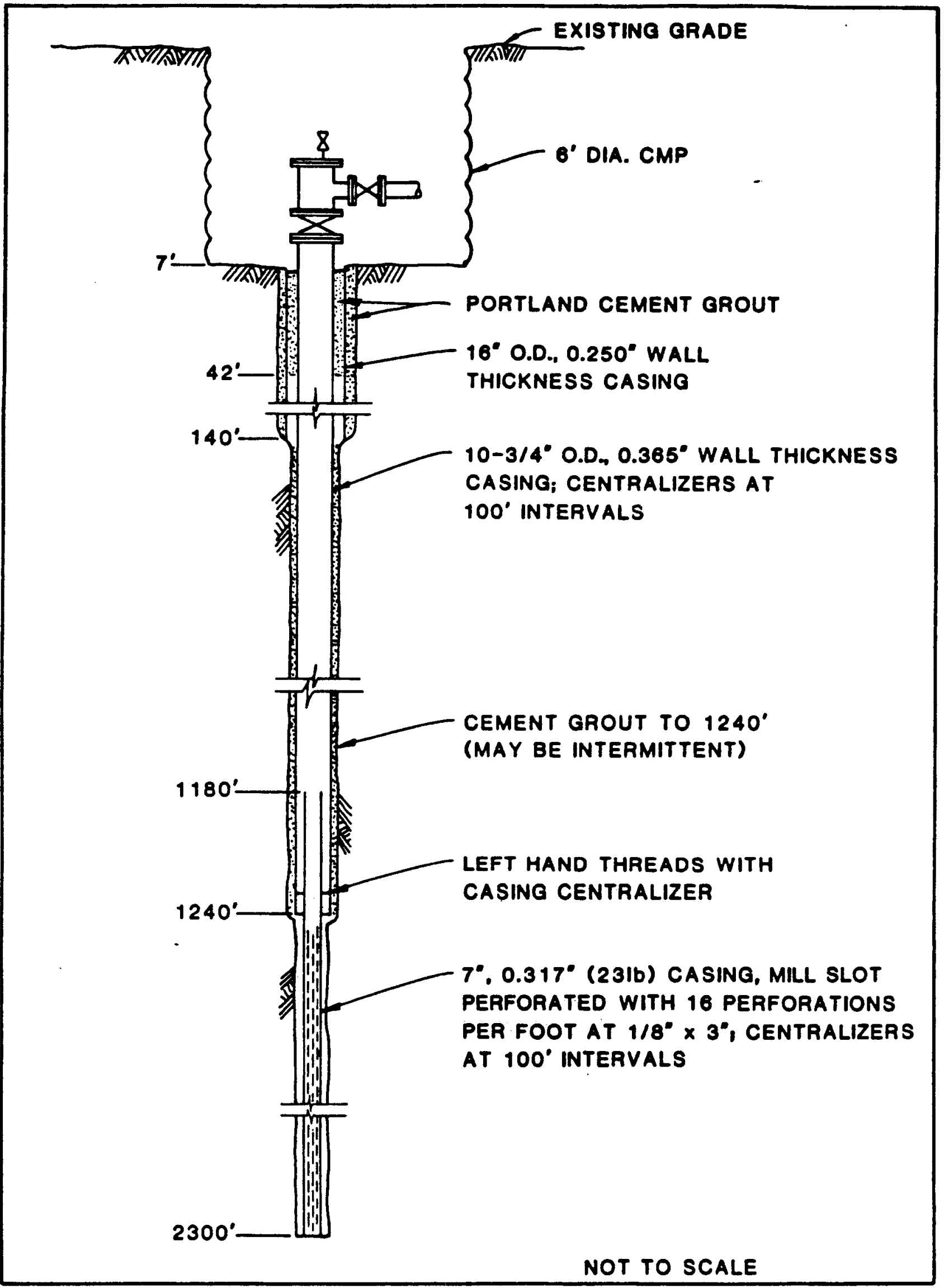

VETERANS ADMINISTRATION GEOTHERMAL INJECTION WELL BOISE, IDAHO 